

\section{DISCLAIMER}

This report was prepared as an account of work sponsored by an agency of the United States Government. Neither the United States Government nor any agency Thereof, nor any of their employees, makes any warranty, express or implied, or assumes any legal liability or responsibility for the accuracy, completeness, or usefulness of any information, apparatus, product, or process disclosed, or represents that its use would not infringe privately owned rights. Reference herein to any specific commercial product, process, or service by trade name, trademark, manufacturer, or otherwise does not necessarily constitute or imply its endorsement, recommendation, or favoring by the United States Government or any agency thereof. The views and opinions of authors expressed herein do not necessarily state or reflect those of the United States Government or any agency thereof. 


\section{DISCLAIMER}

Portions of this document may be illegible in electronic image products. Images are produced from the best available original document. 


\section{LEGAL NOTICE}

This report was prepared as an account of Government sponsored work. Neither the United States, nor the Commission, nor any person acting on behalf of the Commission:

A. Makes any warranty or representation, expressed or implied, with respect to the accuracy, completeness, or usefulness of the information contained in this report, or that the use of any information, apparatus, method, or process disclosed in this report may not infiringe privately owned rights; or

B. Assumes any liabilities with respect to the use of, or for damages resulting from the uee of any information, apparatus. method. or process disclosed in this report.

As used in the above, "person acting on behalf of the Commission" includes any employee or contractor of the Commission, or employee of such contractor, to the extent that such employee or contractor of the Commission, or employee of such contractor prepares, disseminates, or provides access to, any information pursuant to his employment or contract with the Commission, or his employment with such contractor.

Printed in USA. Price $\$ 3.00$. Available from the Clearinghouse for Federal Scientific and Technical Information, National Bureau of Standards,

U. S. Department of Commerce, Springfield, Virginia 22151 
it.

RELEASED FOR ANNOUNCEMENT

IN NUCLEAR SCIENCE ABSTRACTS
ANL-7135

Metals, Ceramics, and Materials (TID-4500)

AEC Research and

Development Report

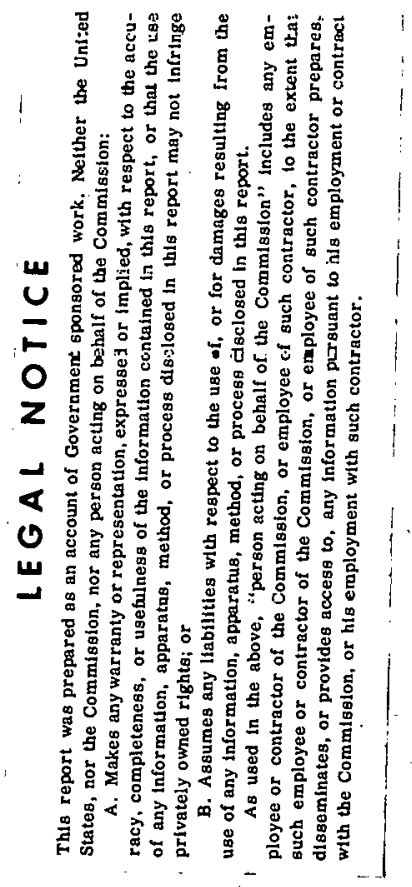

ARGONNE NATIONAL LABORATORY

9700 South Cass Avenue

Argonne, Illinois 60439 .

THE BETA $\rightarrow$ ALPHA TRANSFORMATION

IN HIGH-PURITY PLUTONIUM

by

M. Rosen, R. G. Peterson, and L. T. Lloyd

$\cdot \rightarrow$

Metallurgy Program 4.5.15

Portions of the material in this report have appeared in the following Metallurgy Division Progress Reports:

\begin{tabular}{ll} 
Number & \multicolumn{1}{c}{ Pages } \\
ANL-6516 & $226-228$ \\
ANL-6677 & $227,230-232$ \\
ANL-6868 & $259-263$
\end{tabular}

February 1966

Operated by The University of Chicago under

........ Eontract W-31-109-eng-38

with the

U. S. Atomic Energy Commission 


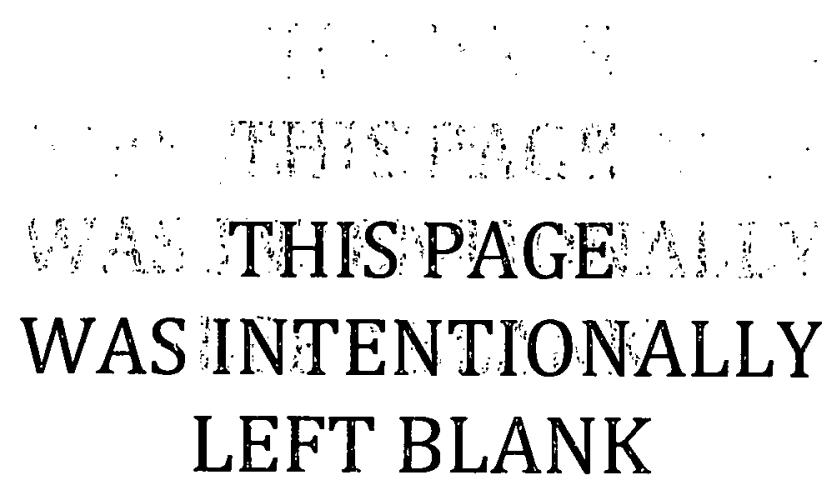


'I'ABLE OF CONTENTS

$\underline{\text { Page }}$

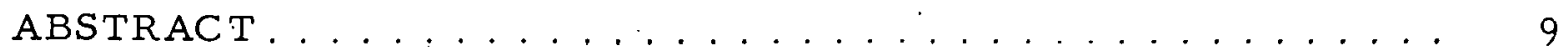

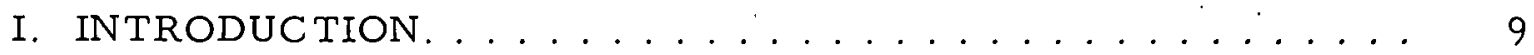

II. POLYMORPHIC TRANSFORMATIONS ............. 10

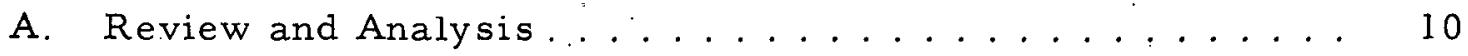

1. Surface Effects ..................... 11

2. Temperature Hysteresis .............. 12

3. Externally Applied Stresses.............. 13

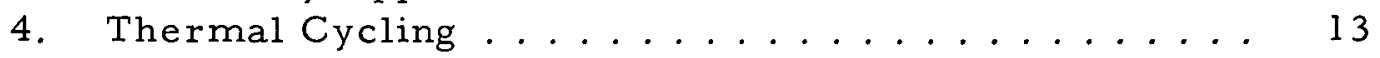

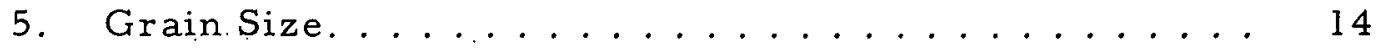

6. Autocatalytic Effects................ 14

7. Crystallographic Relationships............ 14

8. Transformations in. Pure Metals ........... 15

B. The Situation in Plutonium .............. 15

i. The Partially Athermal Characteristics ........ 16

2. Rates of Transformations. ............. 16

3. Surface Effects .................. 17

4. Hysteresis ........................ 17

5. Behavior under Externally Applied Stresses . . . . . 17

6. Behavior during Thermal Cycling .......... 18

III. ULTRASONIC MEASUREMENTS . . . . . . . . . . . . . . . 19

A. Selection of Ultrasonic Measurements ........... 19

B. Correlation of Elastic Properties and Ultrasonic Attenuation with Metallurgical Phenomena .......... 20

1. Velocity of Sound Waves .............. 20

2. Ultrasonic Attenuation. ................ 21

IV. EXPERIMENTAL PROCEDURES. . . . . . . . . . . . . . 24

A. Materials...................... 24

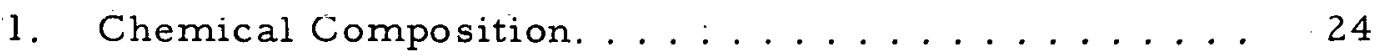

2. Specimen Geometry .................. 25

B. Specimen-clamping Device............... 25

C. Ultrasonic Apparatus .................... 27

D. Calibration of Oscilloscopes . ............. 35

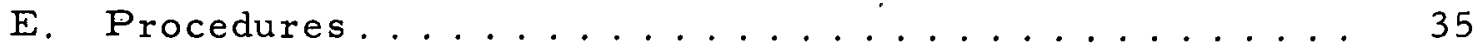

1. Density Measurements .................... 35

2. Room-temperature Ultrasonic Measurements ..... 36

3. Heat Treatments.................. 36 
TABLE OF CONTENTS

Page

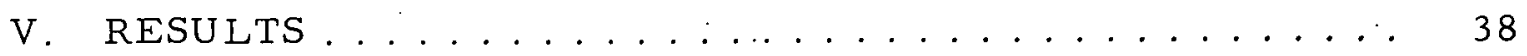

A. Room-temperature Measurements. . . . . . . . . 38

B. Quasi-equilibrium Conditions.............. 39

1. Longitudinal-wave Velocity and Attenuation...... 39

2. Shear-wave Velocity and Attenuation.........446

3. Poisson's Ratio ................. 47

4. Young's Modulus and Shear Modulus .......... 48

5. Effect of Cycling on the 'l'emperaturc-hysteresis Loop . . . . . . . . . . . . . . . 48

C. Isothermal Conditions . . . . . . . . . . . . 48

1. Variation of Sound Velocity with Holding Time. .... 48

2. Sound Velocities in Beta Plutonium at the Transformation Temperatures ............. 52

3. Sound Velocities in Alpha Plutonium at the Transformation Temperatures ............. 52

4. Retention of Beta Plutonium............ 53

5. Time-Temperature-Transformation Diagram for the Beta $\rightarrow$ Alpha Transformation in Plutonium . . . 54

6. Effect of Cycling on the Transformation Kinetics... 55

7. Influence of Interrupted Quenching. . . . . . . . 56

8. Density Decrease upon Alpha $\rightleftarrows$ Beta Transformation . 57

9. Metallographic Observations ............ 58

10. Ultrasonic Attenuation during the Isothermal Tests. 64

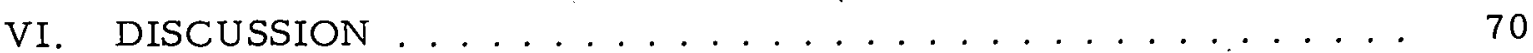

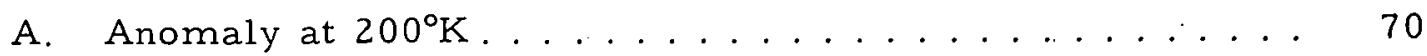

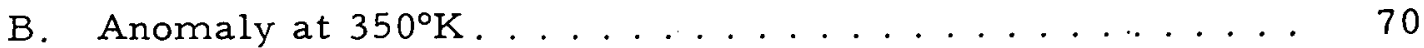

C. Microvoid Formation and Cycling Damage........ 71

D. The Beta $\rightarrow$ Alpha Transformation in High-purity

Plutonium . . . . . . . . . . . . . . . 72

1. Nucleation. . . . . . . . . . . . . . . 72

2. Transformation . . . . . . . ....... 74

3. Kinetics.................... 75

VII. SUMMARY AND CONCLUSIONS . . . . . . . . . . 77

ACKNOWLEDGMENTS . . . . . . . . . . . . . . . . . . . 79

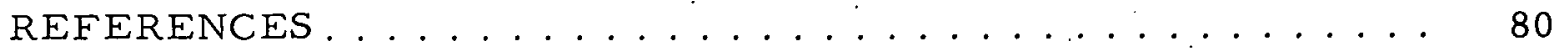


LIST OF FIGURES

No.

1. Time-Temperature-Transformation Curves for 50\% Transformation of Plutonium . ................. 16

2. Specimen-clamping Device. ................. 26

3. Stress Pulse Generation by Thick Transducers . . . . . . . . 30

4. Schematic Drawing of Pulse Generator. . . . . . . . . . 32

5. Line Drawing of Specimen-Transducer Configuration . . . . . 33

6. Photograph of Traces Displayed on Oscilloscope Screen .... 33

7. Block Diagram of Apparatus Used for Generating, Detecting, and Recording the Transit Time and Amplitude Data. . . . . . .

8. Velocity of Longitudinal Waves in Plutonium, as a Function of Temperature . . . . . . . . . . . . . . .

9. Reciprocal of Transit Time of Longitudinal Waves in Specimen CM-29-9, as a Function of Temperature during Slow

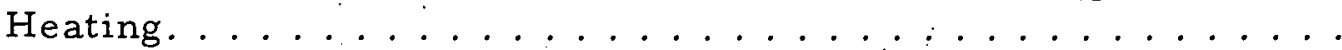

10. Relative Attenuation of Longitudinal Waves in Specimen CM-29-2, as a Function of Temperature............

11. Relative Attenuation of Longitudinal Waves in Specimen CM-29-9, as a Function of Temperature during Slow Heating. .

12. Velocity of Shear Waves in Plutonium, as a Function of Temperature during Slow Heating . . . . . . . . . . . .

13. Relative Attenuation of Shear Waves in Specimen CM-18-P, as a Function of Temperature during Slow Heating . . . . . . . .

14. Poisson's Ratio for Alpha Plutonium, às a Function of

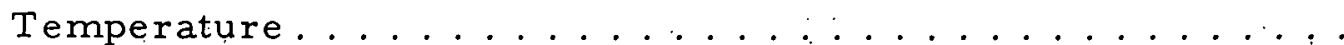

15. Young's Modulus and Shear Modulus for Alpha Plutonium, as a Function of Temperature.................

16. Reciprocal of Transit Time of Longitudinal Waves in Plutonium, as a Function of Time of Holding at Various Isothermal Transformation Temperatures .............

17. Fraction of Beta Plutonium Transformed to the Alpha Phase at 272 and $348^{\circ} \mathrm{K}$, as Functions of Time of Holding . . . . . . .

18. Quenching Curve for a Stainless-steel Specimen . . . . . . . .

19. Velocity of Longitudinal Waves in Metastable Beta Plutonium, as a Function of Temperature. 


\section{LIST OF FIGURES}

No:

20. Velocity of Longitudinal Waves in Alpha Plutonium, as a Function of Temperature ................

21. Fraction of Beta Plutonium Transformed to the Alpha Phase, as a Function of the Isothermal Transformation Temperature.

22. Time-Temperature-Transformation Diagram for the Beta $\rightarrow$ Alpha Transformation in High-purity Plutonium. . . . . . . .

23. Reciprocal of Transit Time of Longitudinal Waves in Specimon CM-29-3, as a Function of the Time of Holding during the 12th Beta $\rightarrow$ Alpha Transformation at $245^{\circ} \mathrm{K} \ldots \ldots \ldots$

24. Fraction of Beta Plutonium Transformed to the Alpha Phase, as a Function of the Time of Holding during the First and. 12th Cycles of Specimen CM-29-3 . . . . . . . . .

25. Reciprocal of the Transit Time of Longitudinal Waves in Specimen CM-29-10, as a Function of the Time of Holding at $291^{\circ} \mathrm{K}$ after Heating to $453^{\circ} \mathrm{K}$, Quenching to $357^{\circ} \mathrm{K}$, Holding for $7 \mathrm{~min}$, and Quenching to $291^{\circ} \mathrm{K} \ldots \ldots \ldots \ldots \ldots \ldots$

26. Fraction of Beta Plutonium Transformed to the Alpha Phase at Room Temperature for Specimens Subjected to Interrupted Quench Treatment and Normal Treatment. . . . . . . . .

27. Decrease in Density Measured at Room Temperature of Plutonium, as a Function of the. Isothermal Transformation

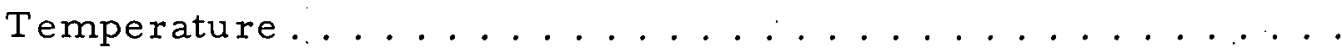

28. Microstructure of Specimen CM-28-10 after Isothermal Transformation at $361^{\circ} \mathrm{K}$ for 1.5 days. . . . . . . . .

29. Microstructure of Specimen CM-29-10 after Isothermal Transformation at $358^{\circ} \mathrm{K}$ for $7 \mathrm{~min}$ and Quenching to $291^{\circ} \mathrm{K}$ to Complete the Beta $\rightarrow$ Alpha Transformation . . . . . . 60

30. Microstructure of Specimen CM-28-2 after Isothermal Transformation at $326^{\circ} \mathrm{K} \ldots \ldots \ldots \ldots \ldots \ldots$

31. Microstructure of Specimen CM-28-1 after Isothermal Transformation at $296^{\circ} \mathrm{K} \ldots \ldots \ldots \ldots \ldots$

32. Microstructure of Specimen CM-29-11 after Isothermal Transformation at $199^{\circ} \mathrm{K} \ldots \ldots \ldots \ldots \ldots \ldots \ldots \ldots \ldots \ldots \ldots \ldots \ldots$

33. Microstructure of Specimen CM-29-3 after 17 cycles through the Alpha Beta Transformation between 453 and $253^{\circ} \mathrm{K}$. . . .

34. Ghost-grain Boundaries in Specimen CM-29-11 that Were Developed by Electropolishing for a Short Period of Time.... 


\section{LIST OF FIGURES}

No

Title

$\underline{\text { Page }}$

35. Relative Attenuation of Longitudinal Waves in Plutonium, as a Function of Holding Time at Various Isothermal Transfor-

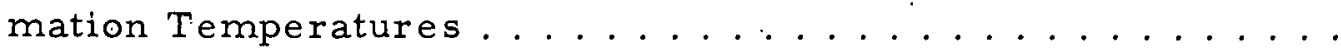

36. Times of the Start and of the Recovery of the Dip in Relative Attenuation of Longitudinal. Waves near the Beginning of the Beta $\rightarrow$ Alpha Transformation, as Functions of the Isothermal Transformation Temperature . . . . . . . . . . . . .

37. Times of the Maxima in the Main Peaks and the Subsidiary Peaks of Relative Attenuation of Longitudinal Waves, as Functions of the. Isothermal Transformation Temperature ......

38. Fraction of Beta Plutonium Transformed to the Alpha Phase at the Times of the Maxima in the: Main Peaks of Relative Attenuation of Longitudinal Waves, as a Function of the Isothermal Transformation Temperature ............

39. Fraction of Beta Plutonium Transformed to the Alpha Phase at the Times of the Maxima in the Subsidiary Peaks of Relative Attenuation of Longitudinal Waves, as a Function of the Isothermal Transformation Temperature ............

40. Magnitude of the Decrease from the Main Peak of Relative Attenuation of Longitudinal Waves to Its Final Value, as a Function of the Isothermal Transformation Temperature. . . .

41. Difference between the Relative Attenuation of Longitudinal Waves at Room Temperature and at the Isothermal Transformation Temperatures after the Completion, or Apparent Completion, of the Beta $\rightarrow$ Alpha Transformation, as a Function of the Isothermal Transformation Temperature. . . . . . . . .

42. Difference between the Rèlative Attenuation of Longitudinal Waves after the Completion, or Apparent Completion, of the Beta $\rightarrow$ Alpha Transformation and While the Specimen Was Beta Plutonium, as a Function of the Isothermal Transformation Temperature...................

43. Relative Attenuation of Longitudinal Waves in Specimen CM-28-3 during the 12 th $\mathrm{Cycle}$ between 453 and $245^{\circ} \mathrm{K}$, as a Function of the Time of Holding at $245^{\circ} \mathrm{K} \ldots \ldots \ldots$

44. Relative Attenuation of Longitudinal $W$ aves in Specimen CM-29-10 during Isothermal Holding at Room Temperature, after Approximately $50 \%$ Transformation at $358^{\circ} \mathrm{K}$, as a Func-

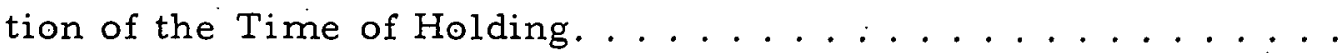




\section{LIST OF. TABLES}

No.

Title

$\underline{\text { Page }}$

I. Analyses of High-purity Plutonium ............... 24

II. Time for Temperature Equalization of a Stainless-steel Specimen Quenched from $453^{\circ} \mathrm{K}$ to Various Temperatures of the Isothermal Bath . . . . . . . . . . . . . . . 


\title{
THE BETA $\rightarrow$ ALPHA TRANSFORMATION IN HIGH-PURITY PLUTONIUM
}

\section{by}

\author{
M. Rosen, R.G. Peterson, \\ and L. T. Lloyd
}

\begin{abstract}
The beta $\rightarrow$ alphatransformation in high-purity plutoniumi nutal was lnvestigated by an ultrasonic-pulse method under both quasi-equilibrium and isothermal conditions. Concurrent observations of sound velocities and relative ultrasonic attenuation yielded information on the kinetics and the mechanism of the transformation. The behavior was consistent with a displacive, or maitensitic-type, transition. The time-temperature-transformation (TTT) diagram displayed two branches. The high-temperature region, above $313^{\circ} \mathrm{K}$, exhibited an athermal character that extrapolated to zero beta $\rightarrow$ alpha isothermal transformation at $367^{\circ} \mathrm{K}$ for the purity of the metal used in the present study. Effects of multiple cycling through the $\alpha \nRightarrow \beta$ transformation and of interrupted quenching are discussed. Structural damage due to the formation of microvoids and cracks was more extensive in specimens transformed at temperatures in the upper region of the TTT diagram. Anomalies in the sound velocities and attenuation were encountered at $200^{\circ} \mathrm{K}$ and at about $350^{\circ} \mathrm{K}$ during slow heating. The possibility of the anomalies at $350^{\circ} \mathrm{K}$ being caused by a recovery process is discussed.
\end{abstract}

\section{INTRODUCTION}

Plutonium has six allotropic forms ${ }^{1}$ between room temperature and its melting point at about $913^{\circ} \mathrm{K}$. The alpha phase is monoclinic ${ }^{2}$ and is stable up to about $385^{\circ} \mathrm{K}$ where it transforms to the body-centered monoclinic beta phase. ${ }^{3}$ The kinetics of the beta $\rightarrow$ alpha transformation have been investigated by Nelson ${ }^{4}$ and by Loasby and Lowe. ${ }^{5}$ Both studies used plutonium with about 1000 ppm by weight of impurities. By applying the fluid displacement method, ${ }^{4}$ linear dilatometry, and electrical resistivity, ${ }^{5}$ Nelson and Loasby and Lowe obtained sigmoidal curves for the fraction transformed versus time of holding at a constant temperature in the alpha range after rapid cooling from the beta range. The maximum rates of reaction were at about $253^{\circ} \mathrm{K}$ after $10 \mathrm{sec}$ holding time. Other portions of the curves 
showed significant differences in their location with respect to the timeand-temperature coordinate system. This behavior may be attributed largely to the differing purity of the plutonium, to the experimental methods, and to the different heat treatments that were given to the specimens. Their observations led the workers to classify the transformation as diffusioncontrolled nucleation and three-dimensional growth, but a critical analysis and reintexpretation of their experimental evidence indicated that the transition was more likely to occur by a martensitic mechanism. The bases for this conclusion are presented in the following section.

\section{POLYMORPHIC TRANSFORMATIONS}

\section{A. Review and Analysis}

A polymorphic phase change can occur through two accepted mechanisms: (1) diffusion process, and (2) martensitic process. The diffusion process, sometimes referred to as a "nucleation and growth" reaction, is based on an atom-by-atom transfer across the interface between the phases; i.e., it is a thermally activated, diffusion-controlled process. The martensitic transformation, on the other hand, is a diffusionless, shearlike reaction that is carried. out by a cooperative movement of atoms. The shearing action, once started, can continue at nearly sonic speeds, even at very low temperatures, ${ }^{6,7}$ until halted or retarded by interfacial boundaries, strain-energy. barriers, or loss of coherency between the phases.

Some of the criteria that have been used in the pașt to distinguish martensitic transformations from. diffusion processes have become meaningless because of experimental evidence accumulated in recent years; among these original criteria were: (1) the exclusively athermal character of a martensitic reaction, (2) the insuppressibility of the martensitic reaction even by rapid quenching, and. (3) the very high rates of propagation of martensitic plates.

Isothermal components have been found in some martensitic reactions. These components may operate to a very limited extent, and they may be effectively obscured by more predominant, athermal characteristics. Where an isothermal component is active, that portion of the reaction may be suppressed by rapid cooling. ${ }^{8}$. Such reactions have been observed in many metals and alloys. ${ }^{9-14}$ Limited isothermal features in a predominantly athermal reaction have been. observed in high-purity powdered cobalt ${ }^{15}$ and in high-purity cerium during transformation while heating. ${ }^{16}$ On the other hand, truly athermal transformations have been observed in some alloys ${ }^{17 ; 18}$ and in a variety of pure metals, such as lithium; ${ }^{19}$ mercury, ${ }^{20}$ massive cobalt, ${ }^{21-24}$ and during. cooling of cerium. ${ }^{16}$ 
The is othermal martensitic reaction: was first considered to proceed by nucleation of new crystallites that propagate at very high velocities similarly to the rapid growth of the athermal martensitic plates. ${ }^{7}$ But experimental evidence shows that slow growth also has been observed in many alloys that have both isothermal and athermal components, for example, aluminum-bronze, ${ }^{25}$. Au-Cd; ${ }^{26}$ In-T1; $;^{27}$ and U-Cr. ${ }^{14}$ A slow rate of transformation, or of propagation of the individual plates, does not necessarily indicate a thermally activated, diffusion-controlled.mechanism. Such kinetics may be due to either a nucleation-controlled process where new nuclei become potent with time and "burst out" to their full size, or, as in the case of $\mathrm{U}-0.5 \% \mathrm{Cr}$ alloy, ${ }^{14}$ the individual plates may grow at a very slow rate. This latter process is probably due to a time-dependent, relaxation of stresses in the untransformed matrix, which.is aided by thermal means. 14;28 The opposing stress factors are diminished when the matrix is able to accommodate the transformation strains. It is obvious that the relative ductility of the product and parent phases plays an. important part. Such recovery of the matrix, if it occurs, is expected to allow further growth of a new phase. Therefore, one may conclude that a high rate of propagation of plates does not typify a martensitic transformation.

In light of thesefindings, the one remaining definition. of a martensitic transformation ${ }^{29}$ is that it is a diffusionless reaction with cooperative movement of atoms through small distances relative to their neighbors. Martensitic reactions in alloys should not involve any composition changes and should invariably be accompanied by a shape deformation in the transformed region. ${ }^{28}$ The reaction results from a coordinated motion of an interface that couples the product to the parent phase. From this definition one can select certain experimental phenomena that characterize the more recent views of martensitic transformations and that are consistent with them. These are: (1) surface: effects, (2) hysteresis between the temperatures of the transformations on heating and cooling, (3) sensitivity to externally applied.stresses, (4) structural damage during thermal cycling through the phase transformation, (5) grain-size effects, (6) autocatalytic effects, and (7) crystallographic relationships.

\section{Surface Effects}

Surface effects are manifested by upheavals on an originally flat sample and by shifts of reference:lines; or: scratches; marked on the surface before the transformation. Measurements of the direction and magnitude of the surface tilts and the line movements in a single crystal give valuable information about the mechanism of the transformation. Such effects are found in all martensitically transformed metals and alloys, ${ }^{29}$ although sometimes they are hardly observable and may even escape detection, as in the case of high-purity cobalt, ${ }^{23,30}$ but they are very obvious in zirconium, $31-33$ titanium,,$^{31,34-36}$ ir on: $3^{-39}$ uranium, and $U-C r$ alloys, ${ }^{14,40}$ etc. The shape 
deformations can induce high internal stresses during the transformation, as evidenced by recrystallization after a phase change, which sometimes occurs when specimens are held at a temperature just below the transformation temperature. ${ }^{30}$ The high stresses also can cause twinning on a fine scale in the transformation product. This was observed by transmission electron microscopy of some iron-base alloy thin foils (1000 $\mathrm{A}) .{ }^{41}$

\section{Temperature Hysteresis*}

Because of the substantial amount of strain energy produced by the shape deformation, the martensitic reaction cannot start at the thermodynamic equilibrium point between the parent phase and the product, where the free-energy difference is zero. Actually the reaction will start whcre the chemical driving force is sufficiently large to balance the nonchemical requirements, such as strain energy, interfacial energy, plastic flow, acoustical vibrations (the audible "clicks" that accompany some martensitic reactions), and heat losses. Extensive superheating (or supercooling) is necessary to make the free-energy difference between the two crystal modifications large enough to compensate for these energy losses. The interfacial and strain energies associated with the transformation are stored in the material and are available for the reverse transformation upon heating. The equilibrium between these energies and the opposing stress fields in the surroundings of a martensitic crystallite is responsible for its lenticular or ellipsoidal shape; it is also responsible for the plane interfaces sometimes found in polycrystalline materials in which the shape deformations of neighboring grains compensate for each other. ${ }^{28}$ On the other hand, the energies spent on plastic flow, heat losses, etc., and, in general, the energy to overcome the resistance of the parent phase to the growth of a new phase, are dissipated because these processes are irreversible. This accounts for the large temperature hysteresis in martensitic reactions. The hysteresis-is a characteristic feature and a required condition for both the cooling and reverse transformations. ${ }^{42}$ Hysteresis will persist even at very low rates of cooling and heating. Contrary to the situation in martensitic reactions, a diffusion process, where the transition is performed by an atom-by-atom movement across the phase interface, requires very little hysteresis. A high activation energy is required in the diffusion process, but very little work is dissipated on the actual displacement of the atoms; therefore, the diffusion transformation can proceed with very low supercooling or superheating.

Exceptions to extensive hysteresis for martensitic reactions can be due only to the induced stresses remaining in the elastic range. ${ }^{43}$ This has led to the concept of "thermoelastic martensite," in an $\mathrm{Fe}-\mathrm{Ni}-\mathrm{Al}$ alloy, ${ }^{25}$ where martensitic plates grew progressively during the cooling reaction. When the cooling was halted, the growth stopped until cooling was resumed.

* In this report, the term temperature hysteresis means the difference between the temperature at the start of the transformation upon heating and the temperature at the start of the transformation upon cooling. 
Similar behavior was demonstrated during the heating transformation; i.e., the plates grew and shrank in balance with the changing driving force.

\section{Externally Applied Stresses}

The martensitic transformation, when considered as a strain reaction with shear and dilatational displacements, can be facilitated by externally applied stresses that produce small strains. This supplement of energy may be added algebraically to the free energy when the variations in the temperature of initiation of the reactions are considered. Tensile and compressive stresses during cooling induce a martensitic reaction at a temperature above the $M s$ for no externally applied stresses (Ms is the starting temperature: on cooling), but a stress-induced transformaliun ciri be stimulated only below a temperature $\mathrm{Md}$, where $\mathrm{Md}>\mathrm{Ms} .{ }^{28}$. Experiments showed that hydrostatic pressure acted only in accord with Le Chatelier's principle, since it does not induce shear components to aid the martensitic shears. 44-46 Plastic deformation also lowered the temperature of the transformation upon heating, thus bracketing the equilibrium temperature. Consequently, external stresses narrow the temperature-hysteresis gap. ${ }^{8}$

Application of external stresses that produce large strains causes strain hardening ${ }^{19}$ and immobilizes dislocations, thus inhibiting atom movements that are necessary for the spontaneous transformation, i.e., stabilizes the high-temperature phase. Severe deformations can retard the subsequent transformations and even completely suppress the process, thus causing retention of the high-temperature phase at subcritical temperatures. ${ }^{47}$ There are many speculations as to the reasons for this behavior. One of them ${ }^{48}$ is that the more coherent a precipitate, the less the probability that it will grow in the regions in which the lattice has been disrupted by slip processes. Kelly and Nutting ${ }^{41}$ suggested that stacking faults resulting from small deformations act as martensitic nuclei in some cases, whereas at higher deformations, although the number of faults are increased, their effect is to hinder the transformation because of their mutual interactions. Also, a tangled dislocation network retards the transformation by hindering the propagation of a martensitic plate.

There.is ample evidence that plastic deformation affects the transformation behavior in pure metals and in alloys. In lithium, ${ }^{19}$ cold working. suppressed the transformation; and it even caused complete retention of the high-temperature phase. Similar effects were found in cobalt ${ }^{22,30}$ and cerium: ${ }^{16}$ Plastic deformation of beta $\mathrm{U}-0.5 \% \mathrm{Cr}$ single crystals accelerated the beta $\rightarrow$ alpha transformation, ${ }^{14}$ and mechanical polishing of a beta uranium specimen reverted it to the $\alpha \cdot$ phase. ${ }^{49}$

4. 'Thermal Cycling

Another consequence of the shape deformation during martensitic transformations and its related strains is the behavior during thermal 
cycling through the temperature range of the transformation. The plastic deformation that accompanies all nonelastic martensitic phase changes causes strain-hardening. effects that increase the resistance to the formation of a new phase. Depending on the relative elastic and plastic properties of the phases, thermal cycling increases the resistance to further transformations in both the high-and.low-temperature phases; i.e., the hysteresis gap is increased by depressing the $\mathrm{Ms}$ and raising the As (starting point of the transformation upon heating) temperatures. The influence of thermal cycling can be diminished when the specimen is kept for prolonged times at a higher temperature if a recovery process occurs. Repeated cycling can cause partial or complete retention of the high-temperature phase. It is obvious that thermal cycling causes effects similar to those of severe plastic deformation. These phenomena were observed in most martensitic transformations investigated thus far. ${ }^{16,22,32,40,50,51}$.

\section{Grain Size}

The grain size in a metal is related to its thermal history and impurity content. Commonly; a larger grain size favors higher Ms temperatures. ${ }^{16,22,23}$. Many discrepancies in experimental observations are attributed to the difference of grain sizes in the materials.

\section{Autocatalytic Effects}

A typical feature of a martensitic transformation is the "autocatalytic effect," 52 in which the formation of martensitic crystallites in a transforming matrix may trigger off a burst of new crystallites, thus accelerating the transformation. Preferred.nucleation sites of the martensitic product are developed around existing plates. Bunshah and $\mathrm{Mehl}^{7}$ : were able to record individual "bursts" of rapid formation of martensitic grains that comprised large areas around newly formed plates. The autocatálytic effect imposes limitations on the correlation between transformation and nucleation rates. For these reasons, nucleation theories ${ }^{8}$ rely primarily on the initial rates of formation, thus avoiding complications due to secondary effects like "autocatalysis" and impingement of crystallites upon each.other.

The nucleation problem has been the subject of extensive studies. Many theories have been proposed, but none of them is completely satisfactory and able to generalize the kinetics in one comprehensive theory. The present situation, from the thermodynamic and kinetic points of view, has been summarized by Cohen et al $^{8,53}$

\section{Crystallographic Rélationships}

A complete study of a martensitic reaction should involve, if possible, the crystallographic aspects. A unique feature of martensitic reactions is that crystals of either phase retain their orientation throughout 
several transformation cycles, although in some cases, as in high-purity uranium, a partial irreversibility, which is due to a rotation during polygonization, ${ }^{40}$ is observed. A single $\beta$ crystal splits up into $\alpha$ crystals during cooling; and it can be regenerated to a single $\beta$.crystal upon reheating. This phenomenon has been observed in many cases, $30,32,36$ but the retention of preferred orientation alone cannot be taken as critical evidence for a martensitic reaction since very low or very high thermal gradients in a specimen can produce preferred orientations. ${ }^{54}$ Orientation relationships are possible in diffusion-controlled processes also, e.g., Widmanstätten patterns, which are due to the intermatching of specific planes in two allotropic modifications.

The crystallographic theories do not differ much in principle; all assume that the shape deformations are due to a homogeneous shear from a 1 macroscopic point of view. Such shear cannot describe exactly the atomic movements required to obtain the observed orientation relationship between the parent and product phases. Therefore, it is necessary to postulate secondary strains that are heterogeneous on a fine scale and that do not contribute to the observed shape deformation. Bilby and Christian ${ }^{28}$ have reviewed the present theories for the crystallography of martensitic reactions.

\section{Transformations in Pure Metals}

The mechanism of polymorphic changes has been investigated in a number of pure metals: $\mathrm{Sn},{ }^{55-5 ?} \mathrm{Mn},{ }^{58} \mathrm{Na},{ }^{19} \mathrm{Li},{ }^{19,59} \mathrm{Hg},{ }^{20} \mathrm{Zr},{ }^{31-33} \mathrm{Ti},{ }^{31,34-36}$ $\mathrm{Fe},{ }^{37-39,60} \mathrm{Co} ;^{15,21-24,30} \mathrm{Ce},^{16}$ and $\mathrm{U}^{14,40,49,61-66}$. All these metals, except the first two, exhibit martensitic transformations when the high-temperature phase is rapidly cooled to the region of the low-temperature modification. This is in accord with the view first expressed by Troiano and Greninger, ${ }^{67}$ as well as by others, that all polymorphic transitions are probably of a martensitic nature. Kaufman ${ }^{68}$ and Kurdyumov ${ }^{69}$ suggested that martensitic transformations in alloys a re the analog of polymorphic modifications in pure metals. The transformation mechanism of the above-mentioned exceptions have not been determined unambiguously. ${ }^{56,57}$

B. The Situation in Plutonium

It is generally accepted that pure metals transform martensitically when the high-temperature modification is rapidly cooled into the region of the low-temperature phase. This is true even though in some cases elevated temperatures are involved, e.g., in $\mathrm{Fe}, \mathrm{Ti}, \mathrm{Zr}, \mathrm{U}$, and Co. Therefore, it would seem unlikely that the beta $\rightarrow$ alphatransformation in plutonium (below $358^{\circ} \mathrm{K}$ ) upon rapid cooling from the beta. phase is a diffusion-controlled reaction. As was pointed out above, an isothermal transformation behavior can be attributed to reasons other than a thermally activated process. Possibly the relative plastic properties of the two phases play an essential role. 
The following paragraphs a re a review and reinterpretation of earlier studies of the beta $\rightarrow$ alpha transformation in plutonium ${ }^{4,50}$ in view of some of the characteristic features of a martensitic reaction. The criteria that will be considered are: (1) isothermal and athermal behavior, (2) rates of transformation, (3) surface effects, (4) hysteresis between the temperatures of the transformation upon cooling and heating, (5) behavior under externally applied stress, and (6) behavior upon thermal cycling through the temperature range of the transformation.

\section{The Partially Athermal Characteristics}

As was shown previously, isothermal behavior does not disprove the operation of a martensitic mechanism, but a nucleation and growth process does not display an athermal behavior. Nelson ${ }^{4,71}$ did not detect any athermal component in the beta $\rightarrow$ alpha transformation during holding at constant temperatures and concluded that the reaction went to completion at all temperatures in the alpha range. Loasby and Lowe, ${ }^{5}$ however, observed a definite athermal character in the high-alpha range.

\section{Rates of Transformations}

Slow rates of transformation and even slow growth of individual plates are encountered in some martensitic reactions. Such kinetics are not due to a thermally activated process, and slow rates of transformation are not proof or justification for classifying the beta $\rightarrow$ alpha transition as a nucleation and growth process. Transformation kinetics alone do not indicate which reaction mode is the correct one. Should slow growth of individual grains be observed, microscopically or by other means, this could be

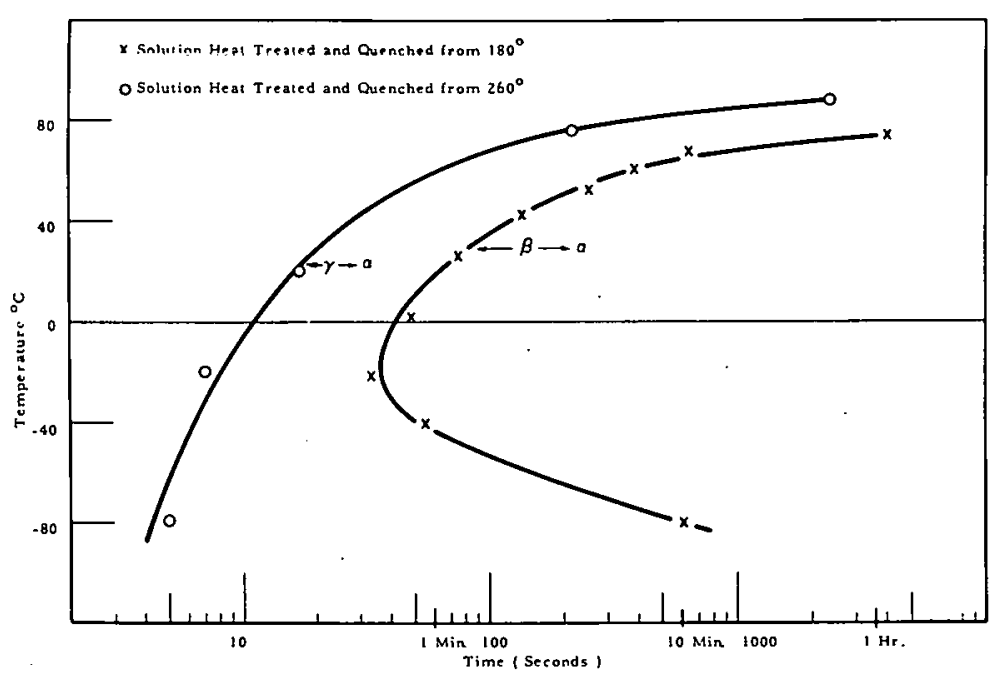

33597

Fig. 1. Time-Temperature-Transformation Curves for $50 \%$ Transformation of Plutonium ${ }^{4}$ attributed to a time-dependent yielding of the parent phase. One indication that such a mechanism is operative in plutonium is the rate of the gamma $\rightarrow$ alpha ${ }^{4}$ transfor mation in plutonium, which is much greater than the beta $\rightarrow$ alpha transformation, since it increases with decreasing temperature of transformation without passing through a maximum. The probable reason for this is that the gamma phase is much softer than the beta phase $^{72}$ and it more readily accommodates the stresses induced during the transformation. The characteristics of the TTT curves for $50 \%$ transformation (Fig. 1) support this as sumption. Down to $253^{\circ} \mathrm{K}\left(-20^{\circ} \mathrm{C}\right)$, 
there is only a small difference in the shapes of the curves, although the gamma $\rightarrow$ alpha transformation is faster. Below $253^{\circ} \mathrm{K}$ the difference in the curves becomes significant. A possible reason for this is that below $253^{\circ} \mathrm{K}$ the temperature is too low for relaxation of stresses in the beta plutonium, and the growth is slowed down considerably, but the gamma phase is still soft enough to allow increasing rates of the gamma $\rightarrow$ alpha reaction with the increase of the driving force brought about by the falling temperature.

\section{Surface Effects.}

A plutonium specimen shows considerable surface roughening when subjected to a alpha $\rightarrow$ beta $\rightarrow$ alpha cycle. ${ }^{73}$. Surface upheavals are known to be produced by the shape deformation accompanying martensitic reactions. Eutectoid decompositions, which-are diffusion-controlled, do not display any surface effects. ${ }^{74}$

\section{Hysteresis}

There is a relatively large temperature hysteresis between the: transformation on heating $\left(\sim 398^{\circ} \mathrm{K}\right)$ and on cooling $\left(\sim 353^{\circ} \mathrm{K}\right),{ }^{75,76,77}$ which depends upon the heating and cooling rates. Such a temperature hysteresis is a typical and required feature of a martensitic transformation where large, free-energy differences between the phases are required to balance the plastic strains that occur during the reaction.

\section{Behavior under Externally Applied Stresses}

Both Nelson ${ }^{4,78}$ and Loasby and Lowe ${ }^{5}$ found that the density of plutonium increased as a result of carrying out the beta $\rightarrow$ alpha transformation under pressure. Loasby and Lowe showed that pressures up to 4 kilobars (kbar) raised the final density to almost its theoretical value. Nelson ${ }^{4}$ attributed the higher densities to the collapse of voids rather than to the transformation of retained beta. He observed that pressures of about $6 \mathrm{kbar}$ accelerated the transformation, but the reaction rates were greatly retarded upon subsequent transformation. The beta $\rightarrow$ alpha transformation also is retarded after hydrostatic pressing at $453^{\circ} \mathrm{K}$ in the beta-phase temperature range.

The effects of hydrostatic pressure on the transformation kinetics in plutonium are characteristic of a martensitic transformation. For pressures up to $7 \mathrm{kbar}$, Bridgman ${ }^{79}$ obtained a value of $0.0109^{\circ} \mathrm{K} / \mathrm{bar}$ for the $\triangle \mathrm{T} / \Delta \mathrm{P}$ ratio of the alpha $\rightarrow$ beta transition. Schonfeld and Spindler ${ }^{80}$ obtained a value of $0.0102^{\circ} \mathrm{K} / \mathrm{b}$ ar at $5-\mathrm{kbar}$ pressure. Based upon the latter data, applying the Clausius-Clapeyron relation, the latent heat of transformation was $985 \mathrm{cal} / \mathrm{g}$ atom, which is in good agreement with the value of $958 \mathrm{cal} / \mathrm{g}$ atom calculated by Dean et al. ${ }^{81}$ from calorimetric determinations of the 
specific heats. Since good agreement was found, it means that hydrostatic pressure does not affect the kinetics other than by Le Chatelier's principle. Indeed, this should be so if the beta $\rightarrow$ alpha transformation is martensitic, since no shear components are involved in a purely hydrostatic stress.

This bulk-thermodynamical aspect has been extensively investigated for martensitic transformations in iron-base alloys. $45 ; 82-84$

Kaufman et al: ${ }^{84}$ found that the transformation was retarded even when the hydrostatic pressure was applied in the austenitic phase only, and the reaction was carried out at atmospheric pressure. The explanation for this behavior was that the hydrostatic pressure decreased the potency of embryos with pseudo-martensitic structure at temperatures in the austenite range. Fewer nuclei were available for the subsequent transformation, thus causing retardation of the phase change.

If the pressure is not purely hydrostatic but has shear components, then additional effects are expected. In this case, the shear components not only should affect the'bulk thermodynamics according to Le Chatelier's principle, but also should contribute to the kinetic aspects of the transformation. Since shear components are added algebraically to: the driving force of the reaction, application of low stress associated with elastic or very low plastic strains at temperatures below the equilibrium beta $\rightarrow$ alpha transformation temperature in plutonium. would be expected to accelerate the transformation. Severe stress would have the opposite effect and retard it. If the stress is applied at temperatures in the beta phase and causes strain hardening, the dislocations that are required for the martensitic phase transition may be immobilized, thus causing mechanical stabilization of the beta phase. These phenomena were observed by Nelson. ${ }^{4}$

\section{Behavior during Thermal Cycling}

Thermal cycling through a martensitic phase transformation can cause extensive physical damage. Such behavior has been observed in most pure metals, although in plutonium this: problem is more: acute because of the large: volume change during the beta $\rightleftharpoons$ alpha transformation. Nels on ${ }^{78}$ attributed the constant decrease in density as a function of the number of cycles through the transformation range to the formation of voids and cracks. But there probably was an additional effect, namely, the depression of the transformation temperature and thus an: accumulative increase in the amount of retained beta phase. 


\section{ULTRASONIC MEASUREMENTS}

\section{A. Selection of Ultrasonic Measurements}

The following factors contributed to: the selection of ultrasonic measurements as a means of studying the behavior of plutonium during the beta $\rightarrow$ alpha transformation:

1. The difference between the Young's moduli of the two phases at the transformation temperature is unusually large $\left(\mathrm{E}_{\alpha} / \mathrm{E}_{\beta}=2.5\right)^{72,85}$ Since the velocity of longitudinal waves is a function of the square root of the elastic constants, a $60 \%$ increase in velocity is expected during the beta $\rightarrow$ alpha transformation. A system:containing a mixture of the phases would have:an instantaneous velocity somewhere between the two limiting values, depending on the relative amounts of the phases. Because measurements of sound velocity can be performed at an accuracy of $\sim 1 \%$, an ultrasonic technique should be-a sensitive method for accurately determining the tranșformation kinetics.

2. Because voids can be created in plutonium during the beta $\rightarrow$ alpha transformation, the end point of the transformation cannot be defined clearly by experimental measurements in which dimensional changes of the specimen have a significant effect upon the value of the property. Measurements based upon the fluid-displacement method, or the $\sim 10 \%$ volume change during the beta $\rightarrow$ alpha transformation, cause confusion because the presence of voids can be interpreted as the partial retention of beta plutonium. Likewise, the formation of voids decreases: the $\sim 3 \%$ linear contraction and increases the $\sim 40 \%$ change in electrical resistivity. Because sound waves pass along nearly straight paths: through the solid portion of the sample, their. velocities are not affected significantly by voids. An erior in determining the thickness of a specimen, which is required to calculate the velocities from experimental determinations of acoustic transit times, results in a very small error in velocity.

3. Concurrently with the velocity determinations, the relative attenuation (i.e., dissipation of sound energy) can be obtained. Contrary to velocity, which is a rather structure-insensitive property, attenuation is highly structure-sensitive. This property can be used to gain some insight into the mechanism of the transformation, since attenuation.is influenced by the dynamics of dislocations during the phase change. But attenuation is affected by voids also, because an ultrasonic beam is scattered by a void, thus generally increasing the observed relative:attenuation. 
B. Correlation of Elastic'Properties and Ultrasonic Attenuation:with.

Metallurgical Phenomena

1. Velocity of Sound Waves

The elastic constants and the corresponding velocities of sound in a material are described in terms. of Hooke's law, wherein an elastic constant relates a linear stress to a linear strain. But morefundamentally, the elastic constants are functions of the thermodynamic state-of the material and of the interatomic binding forces in the crystal lattice. Transitions of the first and second order invariably produce measurable velocity changes that can be correlated to the specific mechanisms that cause the anomalies.

Two types of elastic waves can be propagated through the interior of a polycrystalline specimen having sufficiently. small grains so that it can be regarded as isotropic over its entire bulk. One type of wave is called longitudinal (or compressional, or dilatational), wherein the particle motion in a plane wave is in the direction of propagation of the acoustic wave. The other type is a transverse (or shear) wave, wherein the particle motion is transverse to the direction of propagation. The action of the acoustic waves on the elastic medium is to set up opposing forces that resist the displacement of the atoms. The elastic strain along the direction of propagation of the acoustic wave is accompanied by a strain of an. opposite sign in the transverse direction. The negative ratio of these two strains, i.e., the transverse contraction over the longitudinal expansion, is called Poisson's ratio, $\sigma$. The relationships between the sound velocities and the elastic moduli are shown in the following equations:

$$
\begin{aligned}
& V_{\ell}=\left[\frac{E}{\rho} \frac{1-\sigma}{(1+\sigma)(1-2 \sigma)}\right]^{1 / 2}, \\
& V_{t}=\left(\frac{\mu}{\rho}\right)^{1 / 2},
\end{aligned}
$$

and

$$
\frac{V_{l}}{V_{t}}=\left(\frac{1 \cdot-\sigma}{\frac{1}{2}-\sigma}\right)_{:}^{1 / 2},
$$

where

$$
\begin{aligned}
& \mathrm{V}_{\ell} \stackrel{=}{=} \text { longitudinal wave velocity } \\
& \mathrm{V}_{\mathrm{t}}=\text { transverse wave. velocity, }
\end{aligned}
$$




$$
\begin{aligned}
& \mathbf{E}=\text { Young's modulus, } \\
& \mu=\text { shear, or rigidity, modulus, }
\end{aligned}
$$

and

$$
\rho=\text { density. }
$$

Elastic constants would not be expected to make any sudden, large changes in value as temperature changes in a region where Hooke's law applied. ${ }^{86}$ Any anomalies in the behavior of these parameters probably would be caused by anelastic processes. Since these types of processes also are responsible for attenuation, it is reasonable to expect that anomalies in elastic constants should be accompanied by, and correlated with, variations in allenuation.

Poisson's:ratio often has been studied in conjunction with obser vations of anelastic properties of solids. It is rather temperature-independent up to about 570 to $670^{\circ} \mathrm{K}$ for metals with relatively high melting points like iron or copper. This idea was suggested by Grüneisen ${ }^{87}$ and was experimentally confirmed for a variety of materials, e.g., high-purity iron and a number of steels, ${ }^{88}$ for $\mathrm{Cu}, \mathrm{Fe}$, and $\mathrm{Pt},{ }^{89}$ and for $\mathrm{Ge} .{ }^{90}$ Cold work, tensile stresses, and transitions of first and second order have a profound effect on Poisson's ratio. Köster and Scherb ${ }^{91}$ reported that Poisson!s ratio of silver was greatly decreased by working; but regained its initial value after recrystallization. Whereas age-hardening of an aluminum-copper alloy has little effect on Poisson!s ratio, ${ }^{92}$ formation of martensite in a plain carbon steel significantly increases its value. Similar drastic changes in Poisson!s ratio were observed near the Curie temperature of Invar ${ }^{93}$ and in chromium 94 between 303 and $313^{\circ} \mathrm{K}$.

\section{Ultrasonic Attenuation}

The reaction of a crystalline solid to a stress wave does not obey fully the elastic stress-strain relationship of Hooke's law. ${ }^{95}$ Any solid medium possesses nonlinear or anharmonic features that give rise to higherorder coefficients in the strain-energy function. The nonlinear effects in a crystal lattice are related to third-or higher-order terms in the strainenergy expression. These features are partly responsible for sound absorption in a solid.

The term "ultrasonic attenuation" incorporates losses of sound energy due to scattering and absorption processes. ${ }^{96}$ Scattering is caused mainly by: (a) imperfections, e.g., voids, cracks, structural defects, grain boundaries, impurities and inhomogeneities; and (b) anisotropy of the elastic constants. Individual grains or grain colonies have different orientations and therefore different elastic properties. This anisotropy gives rise to an acoustic impedance mismatch along the path of the wave, which 
results in its being scattered. At the boundaries, reflection or refraction takes place in a regular or irregular way to produce coherent or incoherent scattering. The exact evaluation of the individual contributions is very complicated since numerous factors affect the scattering process, e.g., size, shape, density and distribution of the scatterers, as well as the frequency of the waves. Nevertheless, by subjecting the specimen to certain heat or mechanical treatments, like rolling to produce a fiber structure, one can estimate the individual contributions to the total attenuation.

The contributions to attenuation by absorption losses due to anharmonic effects can be discriminated from each. other because of their occurrence under different experimental conditions. For instance, the loss due to thermal-conductivity effects results when volumes of compression and of rarefaction are produced by the propagdiun of a longitudinal wave. This causes temperature gradients to be set up, and the resulting heat flow dissipates energy, which is supplied by the sound waves. The thermal conductivity effect is very small and is generally overshadowed by other loss mechanisms in the present experiment. At low temperatures, in the liquidhelium region, under certain experimental conditions the main contribution to attenuation can be due to interaction of sound waves with conduction electrons, with thermal elastic waves of the lattice vibrations; with nuclear spins, etc.

Loss processes due to interaction of high-frequency waves with dislocations have been studied extensively. Attenuation due to dislocation movement generally is observed at frequencies in the high-kilocycle and the megacycle range. If dislocations could move freely, the energy losses would be much greater than those observed; 97 therefore, the motion of the dislocation must be restricted. The various theories and models that try to explain the damping by quasi-static dislocations under the action of a periodic external shear stress differ from each other by their assumptions concerning the nature of these restrictions and by the mechanisms to overcome them.

Attenuation"peaks at low temperatures and at megacycle frequencies, called Bordoni peaks, ${ }^{98}$ : were successfully explained by Seeger ${ }^{99}$ as the relaxation loss resulting. when the dislocations lying near Peierls ${ }^{i}$ valleys; with the aid. of the external shear stresses and thermal fluctuations, throw loops over Peierls' hills. At present, experimental study of the Bordoni peak is the most reliable way to find the Peirelsistress.

Other restrictions to the free motion of dislocations ${ }^{100}$ are foreign atoms, other dislocations, and nodes of dislocation networks. Granato and Lücke 97 developed a theory that quantitatively agrees with the experimental observations. The theory was based on a suggestion originally made by Read ${ }^{101}$ that damping loss and modulus change in metals might 
arise from dislocations. Koehler ${ }^{102}$ developed the idea that a segment of a dislocation line pinned by foreign atoms might vibrate under the influence of an alternating stress field and behave like a damped string. These dis location loops vibrate under the influence of the external shear stress, and the energy loss results from the damping of the dislocation motion. At larger strain amplitudes, the dislocations should break away from the impurity atoms. Granato and Lücke assumed the presence of a dislocation network made up of edge and screw dislocations. They assumed that the dislocations are pinned strongly by the nodes of the dislocation network and weakly by-impurity atoms. Numerous experimental results on the effects of plastic deformation (e.g., Ref. 103) support the correctness of the theory. The interaction with other dislocations was demonstrated, for instance, in heavily deformed metals, where dislocations were sufficiently close together to immobilize each other; thus, the attenuation reached a maximum and then decreased with increasing deformation. ${ }^{104}$ But small amounts of cold work, up to about $2 \%$ strain, increased the dislocation damping due to the initial increase in the number of dislocations. ${ }^{105}$ The behavior of dislocations in irradiated samples ${ }^{106,107}$ also showed satisfactory agreement with the theory. Impurities and lattice imperfections, e.g., vacancies, inhibited the motion of dislocations and consequently caused a decrease of attenuation.

The existing theories that explain the mechanisms of various relaxation phenomena are well established, but attenuation due to phase transformations is much different, although the dynamics of dislocations is responsible for both types. Relaxation attenuation is a function of state; therefore it is displayed under equilibrium conditions and is determined by the relaxation time and the vibration frequency. The relaxation phenomena are observed at different temperatures for different vibration frequencies. The attenuation during phase transformation, on the other hand, is limited to a certain temperature or temperature range and is related directly to the transformation mechanism. In this case, attenuation is caused by dislocation motion and by changes in dislocation structure during the phase conversion. The magnitude of the attenuation is proportional to the speed of the transformation rather than the quantity of the transformed phase. ${ }^{108}$ The transformation attenuation is independent of the vibration frequency in the sense that it will occur at all vibration frequencies at the same temperature since it is related solely to the transformation mechanism. 


\section{EXPERIMENTAL PROCEDURES}

The techniques and procedures adopted in this investigation were dictated by the physical conditions of the experiments and by the experimental objectives, i.e., the study of the behavior of plutonium during the beta $\rightarrow$ alpha transformation by ultrasonic measurements. The highly toxic and radioactive plutonium specimens, as well as the ultrasonic components that came in intimate contact with the specimens, were enclosed in an inertatmosphere glovebox. A variety of additional factors, e.g., availability of high-purity plutonium, desired heat-treating conditions, optimum specimen geometry with respect to metallurgical treatments and ultrasonic measurements, etc., also contributed to the choice of the techniques and apparatus.

\section{A. Materials}

\section{Chemical Composition}

The material used in the present investigation was high-purity. plutonium metal, which was prepared from impure anodes by fused-salt electrolysis. ${ }^{109}$ Electrolytic deposits were consolidated and further purified by vacuum melting ( $10^{-6}$ Torr) and holding in the solid state at an elevated temperature in a resistance furnace. The ingots were cut to form slices about $1 \mathrm{~mm}$ thick. Chemical and spectrographic analyses of the various source ingots are given in Table I.

TABLE I. Analyses of High-purity Plutonium

(number of impurity atoms per million atoms)

\begin{tabular}{|c|c|c|c|c|}
\hline \multirow[b]{2}{*}{ Element } & \multicolumn{4}{|c|}{ Ingot } \\
\hline & CM- 18 & CM-27 & CM- 28 & CM-29 \\
\hline \multicolumn{5}{|c|}{ Chemical Analyses } \\
\hline Am* & 35 & 26 & 25 & 10 \\
\hline C & 363 & 322 & 2035 & 1169 \\
\hline $\mathrm{H}$ & 480 & 360 & 144 & 216 \\
\hline $\mathbf{N}$ & 570 & 173 & 155 & 346 \\
\hline O & 650 & 61 & 45 & 76 \\
\hline $\mathrm{Si}$ & 69 & 198 & 112 & 121 \\
\hline $\mathrm{U}$ & 28 & 42 & $35^{\circ}$ & 39 \\
\hline \multicolumn{5}{|c|}{ Spectrographic Analyses** } \\
\hline $\mathrm{Al}$ & 36 & 90 & 45 & 36 \\
\hline $\mathrm{Cr}$ & 5 & 47 & 37 & 23 \\
\hline $\mathrm{Fe}$ & 87 & 130 & 65 & 43 \\
\hline $\mathrm{Ga}$ & 3 & 17 & 3 & 7 \\
\hline $\mathrm{Mn}$ & 1 & 0.5 & 12 & 2 \\
\hline $\mathrm{Ni}$ & 12 & 82 & 33 & 33 \\
\hline
\end{tabular}

*Americium is continually bred-in by decay of $\mathrm{Pu}^{241}$. Americium content corrected to date of preparation of ingot.

** Other elements analyzed for, but below limits of spectrographic detection, and their lower limits of detection are: $\mathrm{Ag}-2, \mathrm{~B}-22, \mathrm{Ba}-0.4, \mathrm{Be}-3, \mathrm{Bi}-1, \mathrm{Ca}-12$, $\mathrm{Cd}-2, \mathrm{Co}-4, \mathrm{Cu}-4, \mathrm{~K}-12, \mathrm{Li}-0.1, \mathrm{La}-2, \mathrm{Mg}-9, \mathrm{Mo}-1, \mathrm{Na}-20, \mathrm{~Pb}-1, \mathrm{Rb}-3, \mathrm{Sb}-2$, $\mathrm{Sn}-4, \mathrm{Sr}-0.003, \mathrm{Ti}-3, \mathrm{~V}-2, \mathrm{Zn}-2, \mathrm{Zr}-1$, and $\mathrm{W}-2$. 


\section{Specimen Geometry}

The proper specimen geometry depended on two major considerations, one based upon metallurgical factors and the other upon the ultrasonic technique.

From the metallurgical point of view, the plutonium disc should be as thin as possible. Such a specimen would rapidly attain thermal equilibrium with the quenching bath. This is of extreme importance in highpurity plutonium and at low isothermal transformation temperatures where the reaction starts almost immediately. Also, a thin sample more easily accommodates the stresses induced during the transformation and thus mininizes the effect of this variable on the behavior of the specimen during the phase changes.

On the basis of the ultrasonic techniques, the specimen should be thick so that the transit times are long, and, consequently, the errors in the calculated sound velocities are small. A thicker specimen also satisfies, to a better degree, the condition of a homogeneous isotropic solid. The width of the ultrasonic pulse is another limitation to the minimum thickness of the sample; this problem is analyzed in detail in Section C below. The specimen diameter has to be large enough so that the ultrasonic pulse echoes several times in the specimen before the sound beam spreads out enough to contact the lateral edge.

Because of these requirements, the optimum dimensions of the specimens were considered to be approximately $19.0 \mathrm{~mm}$ in diameter and $0.8 \mathrm{~mm}$ thick. The reflecting surfaces were polished through 600-grit silicon carbide papers and were prepared parallel within $0.0025 \mathrm{~mm}$.

B. Specimen-clamping Device

The ultrasonic clamping device (Fig. 2) performed two main functions: (1) it served as a holder for the transmitting and receiving transducers, which were held on a common longitudinal axis, and kept their faces parallel to each other; and (2) it permitted rapid insertion of the specimen into the device, thus allowing recording of ultrasonic measurements within $0.5 \mathrm{sec}$ after insertion. The clamping device was designed so that upon insertion the specimen was lightly pressed between the faces of the transducers and electrically grounded and shielded. Only a small pressure of the transducers on the specimen could be tolerated, otherwise it would affect the transformation behavior of the specimen. 


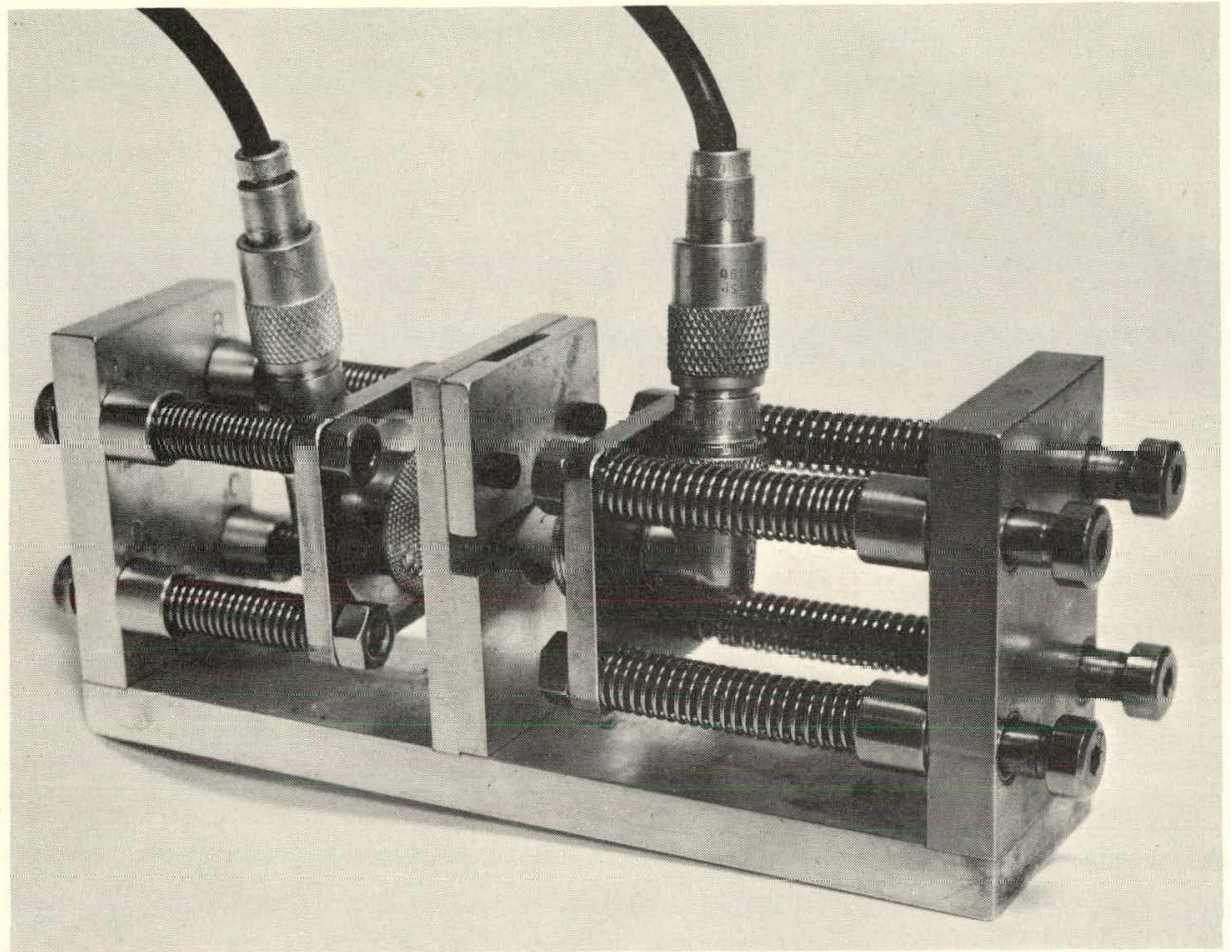

39111

a. Photograph

SLOT INTO WHICH SPECIMENS -
ARE DROPPED

ARE DROPPED

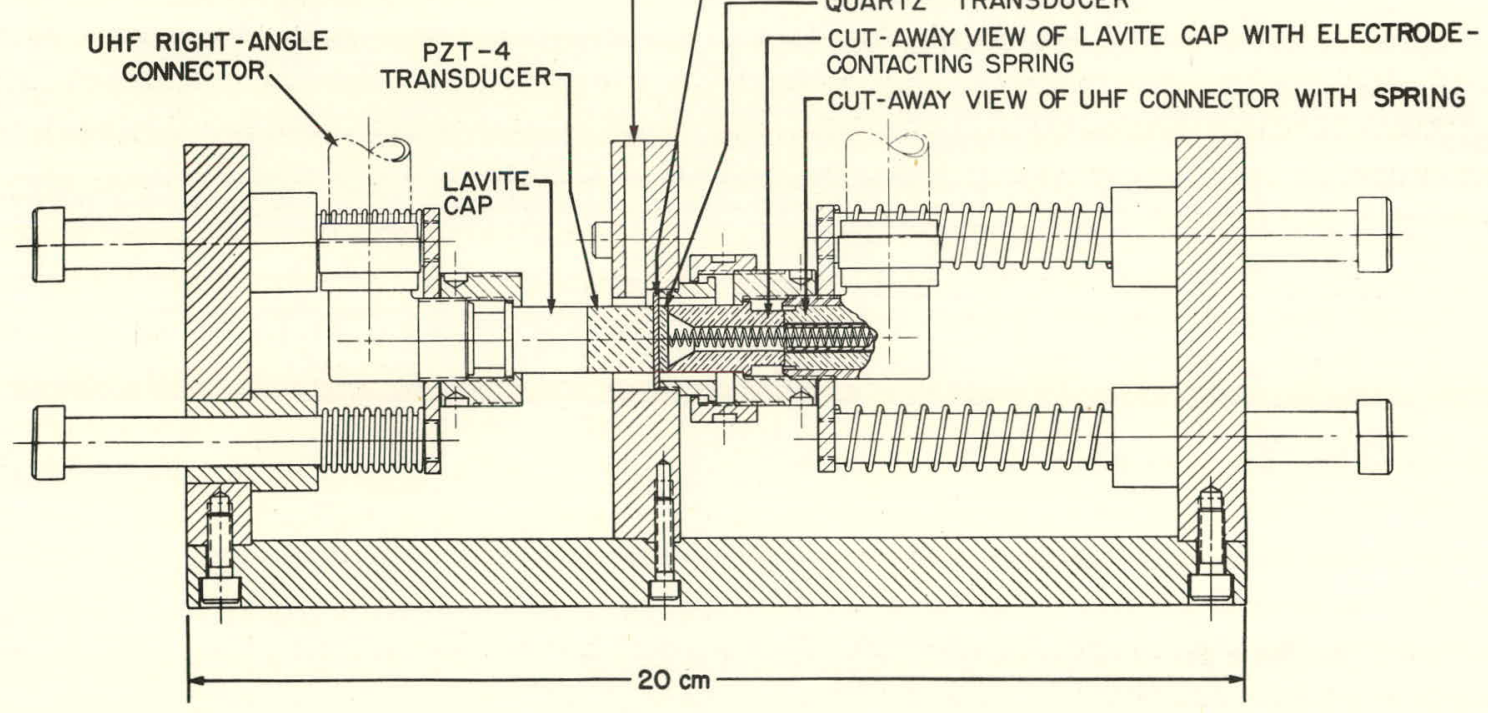

41898

b. Drawing

Fig. 2. Specimen-clamping Device 
The phase-transformation studies were carried out at temperatures between 195 and $473^{\circ} \mathrm{K}$ in different liquid media that served as the quenching bath. Peanut oil was used for temperatures above room temperature; for. those below, acetone and dry ice. Since the insulators in the Ultra High Frequency connectors (Amphenol Corp.) that are mounted on the clamping device could not be used at elevated temperature or with acetone, they had to be replaced by machined and fired Lavite (America Lava Corp.). A stainless-steel vessel was used to contain the liquid media and the clamping device. The container, in turn, was inserted in a split-top heating . mantle (Glas-Col Co.). The quartz-fiber construction of the mantle gave it excellent insulation properties for both elevated-and low-temperature work. Rates of heating and cooling were manually controlled with variable autotransformers.

\section{Ultrasonic Apparatus}

The method used for the generation and detection of ultrasonic waves in the specimens was a through-transmission pulse-echo system. 110 Two separate sound transducers were used: one to generate a short-duration stress pulse at one face of the specimen, the other to detect this pulse at the opposite face. Very little energy of the sound pulse is absorbed by. the receiving transducer and its associated electronic detecting equipment if there is no matching of impedances between the transducer and the electronic circuit; most of the incident sound energy is reflected back to the face of the specimen from which it started. As before, practically all of the energy incident upon this face, i.e., the transmitter face, is reflected back to the face with the receiver, where it again is detected and reflected. The sound pulse reflects back and forth in the specimen and is detected each time it impinges upon the receiving transducer. Energy is continuously extracted from the sound pulse as it traverses the specimen (see Section IIIB- 2 above). The energy of the sound pulse usually decreases exponentially with time and with path length; therefore the attenuation is commonly measured in logarithmic units such as decibels per unit length $(\mathrm{db} / \mathrm{cm})$ or decibels per unit time $(\mathrm{db} / \mu \mathrm{sec})$. Thus the detected signals at the receiving transducer are a series of pulses with exponentially decreasing amplitudes, and the interval between successive pulses is the time required for the stress pulse to make one round trip between the faces of the specimen. The time for a sound pulse to travel from one face of the specimen to the other has been referred to above as the transit time, $\tau$. It is related to the velocity of sound waves, V, and the thickness of the specimen, L, by the equation.

$$
\tau=\frac{\mathrm{L}}{\mathrm{V}} \text {. }
$$

For a plutonium specimen transforming from beta to alpha, the increase in longitudinal sound velocity, $\mathrm{dV} / \mathrm{V}$, is $60 \%$, whereas the decrease in thickness, $-d L / L$, is $3 \%$. By partial differentiation of Equation (4), one obtains 


$$
\frac{d(l / \ddot{T})}{l / T}=\frac{d V}{V}-\frac{d L}{L}
$$

Since - dL/L during transformation is small with respect to $\mathrm{dV} / \mathrm{V}$, the changes in transit time reflect primarily changes in velocity, which, in turn, are directly related to the proportion of the two phases present in the specimen. Therefore, the basis for this experiment is that a continuous record of the progress of the transformation can be kept by continuously monitoring the transit time in a specirren undergoing phase transformation.

A measurement of the transit time depends upon the ability to resolve successive sound pulses; thus, the signal denoting the arrival of one pulse should not arrive until the signal from the preseding pulac lids cullpletely died oul. Since the velocity in alpha plịtonium io approxirialely $2 \times 1 U^{5} \mathrm{~cm} / \mathrm{sec}$, the maximum allowable pulse length for specimens of the size mentioned above would be about $0.6 \mu$ sec. Because conventional techniques and instruments for producing sound pulses for velocity measurement by the pulse-echo method usually do not generate such short pulses, $111-113$ the method used in this experiment is described in detail in the following paragraphs.

It is customary to generate sinusoidally oscillating sound pulses when investigating sonic velocities and attenuations in the megacycle frequency range. ${ }^{114}$ The transducers are designed so that the frequency to be propagated in a test specimen is made equal to the natural mechanical resonance frequency of the transducer, or an odd multiple of it, ${ }^{115}$ by making the thickness of the transducer equal to an odd multiple of half the wavelength of sound in the transducer material. As a result, once a transducer is excited, it will tend to continue oscillating even after the exciting force is removed, unless the transducer is damped either mechanically or electrically. This effect tends to produce a pulse with extremely long duration. Even if the vibration is strongly damped, the very existence of a sine-wave pulse of a more or less definite frequency imposes some restrictions on the minimum length such a pulse may have. To speak of a frequency, one implies a repetition of some event; thus, there must be a few cycles of oscillation of a sound wave. A strictly monochromatic wave, of course, would have infinite duration. If the minimum number of cycles that a wave must have in order to have a frequency assigned to it is arbitrarily chosen to be three, then we see that a $\mathrm{l}-\mathrm{Mc} / \mathrm{sec}$ wave pulse would need to be $3 \mu \mathrm{sec}$ long, whereas a $10-\mathrm{Mc}$ pulse need be only $0.3 \mu$ sec long. The duration of the l-Mc pulse is toolong for use in our plutonium samples, and standard commercial equipment does not produce pulses much shorter than $1 \mu$ sec. A pulse derived from a shott-duration, nonoscillating stress wave was used to overcome the disadvantages of sinusoidal oscillations.

Jacobsen ${ }^{16,117}$ showed that sources of stress in piezoelectric crystals are located in regions in which electric field gradients are present. In general, when a voltage is applied across a piezoelectric crystal, the 
electric field is spatially uniform everywhere inside the crystal, so no stress wave is generated in its bulk. A gradient usually exists at the surface of the crystal, and the stress is generated here. Cook ${ }^{118}$ and Redwood ${ }^{119,120}$ showed that in normal use, where piezoelectric crystals are vibrated near their resonant frequency or at odd harmonic frequencies, the sound produced at one face of the crystal interferes almost instantaneously. with sound produced at the opposite face in such a way that the crystal can be considered as a uniformly: vibrating body. Redwood also described the response of such a transducer under several different types of electrical driving waveforms. Cook showed the waveforms to be expected if a transducer were excited by a very short electrical pulse, one whose duration was sliurt comparcd to the transit time in the transducer. A shortduration stress wave is formed at each surface and moves into the body of the transducer. Figure: 3 a represents a solid piezoelectric material with a.nonoscillating, spatially smooth, electric field between faces $A$ and $B$. Stress pulses are generated only at these faces, and they move into the body of the transducer. The most important requirement is that the duration of the electrical pulse be much shorter than the time it takes each stress pulse to travel from one face to the other. The amount of resonant vibration of the transducer depends upon its composition and how it is damped electrically and mechanically.

Figures 3b-3e illustrate what happens when the transducer is coupled to another medium. In Fig. $3 b$, face B has sent a pulse not only toward the opposite face of the transducer, but also into the coupled semiinfinite medium. The polarity of the pulse represents the vibration of the medium; for instance, an upward-peaked pulse represents a region of compression, while a downward-peaked one denotes a region of rarefaction. Figure 3c illustrates the situation a little later, when the pulses in the transducer have completely crossed over to the other side and have just been reflected off the opposite faces. The point to be noticed is that there are two pulses of opposite polarity in the medium, separated by the transit time in the transducer, $\tau_{C}$. The polarities and amplitudes of succeeding pulses are dependent upon the ratio of acoustic impedances of the transducer and the medium as shown in Fig. 2 of Cook's paper. ${ }^{118}$ : The amplitudes at some point in the medium as a function of time would look like the sketch in Fig. 3d.

When the transducer is coupled to a thin medium instead of the thick one, something important happens. If the medium is thin enough so that the transit time in it is less than the transit time in the transducer, a. pattern like that shown in Fig. $3 e$ is obtained. Here, pulses $B^{\prime}, A^{\prime}$, and $B^{\prime \prime}$ are the 
pulses shown in Fig. 3d, but there are other pulses between them that are due to the sound echoing in the thin medium ( $\tau_{\mathrm{p}}$ is the transit time in this medium).

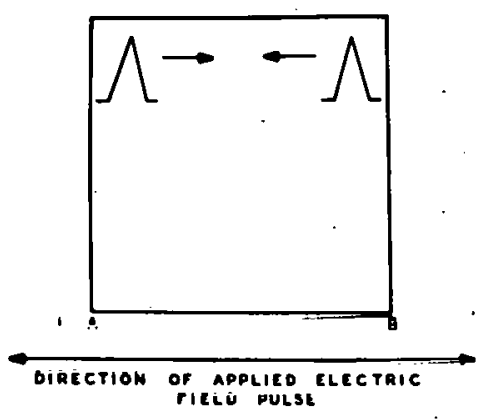

(a)

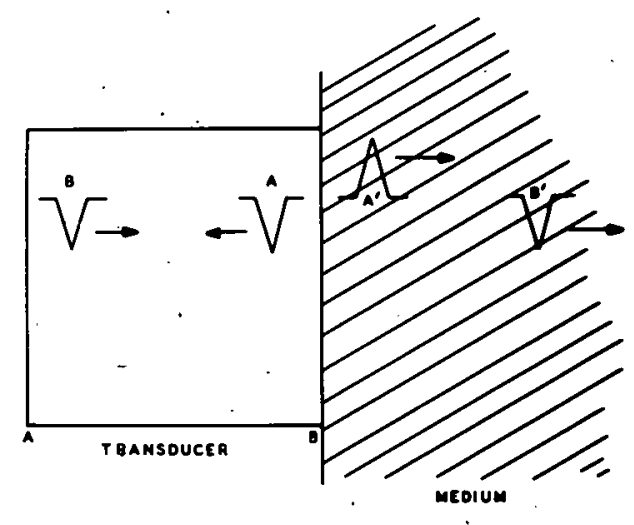

(c)

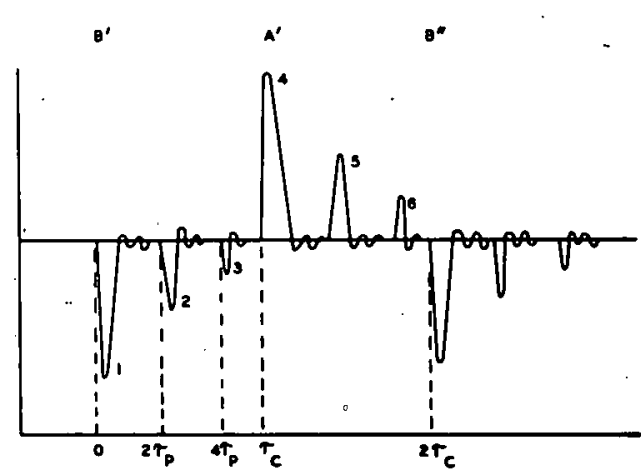

(e)

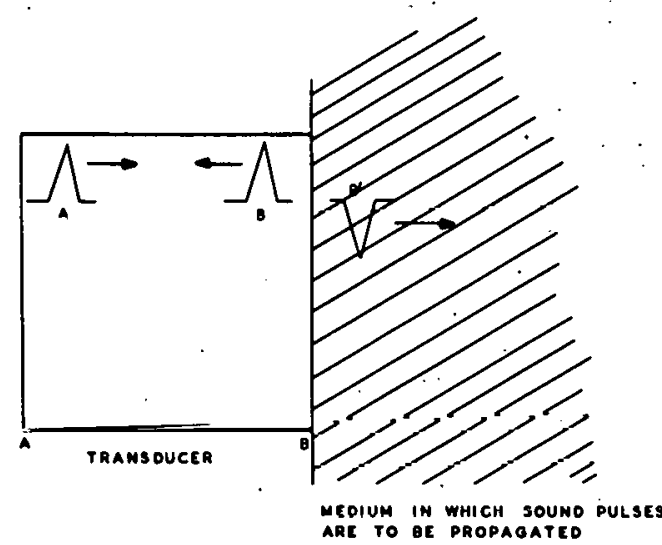

(b)

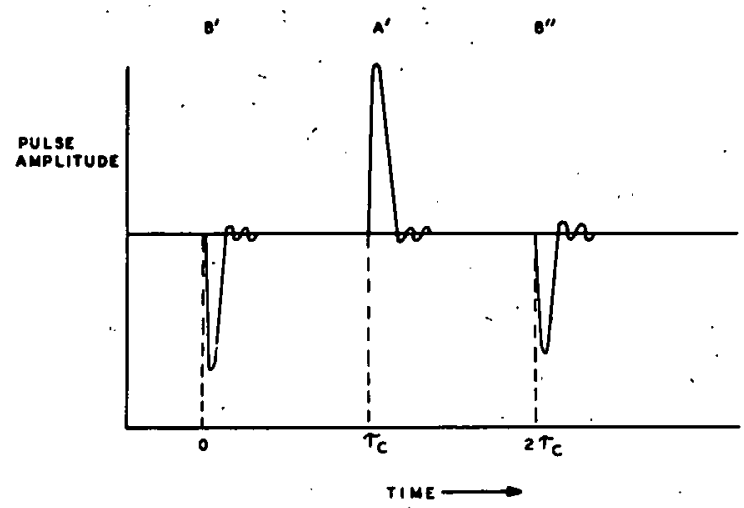

(d)

Fig. 3

Stress Pulse Generation by Thick Transducers.

(a) Stress pulses in an isolated transducer immediately after application of a short electrical pulse, (b) stress pulses in a transducer and in a coupled medium immediately after application of a short electrical pulse, (c) stress pulses in a transducer and in a coupled medium at a time $\tau_{C}$ after application of a short electrical pulse, (d) pulse amplitudes at a point in a thick coupled medium as a function of time, and (e)pulse amplitudes from a thin coupled medium as a function of time. 
Based on some of Cook's work, Henry and co-workers designed. electronic circuitry to produce short-duration, high-voltage pulses and a double-transducer system to nondestructively test thin plates of metal for bonding flaws. ${ }^{121,122}$ Their initial design of the pulse generator has been used in the present work. ${ }^{123}$ The device produces an electrical signal of $0.06-\mu$ sec duration at the base of the pulse with about $600 \mathrm{~V}$ amplitude. This signal is impressed across a transducer to produce stress waves of short duration. Figure 4 shows the schematic diagram of the generator. In general, the electrical signal across the transducer depends on the electrical properties of the transducer, as well as on the electronic components in the circuit. Details on the various mechanical damping features that might be used under certain circumstances will not be given here, nor will the various modifications of pulse-shaping circuits that might be required; only the arrangements used for this experiment are described.

The transmitting transducer was a lead zirconate-lead titanate ceramic, PZT-4 (Clevite Co.), in the form of a cylinder $1.27 \mathrm{~cm}$ thick and $1.27 \mathrm{~cm}$ indiameter, which was made from compacted powder. When such a ceramic is placed under ahigh electric field for a long time, a permanent electric dipole moment is imparted to the element, and it. behaves very much like a piezoelectric single crystal. ${ }^{124}$ Thus, when this transducer is coupled to a thin specimen, short pulses of sound can be propagated into the specimen in the manner described above. The thickness of the transducer was chosen so that the first pulse would echo two or more times in the plutonium specimen before the pulse from the transducer face that was not against the specimen traversed the transducer, entered the specimen, and was detected. The receiving transducer was a quartz single crystal, $1.27 \mathrm{~cm}$ in diameter, with resonant frequency of either 10 or $20 \mathrm{Mc}$; different crystals were used on different occasions. For electrical contact, one of the faces of the quartz disc was coated with a layer of silver suspended in an organic liquid and then baked for an hour at $770^{\circ} \mathrm{K}$ (below the Curie point of quartz, $798^{\circ} \mathrm{K}$ ). The edge of the disc was cleaned to assure electrical separation between its two faces. Finally, the quartz was glued to the Lavite cap (see Fig. 2b) with an Araldite epoxy that did not soften below $623^{\circ} \mathrm{K}$ and did not crack at temperatures down to $195^{\circ} \mathrm{K}$. : The electrical contact between the UHF connector and the silvered face and also the electroless-nickel-coated face of the PZT-4 transmitter, was achieved with phosphor-bronze springs in the center holes of the connectors. This combination of tranisducers gave very good resolution of the pulses.

The configuration of the transducers and the plutonium specimen is illustrated in Fig.: 5; Fig.-3e shows the type of echo pattern from this arrangement. The transit time from face $B$ to face $C$ (Fig. 5) through the plutonium is $\tau_{p}$, and $\tau_{c}$ is the transit time from face $A$ to face $B$ through the ceramic transducer. The transit time through the quartz receiver was so short that it was ignored. Pulse 1 (Fig. 3e) was generated at interface $B$ (Fig. 5) and traveled through the plutonium once to $C$; 


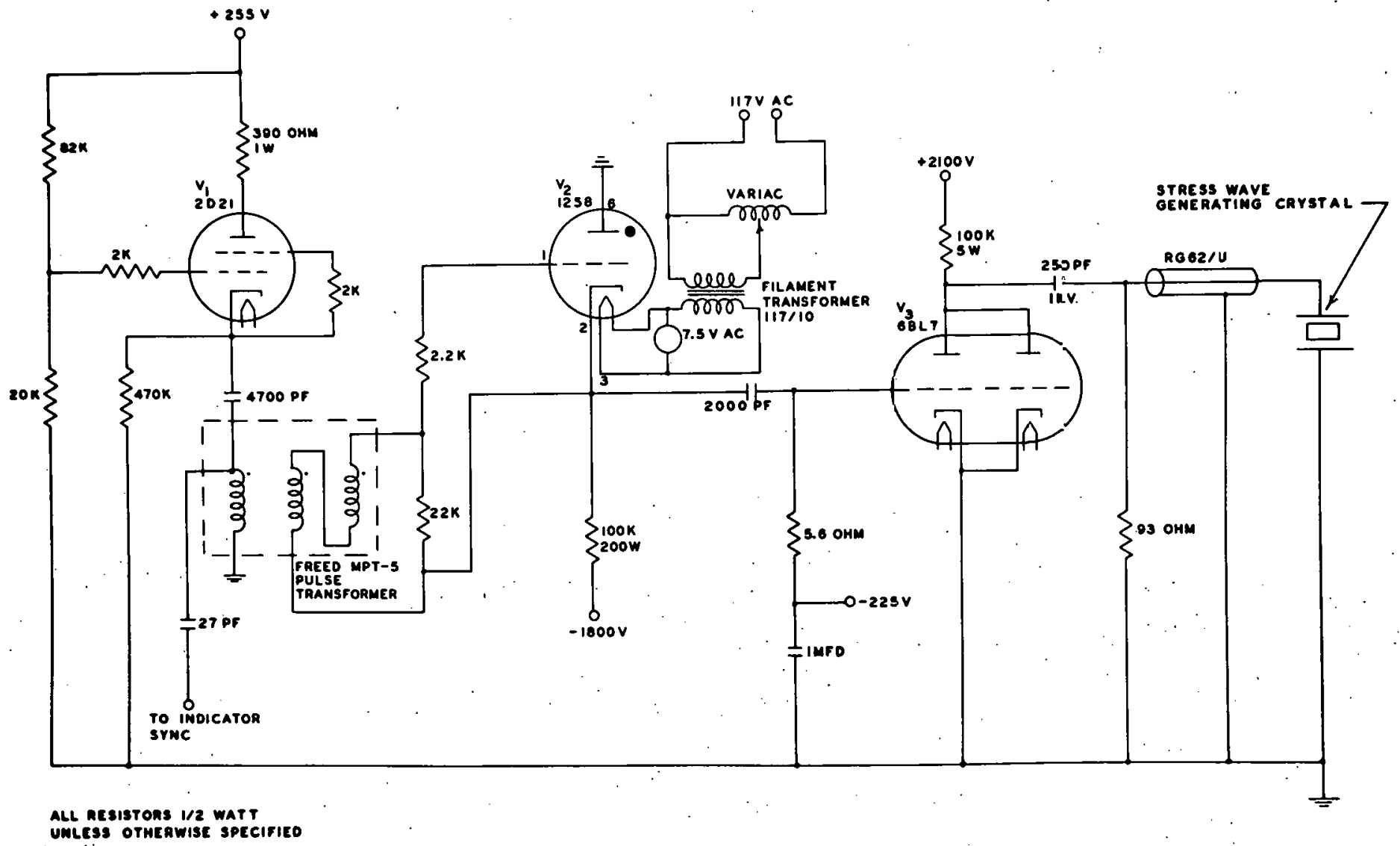

42877

Fig. 4. Schematic Drawing of Pulse Generator 
IO MEGACYCLE/SEC. QUARTZ TRANSQUCER

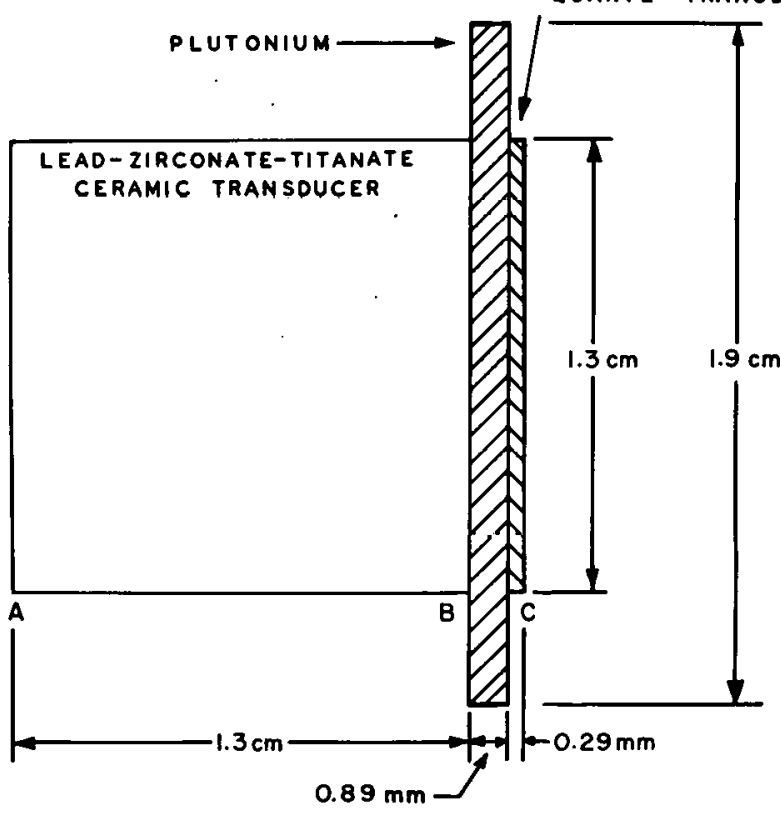

42878

Fig. 5. Liṇe Drawing of Specimen-Transducer Configuration pulse 2 originated at interface $B$ anditraveled the path $B$ to $C$ to $B$ to $C$; pulse 3 originated at interface $B$ and traveled the path $B$ to $C$ to $B$ to $C$ to $B$ to $C$; pulse 4 originated at face $A$ and traveled the path $A$ to $B$ to $C$, pulse 5 originated at face $A$ and traveled the path $A$ to $B$ to $C$ to $B$ to $C$, etc. The third series of pulses were from the pulse generated at $B$ following the path $B$ to $A$ to $B$ to $C$, etc., and many other series of pulses followed. Figure 6 shows a photograph of one such series of echoes on an oscilloscope; they correspond to pulses 4,5 , and 6 of Fig. $3 \mathrm{e}$.

Figure 7 is a block diagram of the apparatus that was

used for generating and detecting the pulses. The specimen and the transducers, along with the associated mounting apparatus, were in a gas-tight glovebox. All the electronic equipment was kept outside the glovebox. The two cables that lead to and from the transducers were each about $4 \mathrm{~m}$ long and wcre attached to gae-tight feed-through connectors at the glovebox wall. The cable from the receiving transducer was connected to the input terminals of an ascilluscope, d Teklrumix "j45A usilloscope with a Type B plug-in preamplifier. With a gain sensitivity of $0.005 \mathrm{~V} / \mathrm{cm}, \mathrm{a}$ signal that was satisfactory for monitoring purposes could be secn read-

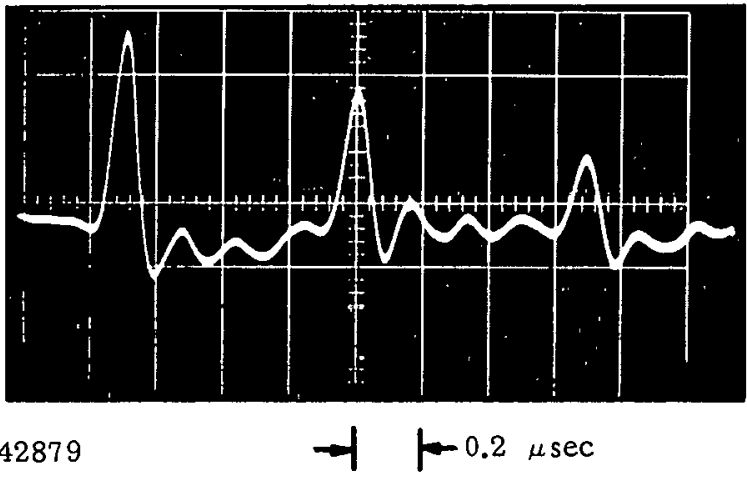

Fig. 6. Photograph of Traces Displayed on Oscilloscopé Screen

ily. Pulse amplitudes for the first series of echoes ranged from 0.005 to $0.02 \mathrm{~V}$ at the oscilloscope. The signal at the receiving crystal undoubtedly was greater, because there were losses in the 93-ohm cables and attenuation due to the $93-0 h m$ resistor at the scope. This resistance was not used to match impedance in the circuit, but more to damp out electrical oscillations from the large accumulated capacitance in the cable. No special impedance-matching networks were used in the apparatus, since satisfactory signal amplitudes and good pulse shapes were obtained without them. 


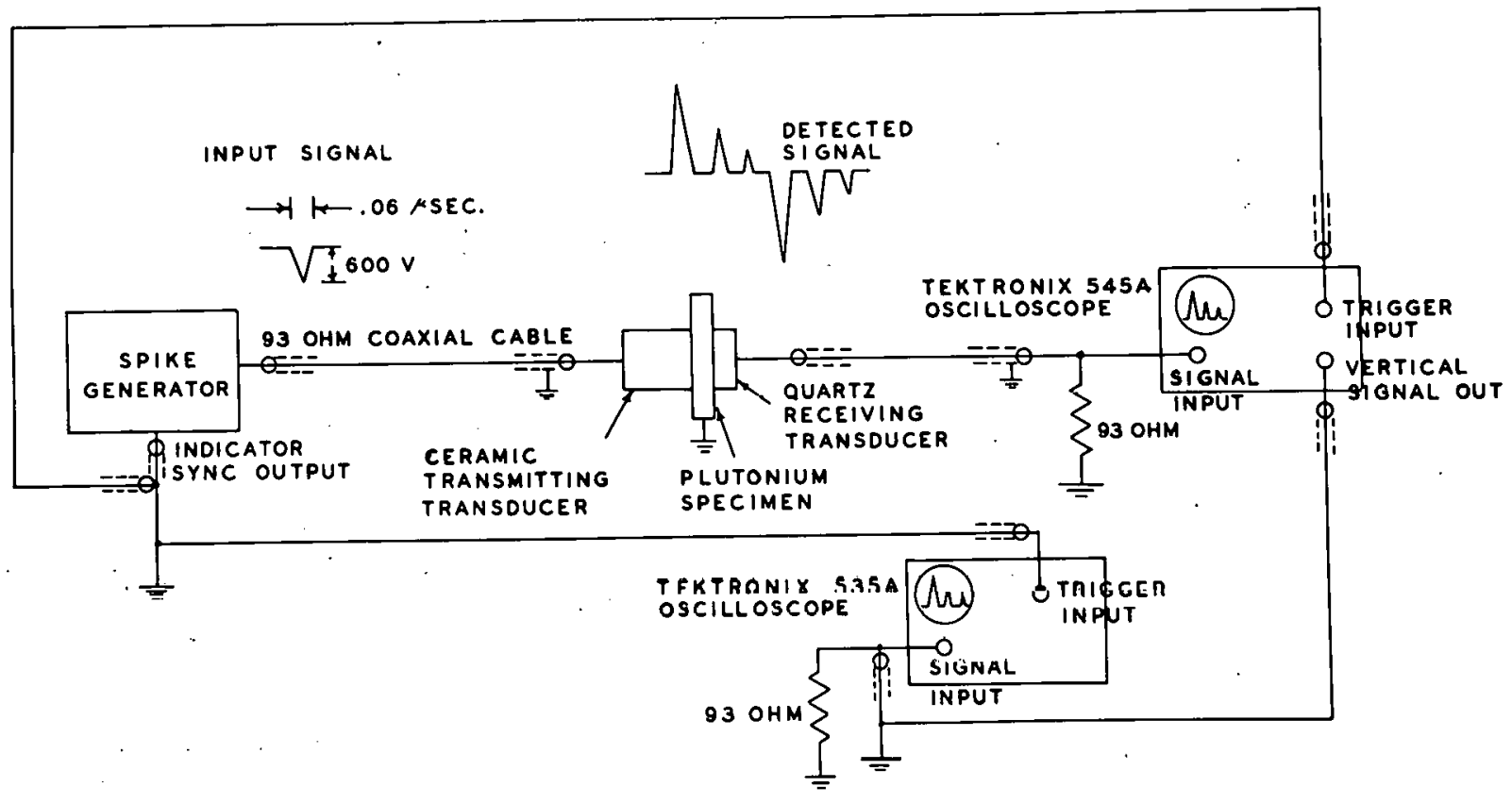

42880

Fig. 7. Block Diagram of Apparatus Used for Generating, Detecting, and Recording the Transit Time and Amplitude Data

The output of the vertical amplifier of this oscilloscope was available at a connector on the front panel; this signal was fed to the input of another oscilloscope, a Tektronix Type 535A, using a Type B plug-in unit. A movie camera, which was controlled by a lapse-time unit, was positioned so that pictures of the face of the cathode-ray tube and of a wrist watch could be taken simultaneously. Thus it was possible to make a record of the pulse-echo pattern as a function of time at intervals ranging from 0.2 to $60 \mathrm{sec}$. Figure 6 shows such a picture; the horizontal axis represents time, and the vertical axis is proportional to the amplitude of sound impinging upon the receiving crystal. The transit time, $\tau_{p}$, of sound within the plutonium was equal to half the time difference between successive peaks. The relative attenuation of the sound was found by measuring the amplitudes of successive echoes. If $A_{1}, A_{2}$, and $A_{3}$ are the measured amplitudes on an arbitrary linear scale, then the attenuation is computed by

$$
\alpha=\frac{10}{\tau} \log _{10} \mathrm{R}_{\mathrm{A}}
$$

where

$$
R_{A}=\frac{1}{2}\left(\frac{A_{1}}{A_{2}}+\frac{A_{2}}{A_{3}}\right) .
$$




\section{Calibration of Oscilloscopes}

Transit times in the plutonium samples during the isothermal treatments were determined by measuring the distance between two successive peaks on a projection of a frame of the movie film. The rectangular graticule (Fig. 6) was used to establish the scale factor of the projected image. The graticule squares were $1 \mathrm{~cm}$ on a side; the sweep-speed selector knob of the oscilloscope was calibrated in terms of the time required for the trace to sweep horizontally over $1 \mathrm{~cm}$. A check was made to find the actual sweep speeds of the Tektronix 535A oscilloscope for the two speeds that were used during the experiments. A $10-\mathrm{Mc} / \mathrm{sec}$ sine wave from a crystalcontrolled oscillator, a Hewlett-Packard Electronic Counter, Model 524B, was displayed on the face of the oscilloscope. This sine wave is stable in frequency to five parts in $10^{8}$ and was used as an absolute standard. The nominal $0.2-\mu_{\mathrm{sec}} / \mathrm{cm}$ sweep speed should correspond to exactly two cycles in $1 \mathrm{~cm}$. The sweep speed between the left-hand edge of the graticule to the graticule line $3 \mathrm{~cm}$ to its right, and also between 8 and $10 \mathrm{~cm}$, was $0.201 \mu \mathrm{sec} / \mathrm{cm}$; also, from the $4-\mathrm{cm}$ line to $7 \mathrm{~cm}$, the calibration was $0.195 \mu \mathrm{sec} / \mathrm{cm}$. Therefore, the error in measurements of transit time depended upon the positions of the peaks on the oscilloscope face; the maximum error arising from this factor was about $2.5 \%$, with smaller errors being more probable. The same procedure was used for calibrating the sweep speed when the speed control was set for $0.5 \mu \mathrm{sec} / \mathrm{cm}$. The speed varied from 0.500 to $0.502 \mu \mathrm{sec} / \mathrm{cm}$, which would produce a maximum error of less than $0.5 \%$.

For some measurements of transit time, a time-delay circuit in the Tektronix Type 545A oscilloscope was used to measure intervals between pulses. Use of the Hewlett-Packard Counter led to the finding that each division on the dial control that nominally represented $2 \mu \mathrm{sec}$ actually represented $1.997 \mu \mathrm{sec}$. All transit-time measurements that were determined by this method were corrected for this error.

\section{E. Procedures}

Each specimen was subjected to a series of prerun and postrun measurements. These will be given in chronological order in the following paragraphs.

\section{Density Measurements}

The density of each specimen was measured within limits of $\pm 0.005 \mathrm{~g} / \mathrm{cm}^{3}$ before and after each test according to the procedure described by Blumenthal. ${ }^{125}$ The measured densities before the tests were about $19.65 \mathrm{~g} / \mathrm{cm}^{3}$. 


\section{Room-temperature Ultrasonic Measurements}

Just before ultrasonic measurements; the flat surfaces of the specimens were cleaned and the thicknesses measured to the nearest $0.0025 \mathrm{~mm}$ by means of a micrometer. The average of 10 micrometer readings was taken as the specimen thickness: The specimen was then inserted into the clamping device and immersed in an oil bath at room temperature. The transit time at room temperature was measured with the time-delay circuits of the 545A oscilloscope, and the pulse amplitudes were read directly from the oscilloscope screen. The peanut oil served as an ultrasonic coupling medium for longitudinal waves. Shear waves, however, cannot be transmitted through liquid coupling media; therefore, a solid bond between the piezoelectric transducers and the plitonium specimen was used for such measurement.

\section{Heat Treatments}

The subsequent thermal treatment dependcd on the type of experiment to be carried out: (1) quasi-equilibrium conditions, i.e., slow heating and cooling; or (2) isothermal conditions.

In the present experiments the heating and cooling rates, from room temperature up to about $433^{\circ} \mathrm{K}$ and back, during quasi-equilibrium tests were about $0.3^{\circ} \mathrm{K} / \mathrm{min}$. For a few tests, higher rates were employed to examine their effect on the magnitude of the hysteresis between the temperatures of the transformation upon heating and cooling. The transit times and pulse amplitudes were automatically photographed by the movie camera: The oil bath provided good ultrasonic coupling for longitudinal waves at all temperatures. No difficulties were encountered for shear velocity measurements from room temperature up to the alpha $\rightarrow$ beta phase change. Upon transformation, the solid bond between the transducers and the specimen broke.because of the large volume change and the drastic roughening of the plutonium surfaces. A variety of Araldite epoxies and other adhesives were tried but to no avail, although some materials seemed to withstand the alpha $\rightarrow$ beta change, but broke off during the reverse transformation on cooling.

In the isothermal experiments the specimen first was heated to $453^{\circ} \mathrm{K}$, a temperature within the beta phase range, and held at that temperature for $45 \mathrm{~min}$. Since high-purity plutonium was expected to transform from the beta phase to the alpha phase rapidly, the prolonged heat treatment was designed to yield a large grain size with the intent of retarding to some degree the rate of the transformation so that the specimen might attain thermal equilibrium with the quenching bath before the reaction started. The specimen was rapidly transferred from the beta bath into the insertion slot of the clamping device in about 0.5 sec. The movie camera, set at the desired frame speed, which depended on the expected rate of the 
phase transformation, was started before the specimen was removed from the beta bath. The time elapsed between immersion of the specimen and the first resolvable sound pulses on the oscilloscope was between 0.8 and 1 sec. This time lapse was due to several contributing factors, e.g., the time of free fall in the clamping device, the time of the release of the transmitting transducer towards the specimen, and the time of the electronic recovery of the oscilloscopes. Because of the electric field radiating from the transmitter, the oscilloscopes were severely overloaded before the sample fell into position; however, the clamping device was designed so that once the metallic sample fell into position the receiver was completely shielded.

The transforming specimen was kept in the bath until apparent completion of the beta $\rightarrow$ alpha transformation. During the test, individual frames on the movie film were exposed automatically at predetermined intervals to obtain a record of the data for determining the transit time and the attenuation. After the reaction apparently was complete, the specimen was brought back to room temperature and the postrun data, i.e., transit times, amplitudes, and thickness, were measured both before and after the surfaces were repolished; the density was remeasured after repolishing. 


\section{RESULTS}

The experimental results will be classified into three main groups according to the type of heat treatments involved:

1. Room-temperature measurements.

2. Quasi-equilibrium conditions. In these experiments, the specimens were slowly heated and cooled through the phase transition range. Both longitudinal and shear modes of vibration were employed, but shear vibrations could be applied only during the heating semicycle, up to about $393^{\circ} \mathrm{K}$.

3. Transformation from beta to alpha under isothermal conditions. The specimens were rapidly transferred from the beta-treatment bath into the clamping device at some temperature in the alpha range. Only longitudinal waves were employed in this type of experiment.

Satisfactory reproducibility and consistency of the experimental observations were obtained in all groups of experiments. The results are given in the paragraphs below; their significance in an understanding of the beta $\rightarrow$ alpha transformation is analyzed and discussed in Section VI.

\section{A. Room-temperature Measurements}

Density and longitudinal-wave velocity were measured primarily to determine how much beta phase had been retained in a specimen after each thermal treatment. Changes in density indicated the magnitude of the combined effects due to retained beta phase and to porosity in a specimen. The sound velocity was changed only slightly by the presence of pores, whereas the presence of beta phase changes it significantly. Thus, the reliability of the assertion that all the specimens returned to the alpha phase at room temperature was based upon the accuracy of room-temperature velocity measurements. It was assumed that all the samples were initially composed entirely of alpha plutonium. This as sumption was borne out by the densities of the samples before the runs; all were typical of pure alpha plutonium with negligible internal porosity. The distribution of the initial values of velocity was studied, and an average value and a standard deviation were obtained. Then the values of velocity that were measured after the runs and after the faces of the samples had been repolished were examined to see if each value could be considered a member of the previous distribution. It was concluded that all the samples were most probably of alpha-phase material at room temperature after their respective runs. On this justification, an average was made over all the pertinent values of velocity, those made after the runs as well as those determined before the runs, and this average value was considered the measured longitudinal-wave velocity of alpha plutonium at room temperature:

$$
(2.420 \pm 0.005) \times 10^{5} \mathrm{~cm} / \mathrm{sec} .
$$


The error figure shown above is the standard deviation in the average value as determined by the preceding procedure.

B. Quasi-equilibrium Conditions

1. Longitudinal-wave Velocity and Attenuation

The purpose of these experiments was to determine the velocity of longitudinal waves as a function of temperature under close-to-equilibrium conditions. The velocity at each temperature was determined by observing the transit time as recorded on the movie film and dividing this into the calculated thickness of the sample, as expressed by Equation (4).

The calculation of the thickness of the sample as it was heated in the alpha phase was fairly straightforward, since the only factor to be taken into account was thermal expansion. In the temperature range of the alpha $\rightarrow$ beta transformation, the effect of the $9.62 \%$ volume change also had to be taken into account.

The basic assumption of this type of measurement was that

$$
V_{T}=f_{\beta} V_{\beta T}+\left(1-f_{\beta}\right) V_{\alpha T}
$$

where

V.T.is the instantaneous velocity at temperature $T$,

$f_{\beta}$ is the fraction of $\beta$ phase present,

$\mathrm{V}_{\beta T}$ is the velocity at temperature $\mathrm{T}$ in pure $\beta$ phase material,

and

$\mathrm{V}_{\alpha \mathrm{T}}$ is the velocity at temperature $\mathrm{T}$ in pure $\alpha$ phase material.

This relation was not strictly true, but was a good enough approximation for use in this experiment.

Let us keep $T$ constant and vary $f_{\beta}$, which approximates the case during a quasi-equilibrium transformation over a narrow temperature range and is exactly true for an isothermal phase change, and assume

$$
\frac{\delta \mathrm{v}}{\Delta \mathrm{v}}=\mathrm{f}_{\beta},
$$

where $\Delta \mathrm{v}$ is the total volume change upon transformation at a constant temperature and $\delta v$ is the instantaneous volume change. 
If is otropic expansion is as sumed, the change in specimen thickness will be given by

$$
\left(\frac{L^{\prime}}{L_{0}}\right)^{3}=\frac{v^{\prime}}{v_{0}}
$$

where $L_{0}$ and $v_{0}$ are the original thickness and volume, respectively,

$$
\mathrm{v}^{\prime}=\mathrm{v}_{0}+\Delta \mathrm{v}
$$

and

$$
\mathrm{L}^{\prime}=\mathrm{L}_{0}+\Delta \mathrm{L}
$$

where $\Delta v$ is the total change in volume and $\Delta L$ is the total change in length. From Equation (10), one obtains

$$
\frac{\Delta v}{v_{0}}=\frac{v^{\prime}}{v_{0}}-1 \text {, }
$$

and

$$
\frac{\Delta \mathrm{L}}{\mathrm{L}_{0}}=\frac{\mathrm{L}^{\prime}}{\mathrm{L}_{0}}-\mathrm{l}=\left(\frac{\mathrm{v}^{\prime}}{\mathrm{v}_{0}}\right)^{1 / 3}-1
$$

Let

$$
\frac{\mathrm{v}^{\prime}}{\mathrm{v}_{0}}-\mathrm{l} \equiv \mathrm{a}
$$

and as sume

$$
\frac{\mathrm{v}^{\prime}}{\mathrm{v}_{0}} \simeq 1
$$

or
$a \ll 1$.

Then

$$
\begin{aligned}
\frac{\Delta \mathrm{L} / \mathrm{L}_{0}}{\Delta \mathrm{v} / \mathrm{v}_{0}} & =\frac{(1+\mathrm{a})^{1 / 3}-1}{\mathrm{a}} \\
& =\frac{1+\frac{1}{3} \mathrm{a}+\ldots-1}{\mathrm{a}} \\
& \simeq \frac{1}{3}
\end{aligned}
$$


Similarly,

$$
\mathrm{v}=\mathrm{v}_{0}+\delta \mathrm{v}
$$

and

$$
L=L_{0}+\delta L
$$

where $\delta \mathrm{v}$ is the incremental change in volume and $\delta \mathrm{L}$ is the incremental change in length during the isothermal transformation. By the same procedure, we get

$$
\frac{\delta \mathrm{L} / \mathrm{L}_{0}}{\delta \mathrm{v} / \mathrm{v}_{0}} \simeq \frac{1}{3}
$$

Therefore,

$$
\frac{\delta \mathrm{L} / \mathrm{L}_{0}}{\Delta \mathrm{L} / \mathrm{L}_{0}} \simeq \frac{\frac{1}{3} \delta \mathrm{v} / \mathrm{v}_{0}}{\frac{1}{3} \Delta \mathrm{v} / \mathrm{v}_{0}}
$$

or

$$
\frac{\delta L}{\Delta L} \simeq \frac{\delta \mathrm{v}}{\Delta \mathrm{v}}
$$

and

$$
f_{\beta} \simeq \frac{\delta L}{\Delta L}
$$

Substituting Equation (22) in Equation (7), one obtains

$$
\mathrm{V}_{\mathrm{T}}=\frac{\delta \mathrm{L}}{\Delta \mathrm{L}} \mathrm{V}_{\beta \mathrm{T}}+\left(1-\frac{\delta \mathrm{L}}{\Delta \mathrm{L}}\right) \mathrm{V}_{\alpha \mathrm{T}}
$$

from which the following relation can be derived:

$$
\frac{\dot{\delta} \mathrm{L}}{\Delta \mathrm{L}}=\frac{\mathrm{V}_{\alpha \mathrm{T}}-\mathrm{V}_{\mathrm{T}}}{\mathrm{V}_{\alpha \mathrm{T}}-\mathrm{V}_{\beta \mathrm{T}}}
$$

For the quasi-equilibrium runs, the temperature change was relatively small during the transformation, and some approximations to Equation (24) can be made: Let us say that $\Delta L$ and $\delta L$ are small compared to $L_{0}$ and that we shall ignore the temperature change. Then,

$$
\therefore v_{\alpha T} \simeq L_{0}\left(\frac{1}{\tau_{\alpha_{393}}}\right)
$$




$$
\begin{gathered}
\mathrm{V}_{\mathrm{T}} \simeq \mathrm{L}_{0}\left(\frac{1}{\tau_{\mathrm{T}}}\right), \\
\mathrm{V}_{\beta \mathrm{T}} \simeq \mathrm{L}_{0}\left(\frac{1}{\tau_{403}}\right),
\end{gathered}
$$

and

$393^{\circ} \mathrm{K}<\mathrm{T}<403^{\circ} \mathrm{K}$

Here, $\tau_{\alpha_{393}}$ was the transit time in the $\alpha$ phase at $393^{\circ} \mathrm{K}, \tau_{\mathrm{T}}$ was the instantaneous transit time at $T$, and $T_{\beta 403}$ was the transit time in the $\beta$ phase at $403^{\circ} \mathrm{K}$.

Referring to Equation (24),

$$
\frac{\delta \mathrm{L}}{\Delta \mathrm{L}} \simeq \frac{\frac{1}{\tau_{\alpha_{393}}}-\frac{1}{\tau_{\mathrm{T}}}}{\frac{1}{\tau_{\alpha_{393}}}-\frac{1}{\tau_{\beta 403}}}
$$

From Equation (16),

$$
\begin{aligned}
\frac{\Delta \mathrm{L}}{\mathrm{L}_{0}} \simeq \frac{1}{3} \frac{\Delta \mathrm{v}}{\mathrm{v}_{0}} & =\frac{1}{3}(9.62 \%) \\
& =3.2 \% .
\end{aligned}
$$

Therefore,

$$
\Delta \mathrm{L}=0.032 \mathrm{~L}_{0}
$$

By combining Equations (18), (26), and (28) and rearranging, one obtains

$$
L=L_{0}\left(1+0.032 \frac{\frac{1}{\tau_{\alpha_{393}}}-\frac{1}{\tau_{T}}}{\frac{1}{\tau_{\alpha_{393}}}-\frac{1}{\tau_{\beta 403}}}\right) \text {, }
$$

which gives the final expression for the length of the sample during the phase change upon quasi-equilibrium heating, based on the length in the $\alpha$ phase at $393^{\circ} \mathrm{K}$. When the transformation was complete, further changes in length were calculated by using published values of the expansion coefficient for the beta phase.

The length changes during cooling were more complicated. Four factors had to be considered: (1) thermal contraction, (2) volume decrease upon transformation, (3) volume change due to formation of voids, and (4) length change due to abnormal "growth" associated with anisotropy of 
thermal-expansion coefficients. The first two factors were the same ones considered during heating. The changes due to formation of voids were computed by knowing the decrease in density after the run. Measurements of velocity at room temperature made upon the sample that was used in the quasi-equilibrium run showed that the velocity after the run was equal to that before the run. Yet the length that was calculated for the sample based upon the first three considerations, combined with the observed transit time as seen on the movie film, did not yield the correct velocity. Length measurements made upon any sample after it underwent a transformation cycle, when combined with a measurement of transit time, did not yield the same velocity as that calculated when the same sample was repolished, its length remeasured, and a new transit time measured. This is due to the very rough surfaces that these samples displayed after cycling; the degree of roughness depended upon the parameters of the heat treatment. The lengths that were computed by using the four factors discussed above were adjusted so that the final calculated length at room temperature, coupled with the roomtemperature transit time as shown on the film, gave the same velocity as that measured on the specimen after it was repolished. Addition of the mechanisms of growth due to anisotropic expansion coefficients rationalized the calculation, and was justified by the analogous behavior in uranium. ${ }^{126}$ Here this mechanism is used to explain a discrepancy of less than $3 \%$ of the length change during the beta $\rightarrow$ alpha transformation.

Based upon the above considerations, calculations of the accuracy to be expected in the quasi-equilibrium curves (Fig. 8) revealed that the plot is accurate to about $\pm 1 / 2 \%$ from 193 to $395^{\circ} \mathrm{K}$ during the heating; it is accurate to about $\pm 1 \%$ above this temperature. During the cooling, it is accurate to $\pm 1 \%$ down to $363^{\circ} \mathrm{K}$ and is good to about $\pm 3 \%$ below that. The rates of heating and cooling during the quasi-equilibrium runs were determined from the continuous recording of the temperature variation of the oil bath. The

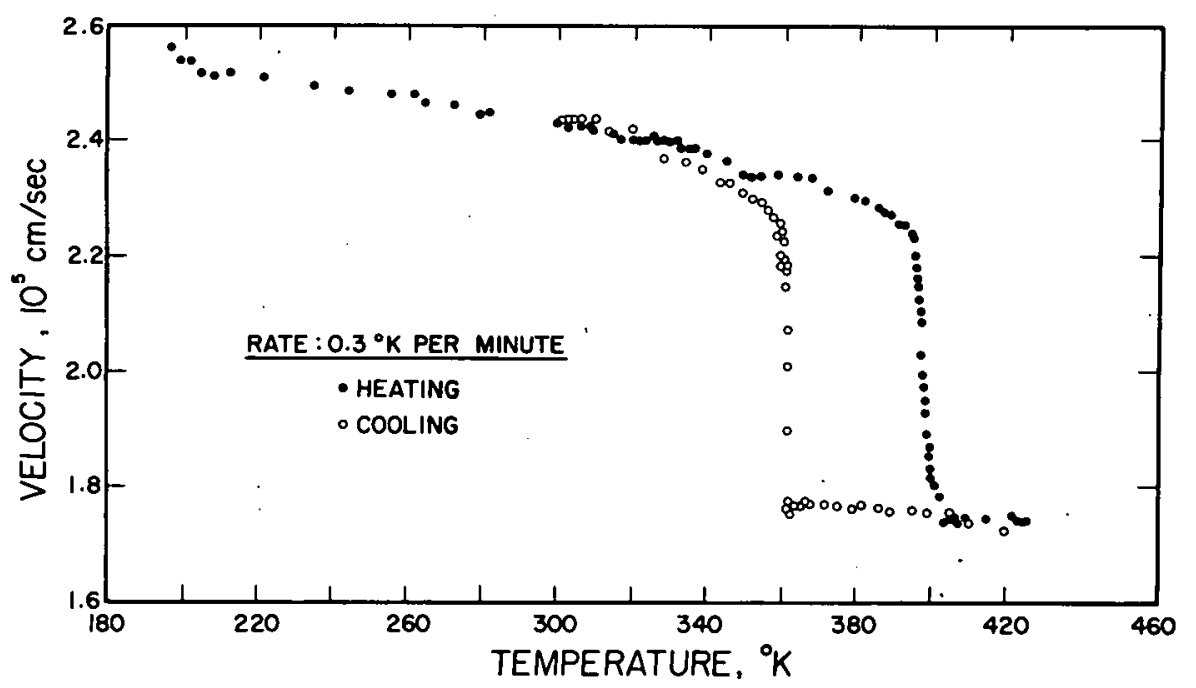

42881

Fig. 8. Velocity of Longitudinal Waves in Plutonium, as a Function of Temperature 
desired rates of heating, and particularly of cooling, e.g., $0.3^{\circ} \mathrm{K} / \mathrm{min}$, were easily attained due to the thermal properties of the oil bath and of the quartz fiber-insulated heating mantle around the oil bath.

Figure 8 shows the variation of velocity with slow rates of temperature change. These data represent measurements from two different specimens; one for the region below room temperature, and another for the alpha $\rightarrow$ beta $\rightarrow$ alpha cycle. The fact that the data can be incorporated into one plot demonstrates the consistency of the experimental results. The value for velocity at room temperature $\left(-2.43 \times 10^{5} \mathrm{~cm} / \mathrm{sec}\right)$ compares favorably with the average value of velocity as discussed in Section IV.

Figure 8 , and more clearly Fig. 9 (where $1 / T$ was considered to be proportional to $\mathrm{V}$ ), shows a change of slope around $200^{\circ} \mathrm{K}$. The nature of this discontinuity is not understood. Up to about $340^{\circ} \mathrm{K}$ the velocity decreases steadily with increasing temperature. A second discontinuity is observed between 340 and $360^{\circ} \mathrm{K}$. The relative attenuation shows a corresponding peak in this temperature region, as seen in Fig. 10. The start of the alpha $\rightarrow$ beta transformation at $395^{\circ} \mathrm{K}$ is marked by a sharp drop in velocity ( $\mathrm{Fig}$. 8) as well as in attenuation (Fig. 10). The phase transition continues over a temperature range up to about $403^{\circ} \mathrm{K}$. Since the rate of heating was $0.3^{\circ} \mathrm{K} / \mathrm{min}$, the transformation was complete within $30 \mathrm{~min}$.

On cooling, the reverse transformation starts at $362^{\circ} \mathrm{K}$; i.e., there is a temperature hysteres is of $33^{\circ} \mathrm{K}$. Contrary to the alpha $\rightarrow$ beta phase change, the first stage of the beta $\rightarrow$ alpha transformation was much more rapid. Within the first 2 min, approximately $50 \%$ beta transformed

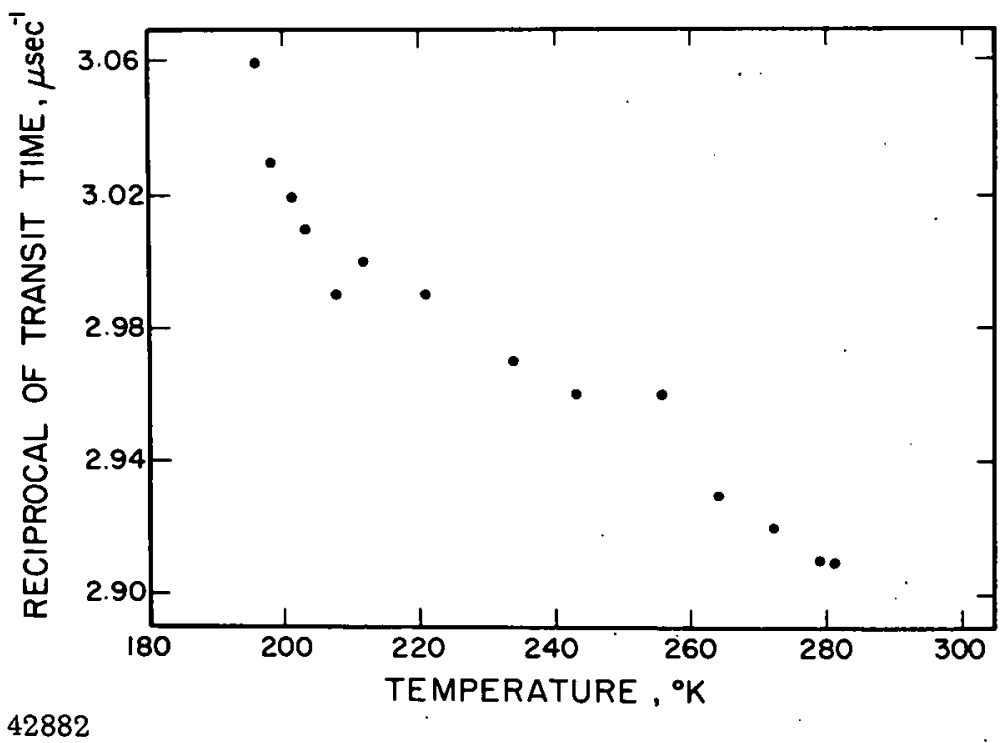

Fig. 9. Reciprocal of Transit Time of Longitudinal Waves in Specimen CM-29-9, as a Function of Temperature during Slow Heating 


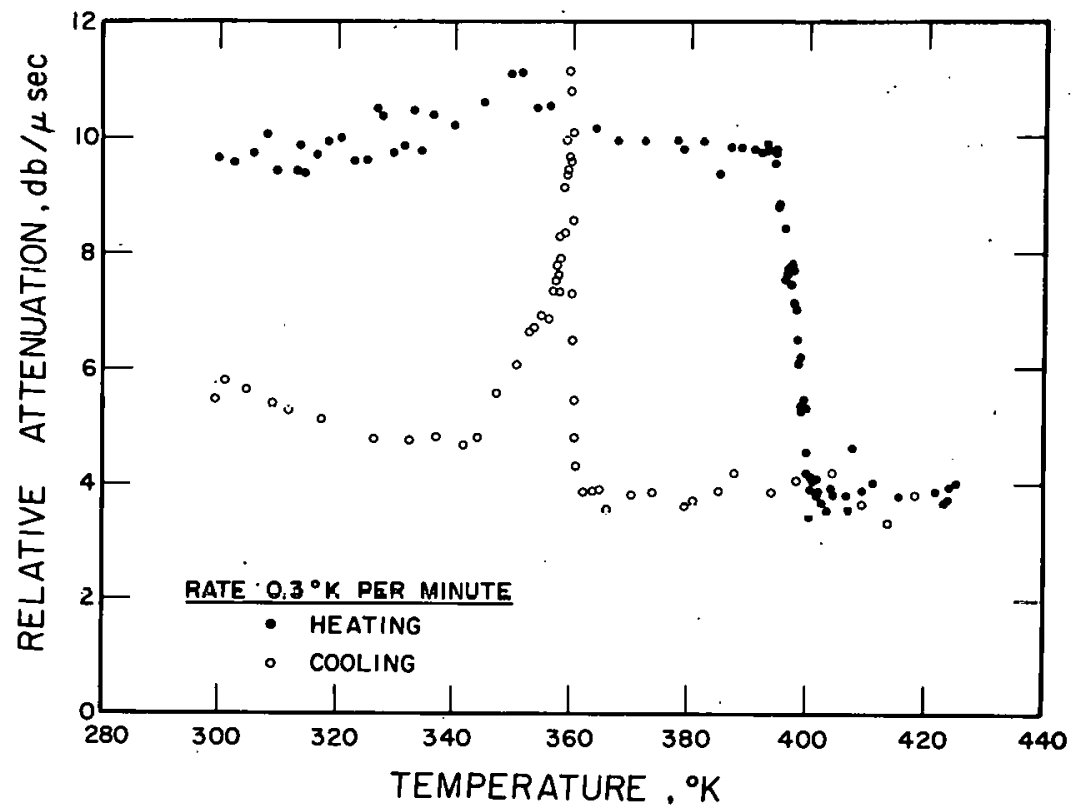

42883

Fig. 10. Relative Attenuation of Longitudinal Waves in Specimen CM-29-2, as a Function of Temperature

to alpha, but from there on the reaction proceeded in a sluggish manner. Finally, the cooling and heating curves merge at about $323^{\circ} \mathrm{K}$ where both represent the velocity in alpha plutonium. Figure 10 also shows the variation of the attenuation with temperature during the cooling semicycle. The beginning of the transformation is accompanied by a sharp increase in attenuation. As the transformation goes to completion, the attenuation decreases and goes through a minimum in the vicinity of $328^{\circ} \mathrm{K}$. From this temperature and down, the attenuation increased uniformly.

The plot of attenuation in Fig. 11 is for a specimen that was cooled down to $196^{\circ} \mathrm{K}$ and brought back to room temperature at a slow heat-

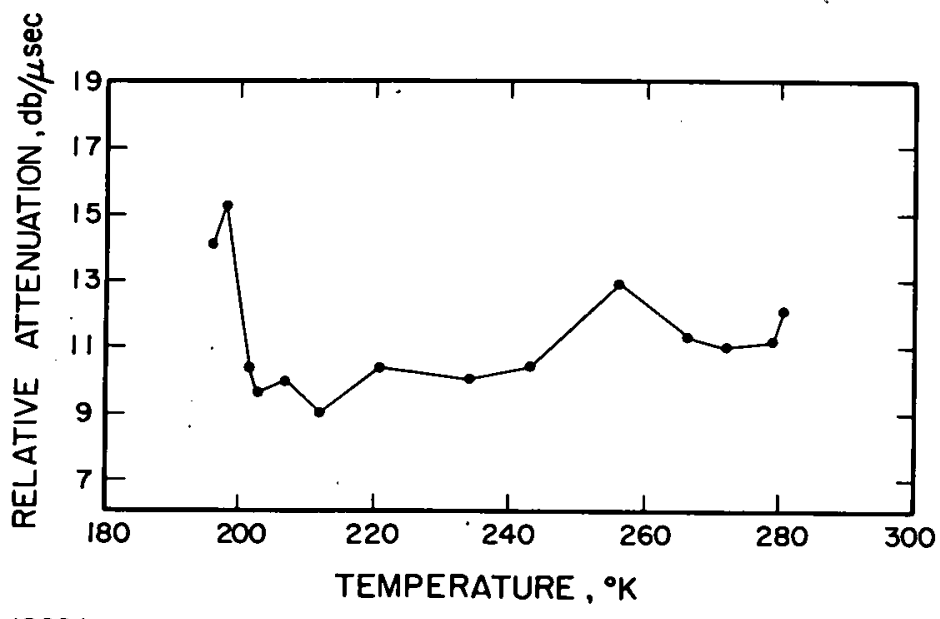

42884

Fig. 11. Relative Attenuation of Longitudinal Waves in Specimen CM-29-9, as a Function of Temperature during Slow Heating ing rate. It corresponds to the plot of velocity data in Fig. 8. Similar to the behavior of velocity, the attenuation shows a sharp drop at approximately $200^{\circ} \mathrm{K}$.

The measurement of absolute attenuation is extremely difficult and is rarely attempted. The best that can be hoped for is that, out of several mechanisms that contribute to the attenuation, the mechanism causing the greatest change in attenuation is the effect that is under 
study. In this experiment, the mechanisms under observation are those occurring in the interiors of the specimens; these probably cause the greatest changes in attenuation, but surface changes cause attenuation changes approaching the magnitude of the internal effects. As an example of this, consider the following: A calculation was made of the loss in amplitude that might be expected every time the sound wave encountered the specimenPZT-4 interface in its successive round trips through the plutonium. One would expect that a certain fraction of the energy would be transimitted into the transducer, while the rest would be reflected back into the plutonium. Assuming perfect coupling of the two materials, an attenuation of $18 \mathrm{db} / \mu \mathrm{sec}$ would be expected in a sample of the size used in the quasi-equilibrium run. The actual measured values, as seen in Fig. 10, were less than $18 \mathrm{db} / \mu \mathrm{sec}$ at all times. This merely means that the coupling was far from perfer.t. Figure 10 shows, furthermore, that the coupling became worse during the heat treatment because the apparent attenuation at the end of the run at room temperature $(\sim 5.8 \mathrm{db} / \mu \mathrm{sec})$ was less than the measured attenuation before the run $(\sim 9.5 \mathrm{db} / \mu \mathrm{sec})$. This result is consistent with the observation that the surface of the specimen was visibly roughened at the end of the heat treatment. This decrease in attenuation overwhelmed the increase in attenuation that must have occurred because of the voids and dislocations that were produced inside the plutonium, especially during the cooling cycle. Thus, the absolute values of attenuation have no significance, but changes in attenuation during the experiment give an indication of processes occurring in the specimen.

\section{Shear-wave Velocity and Attenuation}

Figure 12 shows the variation of shear-wave velocity with temperature for two different specimens. In contrast to the data for velocity of longitudinal waves, these data do not agree well. The values differ by as

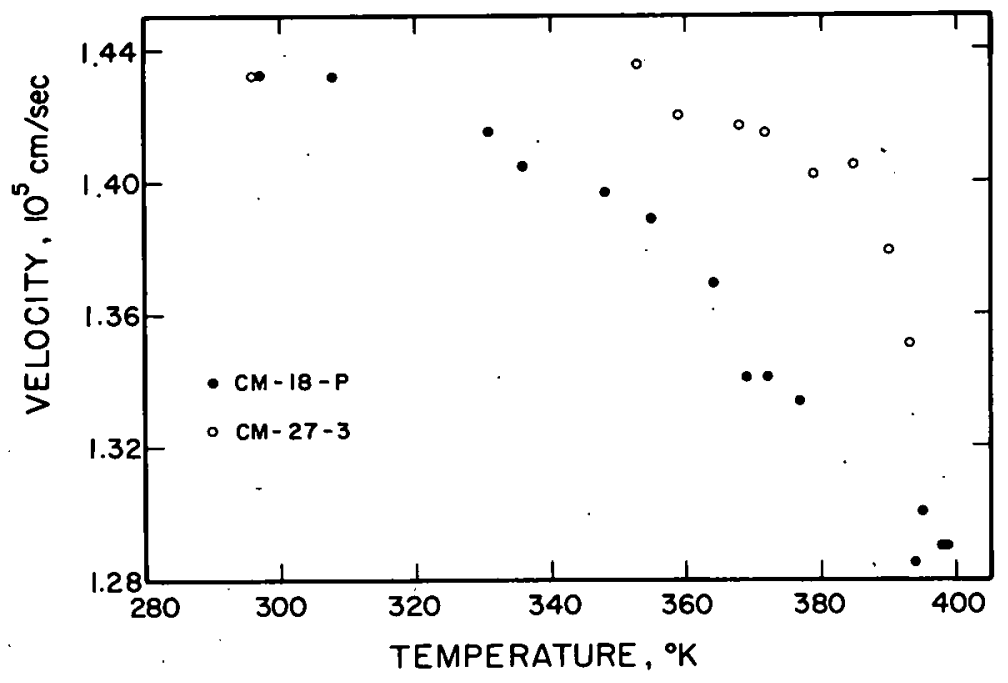

42885

Fig. 12. Velocity of Shear Waves in Plutonium, as a Function of Temperature during Slow Heating 
much as $5 \%$ in some regions. Both curves do show the discontinuity in the vicinity of $360^{\circ} \mathrm{K}$. The velocity decreased steadily to about $398^{\circ} \mathrm{K}$, where suddenly no echoes were visible. The solid bond between the transducer and the specimen did not survive the large expansion that occurred on passing through the transformation. Figure 13 is a plot of attenuation versus temperature for one of the above specimens. The attenuation seemed to decrease faster between 363 and $398^{\circ} \mathrm{K}$ than between 300 and $363^{\circ} \mathrm{K}$.

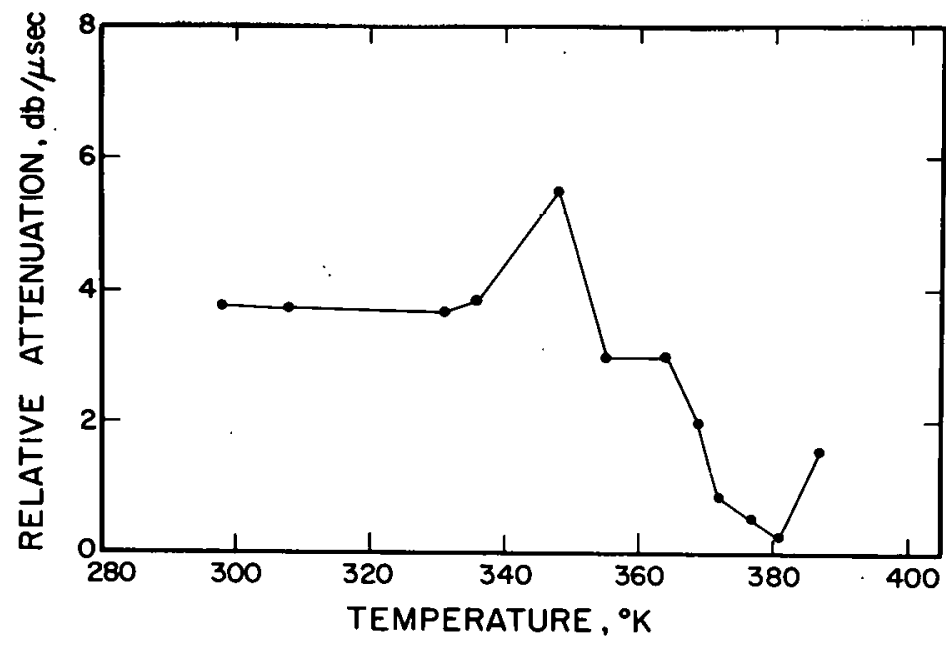

Fig. 13

Relative Attenuation of Shear Waves in Specimen CM-18-P, as a Function of Temperature during Slow Heating

42886

\section{Poisson's Ratio}

The variation of Poisson's ratio with temperature is shown in Fig. 14. These values were calculated, by means of Equation (3), from longitudinal and shear-wave velocities that were measured from different samples. Poisson's ratio maintains a constant value up to about $335^{\circ} \mathrm{K}$. In the range from 335 to $363^{\circ} \mathrm{K}$, there is a significant dip in the curve, followed by a subsequent increase.

Fig. 14

Poisson's Ratio for Alpha Plutonium, as a Function of Temperature. Values were calculated from the data for velocity of longitudinal waves in specimen CM-29-2 and velocities of shear waves in specimens $C M-18-P$ and $\mathrm{CM}-27-3$

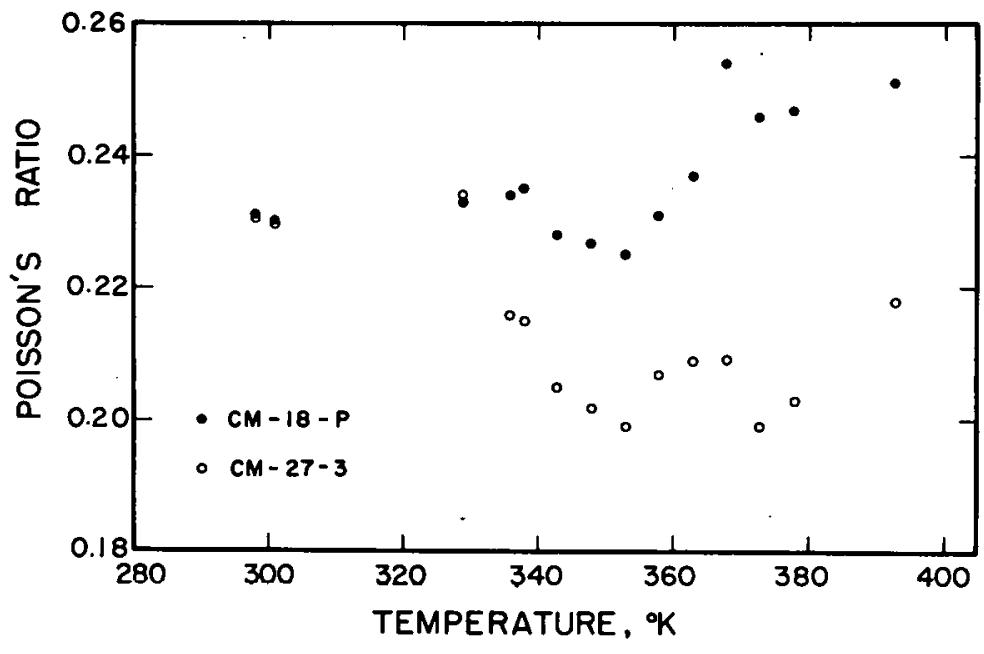

42887 


\section{Young's Modulus and Shear Modùlus}

The variations of Young's modulus and shear modulus with temperature are shown in Fig. 15. These values were calculated by using Equations (1), (2), and (3) and the longitudinal and shear-wave velocities that were measured from different samples.

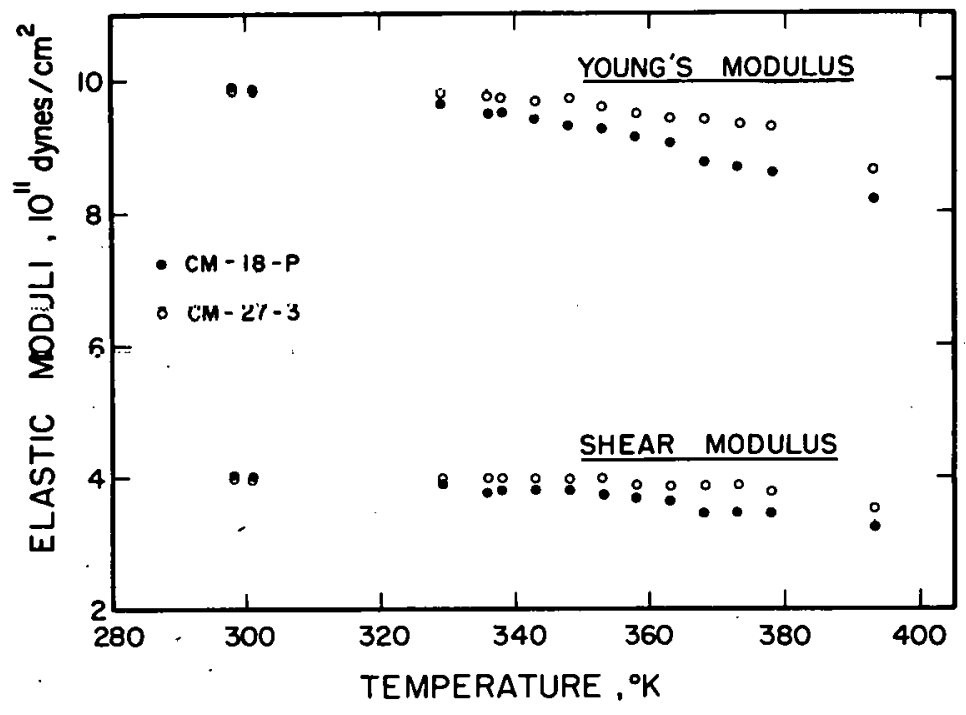

Fig. 15

Young's Modulus and Shear Modulus for Alpha Plutonium, as a runction of 'l'emperature, Values were calculated from the data for velocity of longitudinal waves in specimen $\mathrm{CM}$ 29-2 and velocities of shear waves in specimens CM-18-P and CM-27-3.

42888

5. Effect of Cycling on the Temperature-hysteresis Loop

Several specimens were cycled for three to four times through the alpha $\rightleftarrows$ beta transformations. No important changes were observed in the temperature-hysteresis loop. It appeared, however, that higher rates of cooling tended to increase the hysteresis; a rate of $0.5^{\circ} \mathrm{K} / \mathrm{min}$ widened it by about $10^{\circ} \mathrm{K}$.

C. Is othermal Conditions

\section{Variation of Sound Velocity with Holding Time}

Data from isothermal tests at 11 different temperatures were recorded and analyzed. The temperatures were: 199, 223, 253, 272, 296, $312,326,337,348,355$, and $361^{\circ} \mathrm{K}$. Figure 16 gives the corresponding time-transformation curves. To see how these curves were constructed and what they represent, refer back to Equations (5) and (7). The sound velocity at any time during the is othermal transformation is a function of $\mathrm{f}_{\beta}$, and the velocity, $\mathrm{V}_{\mathrm{T}}$, is proportional to $\tau_{\mathrm{T}}^{-1}$. As discussed in Section IV-C, following the change in $\tau_{\mathrm{T}}^{-1}$ is, for all practical purposes, the same as following the change in $\mathrm{V}_{\mathrm{T}}$; and, in turn, the change in $\mathrm{V}_{\mathrm{T}}$. is indicative of the change in $\mathrm{f} \beta$. Thus the curves in Fig. 16 are plotted as $\tau \overline{\mathrm{T}}^{1}$ versus $t$, the time after immersion of the plutonium specimen into the is othermal holding 

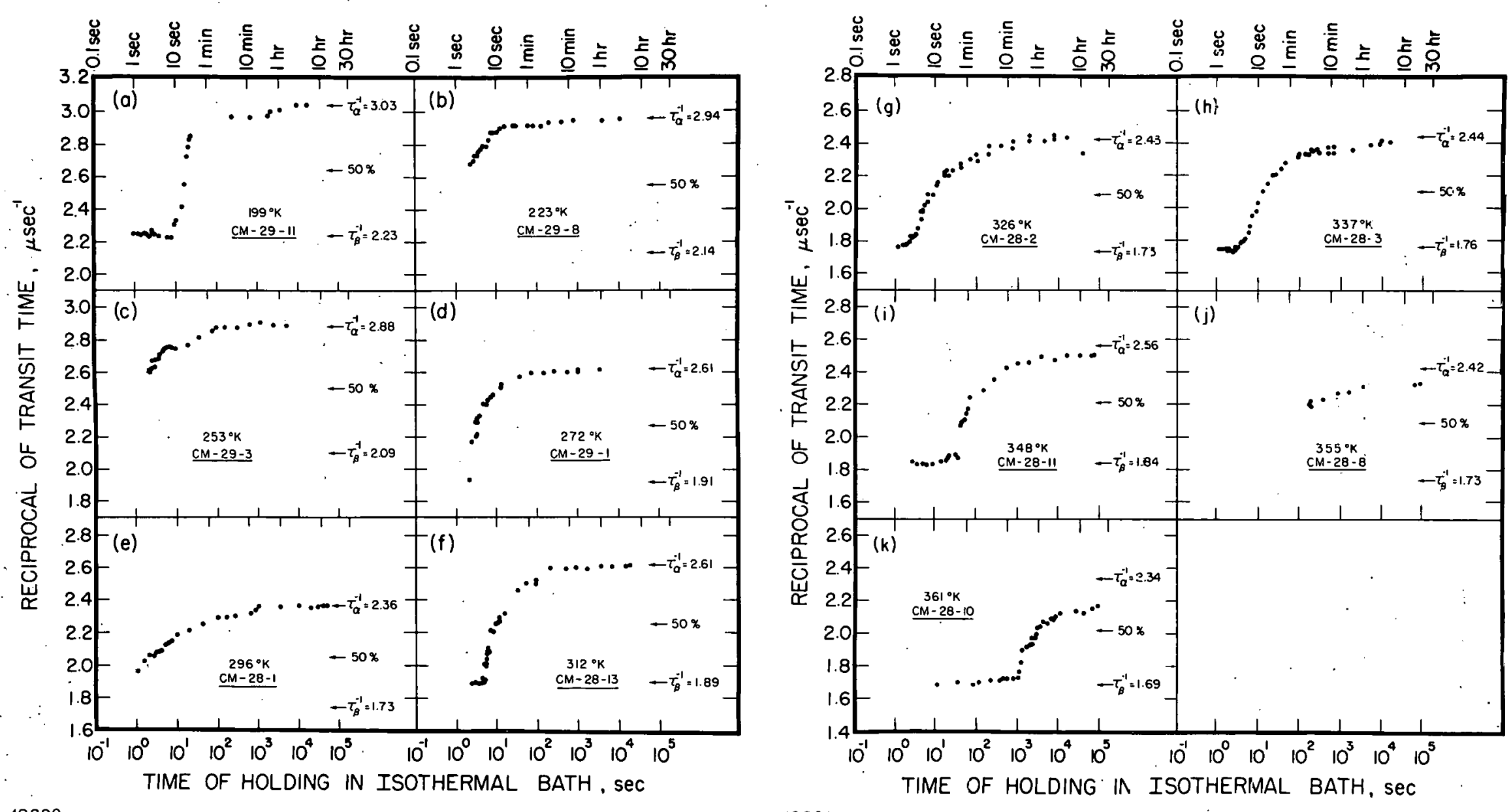

Fig. 16. Reciprocal of Transit. Time of Longitudinal Waves in Plutonium, as a Function of Time of Holding at Various Isothermal Transformation Temperatures 
bath; $\tau_{\alpha}^{-1}$ and $\tau_{\beta}^{-1}$ indicate the reciprocal values of the transit times for $100 \%$ alpha or beta phases, respectively, at the test temperature.

The curves in Fig. 16 can be converted into ones that show the actual fraction of beta phase remaining in the specimen at any time during the transformation. The following equation, which is a rearrangement of Equation (7), was used:

$$
f_{\beta}=\frac{V_{\alpha T}-V_{T}}{V_{\alpha T}-V_{\beta T}} .
$$

Approximations similar to those shown in Equation (25) lead to

$$
\mathbf{f}_{\beta}=\frac{\frac{1}{\tau_{\alpha \mathrm{T}}}-\frac{1}{\tau_{\mathrm{T}}}}{\frac{1}{\tau_{\alpha \mathrm{T}}}-\frac{1}{\tau_{\beta \mathrm{T}}}}
$$

Examples of the types of curves that were obtained from the above equation and the data shown in Fig. 16 are given in Fig. 17.

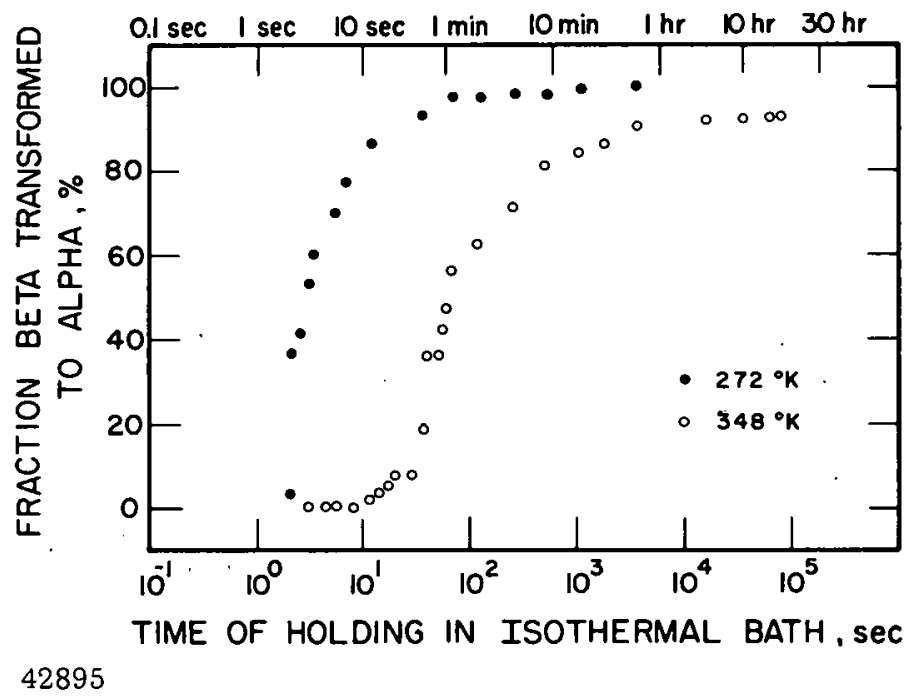

Fig. 17. F raction of Beta Plutonium Transformed to the Alpha Phase at 272 and $348^{\circ} \mathrm{K}$, as Functions of Time of Holding
It has been determined that $1 / T$ could be measured to within $1 \%$, and that $V_{\alpha T}$ could be calculated to within $1 \%$ for those runs in which the phase transformation went to completion (compare Fig. 8 with Fig. 20, shown later). $\mathrm{V}_{\mathrm{T}}$ and $\mathrm{V}_{\beta \mathrm{T}}$ could be determined to about $1.5 \%$. When the phase transformation did not go to completion, $\mathrm{V} \alpha \mathrm{T}$ was good to $1.5 \%$, based upon extrapolation of velocities from runs in which the complete transformation took place, as well as with a comparison of the velocities for the alpha phase as shown

in Fig. 8. Based upon these estimates, the maximum uncertainty in $\mathrm{f}_{\beta}$ varies from $7.9 \%$ in the beta phase to $6.5 \%$ near the alpha phase, although subsequently it will be shown that deviations from a smooth curve of $\mathrm{f}_{\beta}$ after the transformation plotted as a function of transformation temperature are much smaller than the above uncertainties.

Since it was important to know the quenching rates upon transferring the plutonium specimen from the beta bath into the isothermal bath, and because an analytical approach would have been complex and not practical, it was decided to establish the quenching rates experimentally. 
Preparation of a test specimen for these experiments involved operations that would have been difficult to perform on plutonium; therefore, stainless steel, which.approximates plutonium as far as thermal diffusivity is concerned, was used as a dummy sample. The sample was about $0.91 \mathrm{~mm}$ thick and $2.06 \mathrm{~cm}$ in diameter. An oval-shaped hole was cut radially from the circumference of the disk to its center to receive an iron-constantan thermocouple made of $0.25-\mathrm{mm}$-diam, Fiberglas-insulated wire. The bare tips of the wires were spot-welded together, and the bead was then spotwelded to the bottom of the hole. The location of this latter weld junction was confirmed by an X-radiograph. Araldite epoxy was used to prevent the liquid of the immersion bath from entering the hole. The disk was subjected to the same treatment as a plutonium sample underwent in a standard isothermal run. The output of the thermocouple was monitored with a d.c.coupled, Type D plug-in preamplifier, installed in a Tektronix Type 535A oscilloscope. The tube face of the oscilloscope was photographed by means of a Polaroid Land camera to produce a still photograph. The experimental procedure was as follows: The sample was heated to $453^{\circ} \mathrm{K}$. The oscilloscope was adjusted to a convenient sweep speed, e.g., $0.5 \mathrm{sec} / \mathrm{cm}$, while the gain of the scope amplifier was set to a suitable level, e.g., $1 \mathrm{mV} / \mathrm{cm}$. Then the vertical position of the oscilloscope trace, which was tracing out a horizontal line representative of the $453^{\circ} \mathrm{K}$ temperature, was set to a location near the top line of the graticule. Just as the trace reached the end of its sweep, the camera shutter was opened, the sample taken out of the hot bath and plunged into the clamping device, and the transducer released to contact the specimen. When the scope trace reached the end of its sweep again, the camera shutter was closed. A minute or so later, the camera was opened to allow a horizontal trace, which represented the temperature of the isothermal bath, to be recorded on the film. Thus a graph of time versus temperature of the center of the metal sample was made; one such trace at $201^{\circ} \mathrm{K}$ is shown in Fig. 18. From photographs taken at several bath temperatures, the times shown in Table II were found for essentially complete cooling from $453^{\circ} \mathrm{K}$.

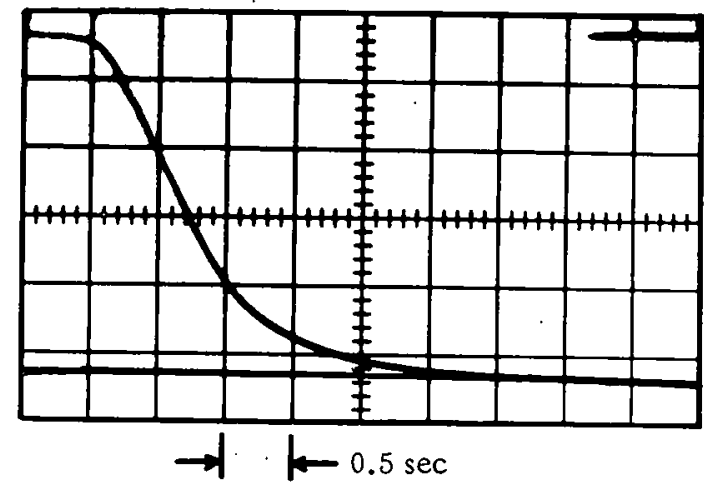

42891

Fig. 18. Quenching Curve for a Stainless-steel Specimen
TABLE II. Time for Temperature Equalization of a Stainless-steel Specimen Quenched from $453^{\circ} \mathrm{K}$ to Various Temperatures of the Is othermal Bath

\begin{tabular}{cc}
$\begin{array}{c}\text { Immersion-bath } \\
\text { Temperature, }{ }^{\circ} \mathrm{K}\end{array}$ & $\begin{array}{c}\text { Time to Cool, } \\
\text { sec }\end{array}$ \\
\hline 360 & 15 \\
297 & 20 \\
253 & 2.5 \\
201 & 3 \\
\hline
\end{tabular}


Although the experimental technique permitted data to be taken about $0.5 \mathrm{sec}$ after insertion of the specimen into the clamping device, the time required for thermal equilibration was relatively long. Therefore, complete information on the kinetics of the beta $\rightarrow$ alpha transformation could be obtained only at temperatures at which the induction period was quite long, notably at $199^{\circ} \mathrm{K}$ and from $312^{\circ} \mathrm{K}$ and upwards. But in all cases, the upper part of the time-transformation curve, beginning at about $50 \%$ transformation, was well defined.

\section{Sound Velocities in Beta Plutonium at the Transformation \\ Temperatures}

Figure 19 shows the longitudinal-wave velocities for metastable beta plutonium at the transformation temperatures. The plot is based upon data from those experiments in which the transit time could be measured while the specimen was still in the beta phase; this was true for about half the experiments. The values of velocities for runs in which the induction period was not recorded were interpolated between the above data. The variation of the velocity with temperature for metastable beta plutonium, as determined from the slope of the plots, is $85 \mathrm{~cm} / \mathrm{sec} /{ }^{\circ} \mathrm{K}$.

Fig. 19

Velocity of Longitudinal Waves in Metastable Beta Plutonium, as a Function of Temperature

42892

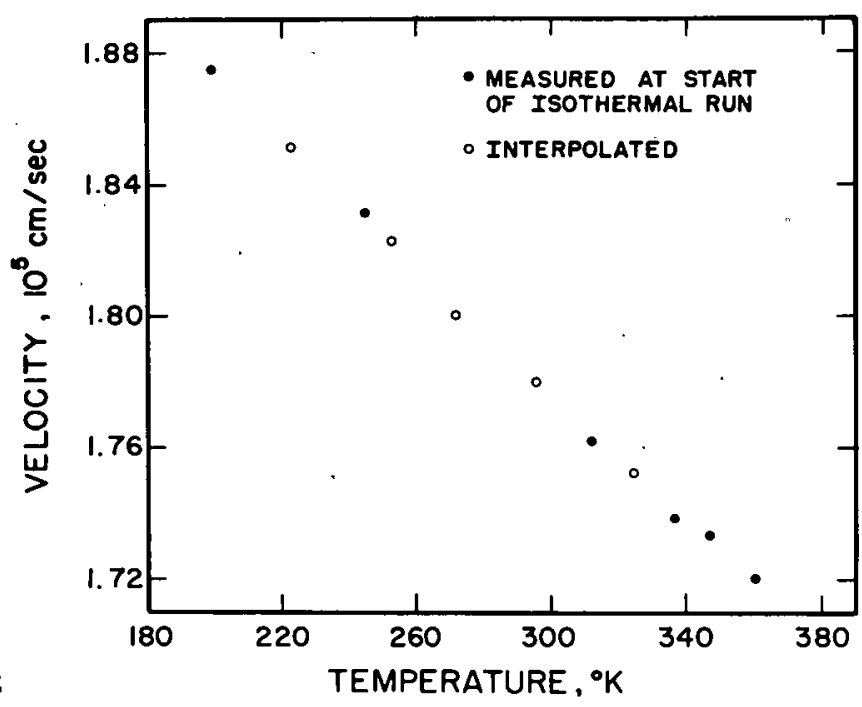

3. Sound Velocities in Alpha Plutonium at the Transformation Temperatures

A similar procedure was adopted for determining the velocities in alpha plutonium at the transformation temperatures, as plotted in Fig. 20. It was assumed that the beta $\rightarrow$ alpha transformation went to completion after reasonably long holding times in the cases of the lower-temperature isothermal experiments. Thus, the asymptotic values of reciprocal transit times of the upper branches of the time-transformation curves (e.g., $1 / T_{\alpha}=$ $2.88 \mu \mathrm{sec}^{-1}$ at $253^{\circ} \mathrm{K}$, as plotted in Fig. 16c) were taken as the values for complete beta $\rightarrow$ alpha transformation and were used to calculate the velocities. Values of velocity for the high-temperature experiments, where there 


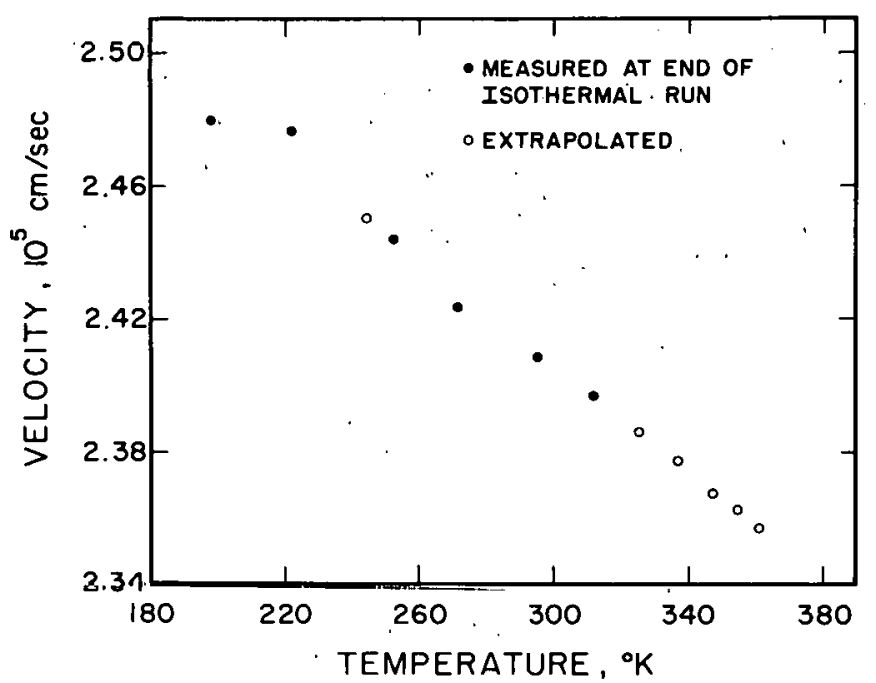

42893

Fig. 20. Velocity of Longitudinal Waves in Alpha Plutonium, as a Function of Temperature was reason to believe that the transformation did not go to completion, were extrapolated from these data and are shown in Fig. 20. A comparis on of this figure with Fig. 8 reveals good agreement. The variation of the velocity with temperature for alpha plutonium, as determined from the slope of the plot, is $99.6 \mathrm{crr} / \mathrm{sec} /{ }^{\circ} \mathrm{K}$.

\section{Reterilion of Beta Plutonium}

Comparison of the velocities that corresponded to the apparent completion of the

beta $\rightarrow$ alpha transformation with the velocities shown in Fig. 20 yielded information on the extent of the beta $\rightarrow$ alpha transformation. Figure 21 shows the fraction of betatrans formed to alpha at different temperatures. Complete transformation was achieved only be: low $313^{\circ} \mathrm{K}$. At $361^{\circ} \mathrm{K}$, the amount of retained beta after the apparent completion of the reaction was $26 \%$.

Based on the calculations of error in $f_{\beta}$, discussed in Section V-C-l above, the following conclusions can be drawn about the uncertainty in the amount of retained beta phase:

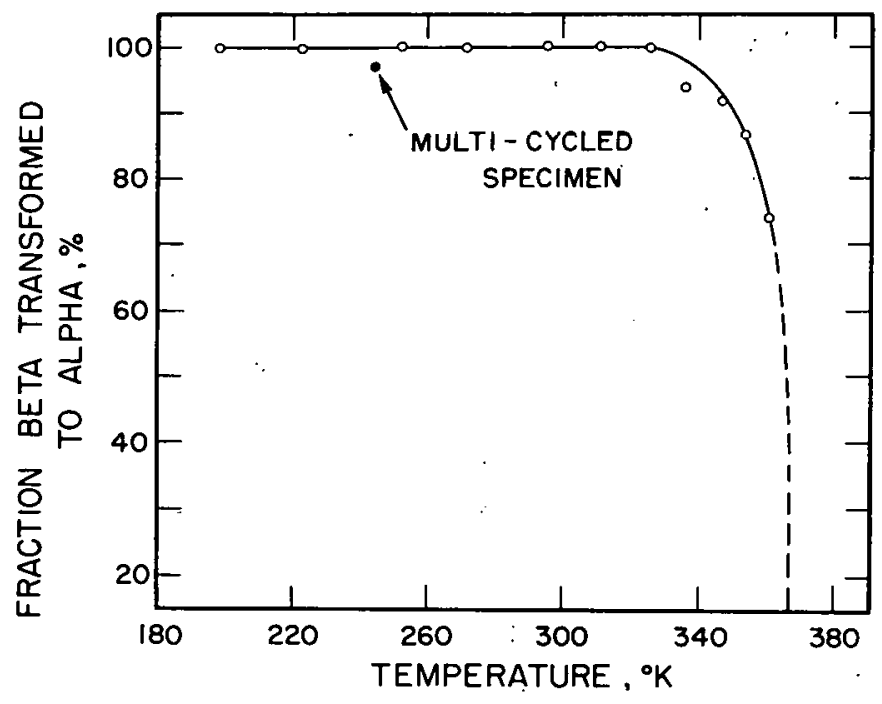

42894 .

a. For all types of runs, the error in $f_{\beta}$ arising from the substitution of Equation (31) for

Fig. 21. Fraction of Beta'Plutonium Transformed to the Alpha Phase, as a Function of the Isothermal Transformation Temperature

Equation $(30)$ is $3 / 4 \%$ and is neg-

lected. The error is so small because the length change during the transformation is only $\sim 3 \%$, and has much less effect on the changes in transit time than does the change in velocity during the transformation..

b. For runs in which all the beta material apparently was transformed to alpha, the precision of $f_{\beta}$ was calculated to be $\pm 5.5 \%$ on the basis of the limits of accuracy in the transit time given previously, while for runs in which the transformation did not go to completion, the expected precision was $\pm 6.6 \%$. 
Figure 21 shows that the actual precision was probably much better than the above figures, for the deviation from the smooth curve, in the worst case, is $4 \%$.

It may be concluded that the athermal character of the beta $\rightarrow$ alpha transformation at temperatures above $313^{\circ} \mathrm{K}$ is firmly established. It should be repeated that when the specimens were brought back to room temperature, their structures were completely alpha plutonium.

An extrapolation of the curve for fraction transformed versus transformation temperature, as seen in Fig. 21, shows that the beta $\rightarrow$ alpha transformation cannot be made to start at temperatures above $367^{\circ} \mathrm{K}$. Of course, this zero-transformation point depends on the purity of the plutn= nium metal, and to a certain extent on the thermal history rif the sperimen, i.e., the rate of cooling and the time and the temperature of anneal, in the beta-phase temperature range.

5. Time-Temperature-Transformation Diagram for the Beta $\rightarrow$ Alpha Transformation in Plutonium

The ultimate result of the is othermal heat treatments was the construction of a TTT diagram (Fig. 22) summarizing the kinetics of the beta $\rightarrow$ alpha transformation in plutonium, which were determined from Fig. 16. The diagram is a double "C" type. The high-temperature region, which exhibits an athermal character, has its maximum initial rate of transformation at approximately $323^{\circ} \mathrm{K}$, starting $3 \mathrm{sec}$ after immersion of the specimen into the is othermal bath. In the low-temperature region; the transformation goes to completion. The nose of this portion is at $253^{\circ} \mathrm{K}$, and the transformation starts less than $1 \mathrm{sec}$ after immersion of the specimen into the is othermal bath. The data points for start of the transformation in this region of the diagram were found by extrapolation, but the $50 \%$ transformation points were determined unambiguously. The initial rates of

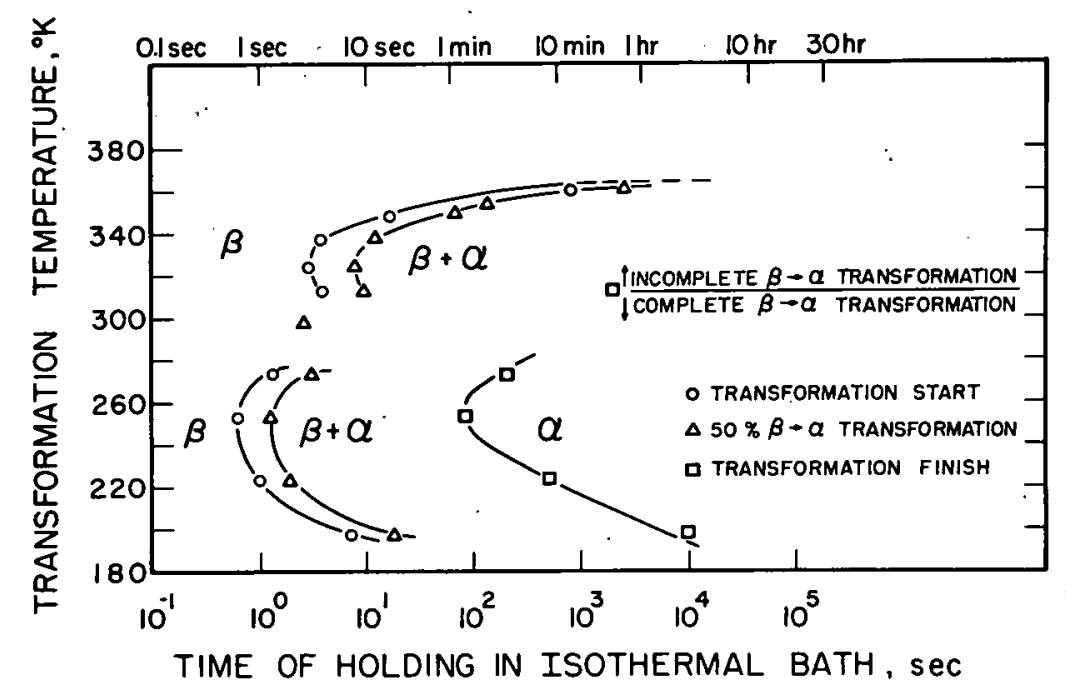

Fig. 22

Time-Tempèrature-Transformation Diagram for the Beta $\rightarrow$ Alpha Trans formation in High-purity Plutonium 
transformation are very high, as can be seen by the proximity of the "start" and $50 \%$ curves. The transformation at $253^{\circ} \mathrm{K}$ goes to completion only 1.5 min after immersion.

\section{Effect of Cycling on the Transformation Kinetics}

Figure 23 shows the kinetics of transformation during the 12 th cycle at $245^{\circ} \mathrm{K}$ of a specimen repeatedly transformed at about $250^{\circ} \mathrm{K}$. There is an appreciable induction period followed by a rapid rate of transformation, which subsequently levels off at an apparent completion. At the time of the apparent completion, about $2 \mathrm{hr}$ after immersion of the sample in the isothermal bath, the specimen was $21 \%$ beta phase, but the postrun density measurements indicated that the transformation proceeded to its completion after the specimen was removed from the isothermal bath. Figure 24 compares the kinetics of isothermal transformations at $245^{\circ} \mathrm{K}$

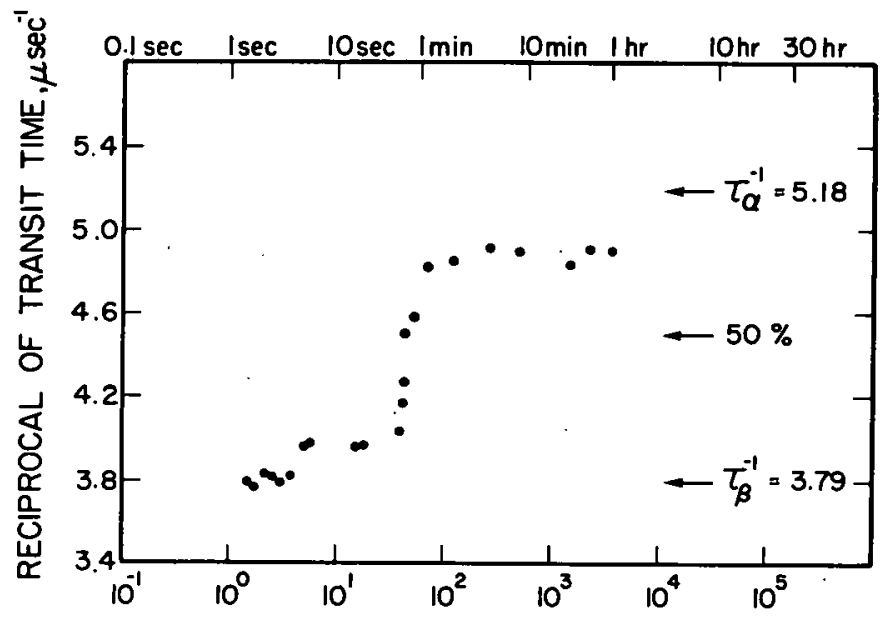

Fig. 23

Reciprocal of Transit Time of Longitudinal Waves in Specimen CM-29-3, as a Function of the Time of Holding during the 12th Beta $\rightarrow$ Alpha Transformation at $245^{\circ} \mathrm{K}$

TIME OF HOLDING IN ISOTHERMAL BATH, sec 42897

Fig. 24

Fraction of Beta Plutonium Transformed to the Alpha Phase, as a Function of the Timc of Holding during the First and 12th Cycles. of Specimen CM-29-3

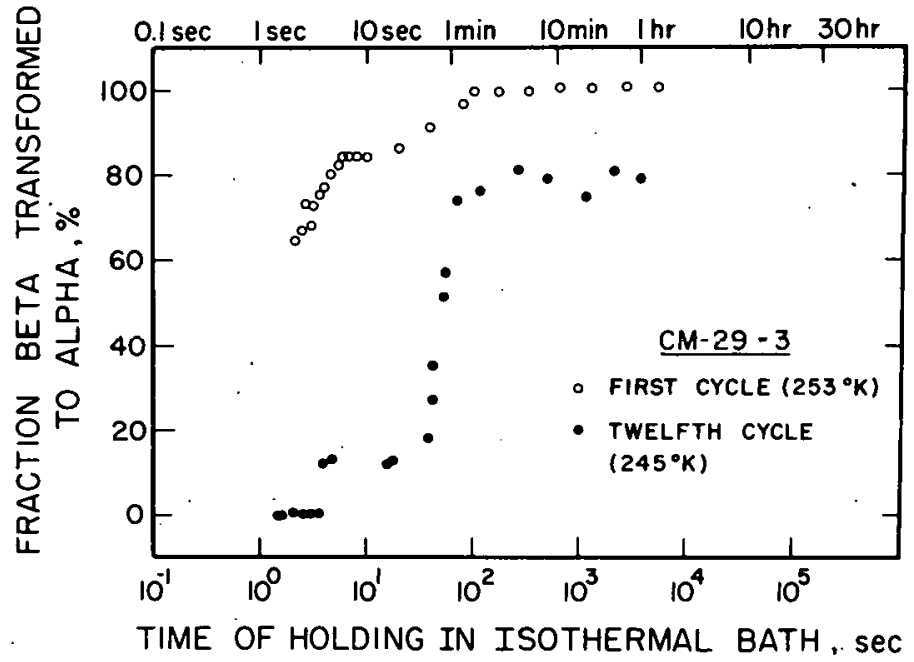


for the 12 th treatment of the multicycled specimen with a specimen transformed in the regular manner. As expected, the uncycled specimen transformed at a much higher rate and the transformation went to completion.

\section{Influence of Interrupted Quenching}

The effect of an interrupted quench upon the isothermal transformation at room temperature was examined by carrying out a stepquenching experiment. A specimen was partially transformed at $358^{\circ} \mathrm{K}$ for 7 min to yield about 50\% transformation from beta to alpha, as shown in Fig. 22. Subsequently, the specimen was rapidly transferred into the clamping device at room temperature. Figure 25 shows the variation of transit time with holding time. The values of the transit time are consistent with the fact that the specimen was previously transformed by $50 \%$.

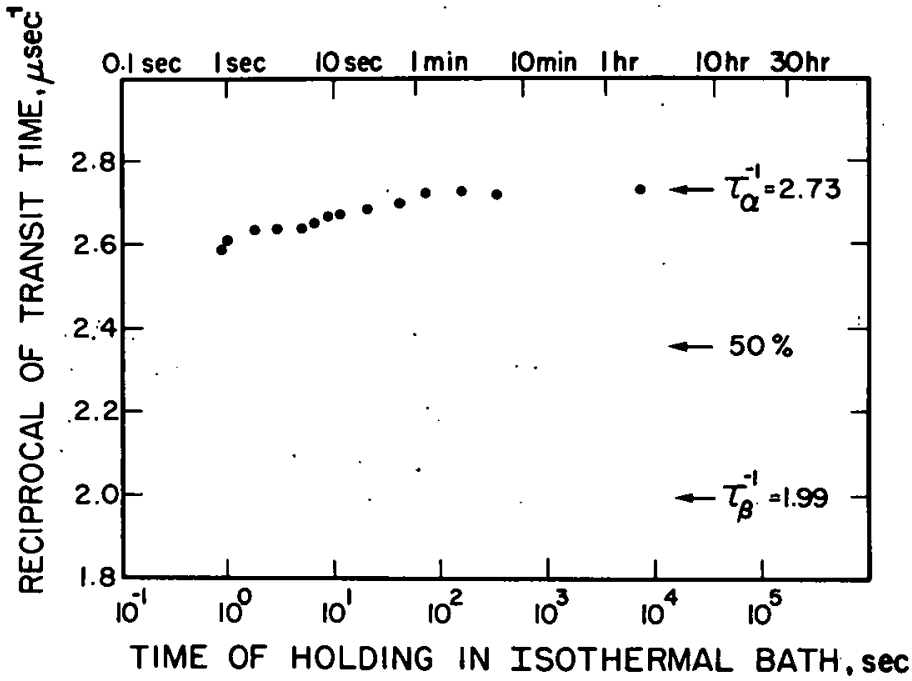

Fig. 25

Reciprocal of the Transit Time of Longitudinal Waves in Specimen $\mathrm{CM}-29-10$, as a Function of the Time of Holding at $291^{\circ} \mathrm{K}$ after Heating to $453^{\circ} \mathrm{K}$, Quenching to $357^{\circ} \mathrm{K}$, Holding for $7 \mathrm{~min}$, and Quenching to $291^{\circ} \mathrm{K}$

42899

Figure 26 compares a regular isothermal run at room temperature and the interrupted quench. By noting the time interval on both curves

Fig. 26

Fraction of Beta Plutonium Transformed to the Alpha Phase at Room Temperature for Specimens Subjected to Interrupted Quench Trea tment and Normal Treatment

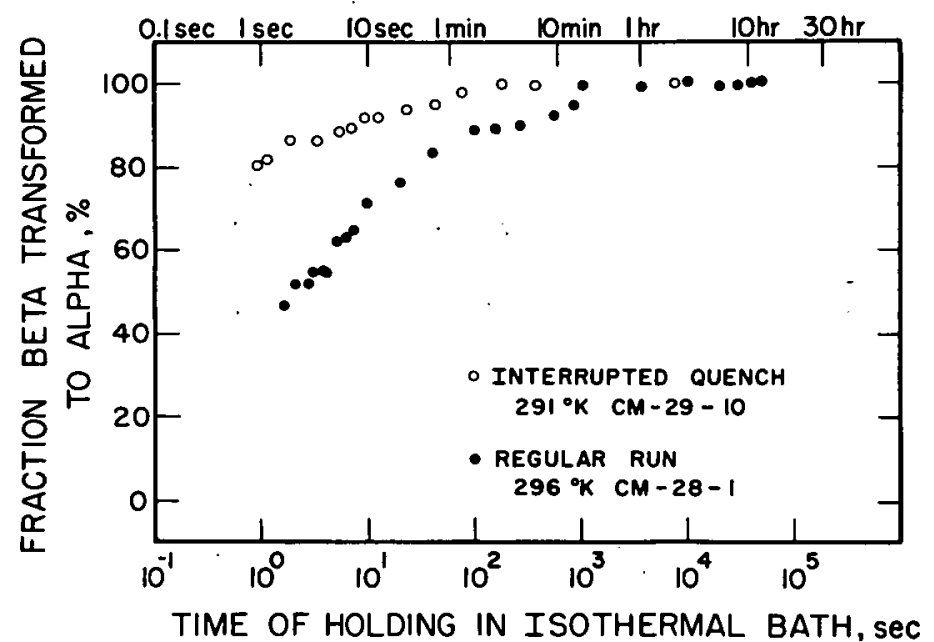

42900 
between 60 and $90 \%$ transformation; one can see that the regular run progressed at a lower rate. 'On the curve for the interrupted quench, the time interval was $7 \mathrm{sec}$, whereas the regular run required $48 \mathrm{sec}$.

\section{Density Decrease upon Alpha $\rightleftarrows$ Beta Transformation}

The density of the plutonium specimens after a complete alpha beta-alpha cycle was influenced greatly by the thermal conditions. At the

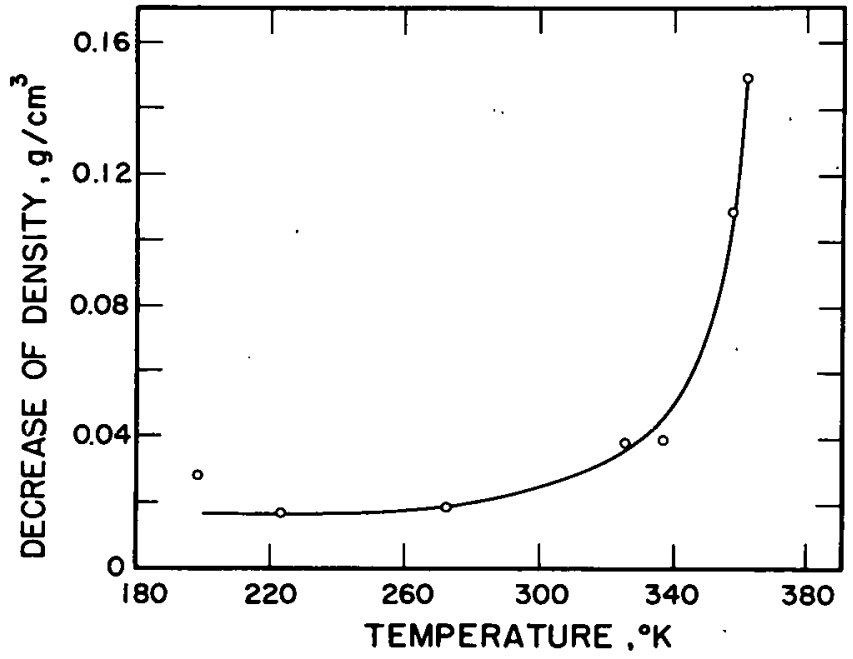

42901

Fig. 27. Decrease in Density Measured at Room Temperature of Plutonium, as a Function of the Isothermal Transformation Temperature higher holding temperatures the density defect was greater, as shown in Fig. 27. Such behavior was particularly obvious for transformation temperatures above $313^{\circ} \mathrm{K}$. At temperatures within the low-temperature branch on the TTT diagram (Fig. 22), the density defect was small and uniform. In this temperature range, the density decrease was about $0.02 \mathrm{~g} / \mathrm{cm}^{3}$ per cycle as compared to $0.15 \mathrm{~g} / \mathrm{cm}^{3}$ for a specimen isothermally transformed at $358^{\circ} \mathrm{K}$.

One sample, which underwent a quasi-equilibrium cycling heat treatment up to the deltaplutonium temperature range,

showed a more extensive density decrease of about $20 \%$ beyond that occurring in a sample that was subjected to a similar number of cycles through the alpha $\vec{z}$ beta transformation. This additional decrease in density indicated that the high-temperature phase transformations also contribute to the density change, but, evidently, their contributions are much smaller than that during the alpha $\rightleftarrows$ beta phase change.

The effect of rapid quenching through the beta $\rightarrow$ alpha transformation on the change in density is worth noting. The total density decrease of a specimen rapidly cycled seven times between $453^{\circ} \mathrm{K}$ and room temperature was $0.07 \mathrm{~g} / \mathrm{cm}^{3}$. Another specimen rapidly cycled between the betaphase temperature range and $250^{\circ} \mathrm{K}$ yielded a density decrease of $0.10 \mathrm{~g} / \mathrm{cm}^{3}$, and extensive physical damage was evident, particularly at the periphery of the specimen.

A step-quenching procedure, wherein the specimen was $50 \%$ transformed at $358^{\circ} \mathrm{K}$ and the remainder at room temperature, demonstrated the weighted effect of the holding temperature on the overall decrease in density. A total density decrease of $0.09 \mathrm{~g} / \mathrm{cm}^{3}$ was observed. This meant that 
the first $50 \%$ of the beta $\rightarrow$ alpha transformation at $358^{\circ} \mathrm{K}$ had an appreciable effect and contributed the major portion of the total density decrease, as seen in Fig. 27.

Because the sound velocities that were measured at room temperature before and after the isothermal treatments were identical within the limits of the experimental error, it may be assumed that the specimens were $100 \%$ alpha plutonium at room temperature. Thus, the changes in density represented the extent of void formation during the alpha $\rightleftarrows$ beta transformation. Qualitatively, this assertion was confirmed by metallographic examinations; however, no attempt was made to determine quantitatively the extent of void formation by metallographic observations.

\section{Metallographic Observations}

Figure 28 shows a specimen transformed at $361^{\circ} \mathrm{K}$ for more than a day and then slowly cooled to room temperature. The important features are the large columnar grains and the clusters of fine grains. The columnar grains were larger than those in any other specimen. This grain structure extended over large areas of the specimen. The clusters of fine grains, which occupied about $25 \%$ of the total area, were in localized regions. A certain number of beta grains appear to have transformed to alpha at $361^{\circ} \mathrm{K}$ to yield the columnar structure. Once a portion of a beta grain started to transform, it triggered off the transformation in the remainder of the beta grain. Thus a group of columnar grains with similar orientation was considered to represent the entire area of a prior-beta grain. The cluster of fine grains indicated that some of the beta grains did not undergo transformation at $361^{\circ} \mathrm{K}$, but rather they were transformed at lower temperatures during the cool-down to room temperature. This was in accord with the ultrasonic measurements, as plotted in Fig. 21. Mechanical polishing revealed extensive structural damage that consisted of numerous voids and microcracks but only a few macrocracks.

Figure 29 shows the microstructure of the step-quenched specimen that was partially transformed at $358^{\circ} \mathrm{K}$, and then was quenched to room temperature where the beta $\rightarrow$ alpha transformation went to completion. The equiaxed and columnar-type grains were present, although the differences in sizes were not as spectacular as in the specimen transformed at $361^{\circ} \mathrm{K}$ (see Fig. 28). Figure 29 shows clusters of fine grains with jagged boundaries. These were considered to represent the portion of the specimen that transformed at room temperature. Ultrasonic measurements showed that $50 \%$ of the transformation was carried out at each isothermal treatment. Qualitatively, Fig. 29 confirms this observation. Voids and microcracks were fewer than in the specimen transformed at $361^{\circ} \mathrm{K}$. 


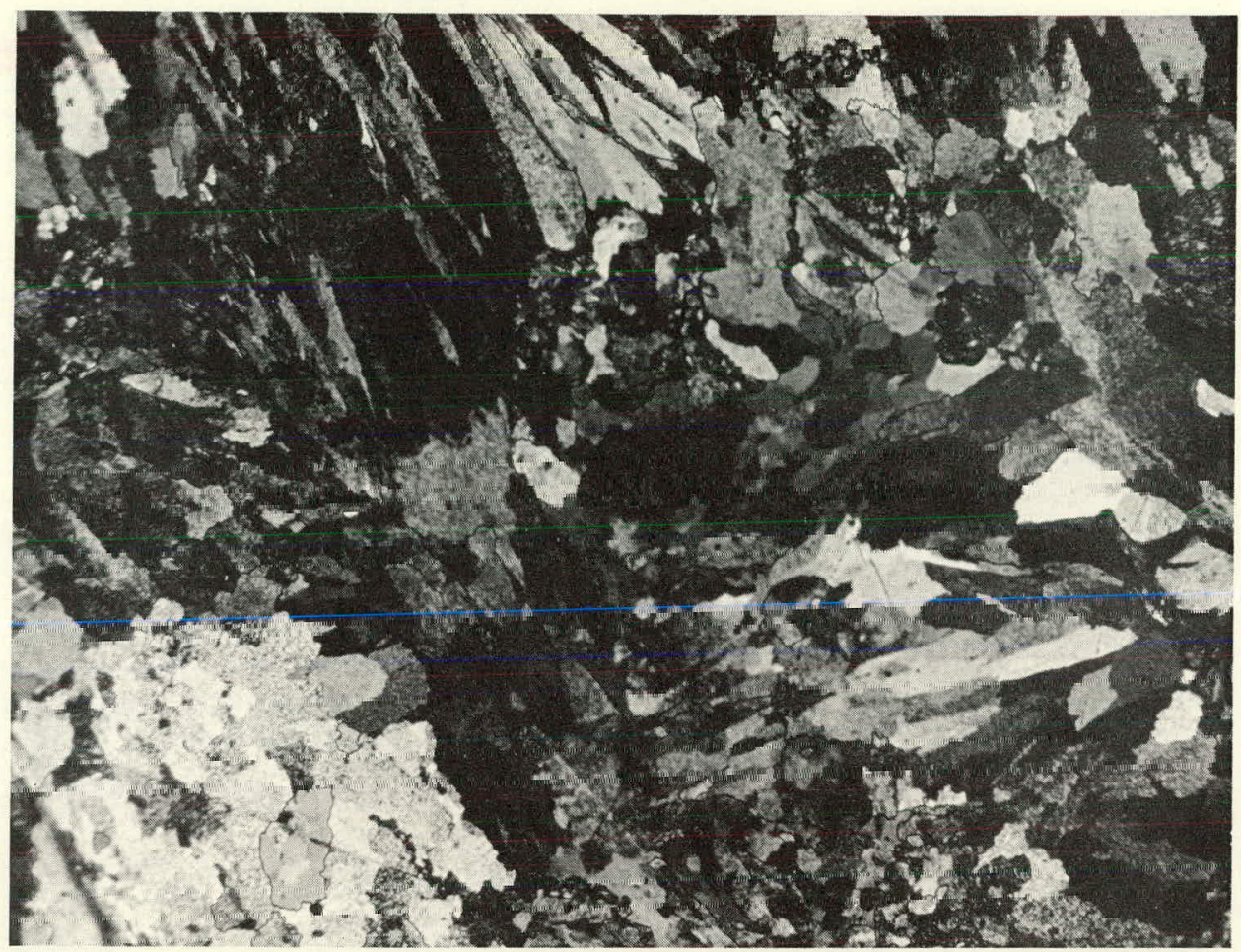

36838

Polarized Light

$250 X$

a. Representative Area

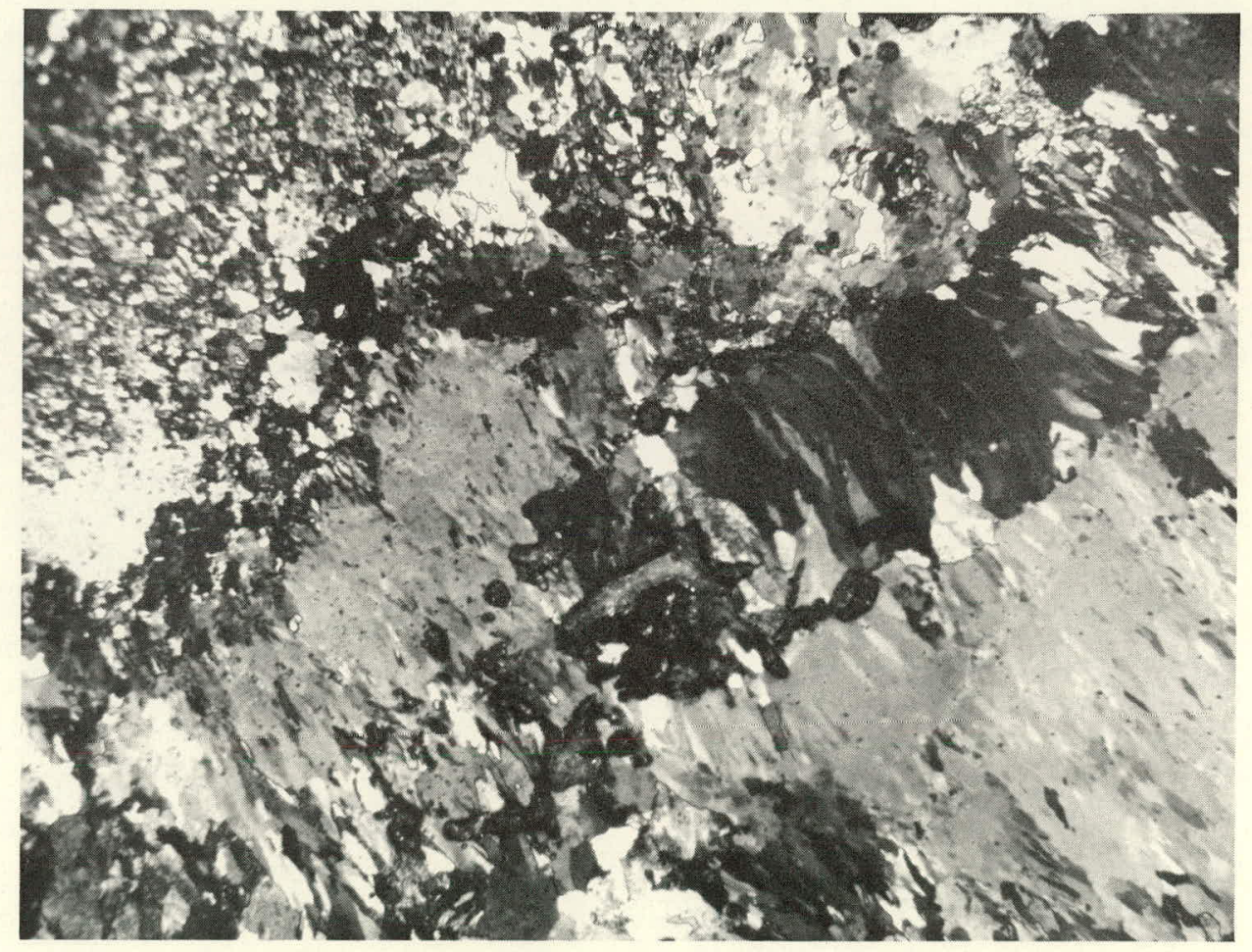

b. Nonrepresentative Area

Fig. 28. Microstructure of Specimen CM-28-10 after Isothermal Transformation at $361^{\circ} \mathrm{K}$ for 1.5 days 


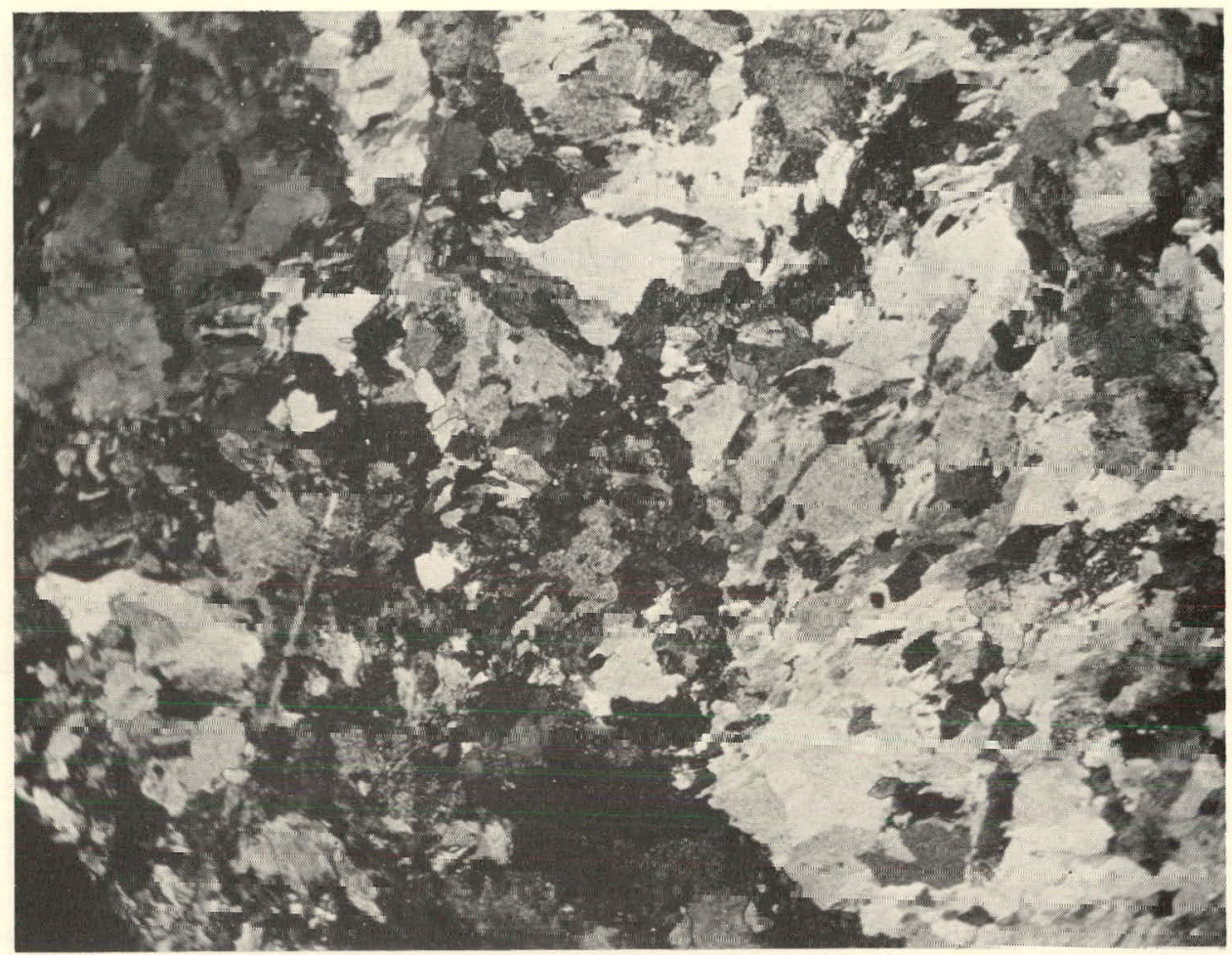

36841

Polarized Light

$250 \mathrm{X}$

a. Representative Area

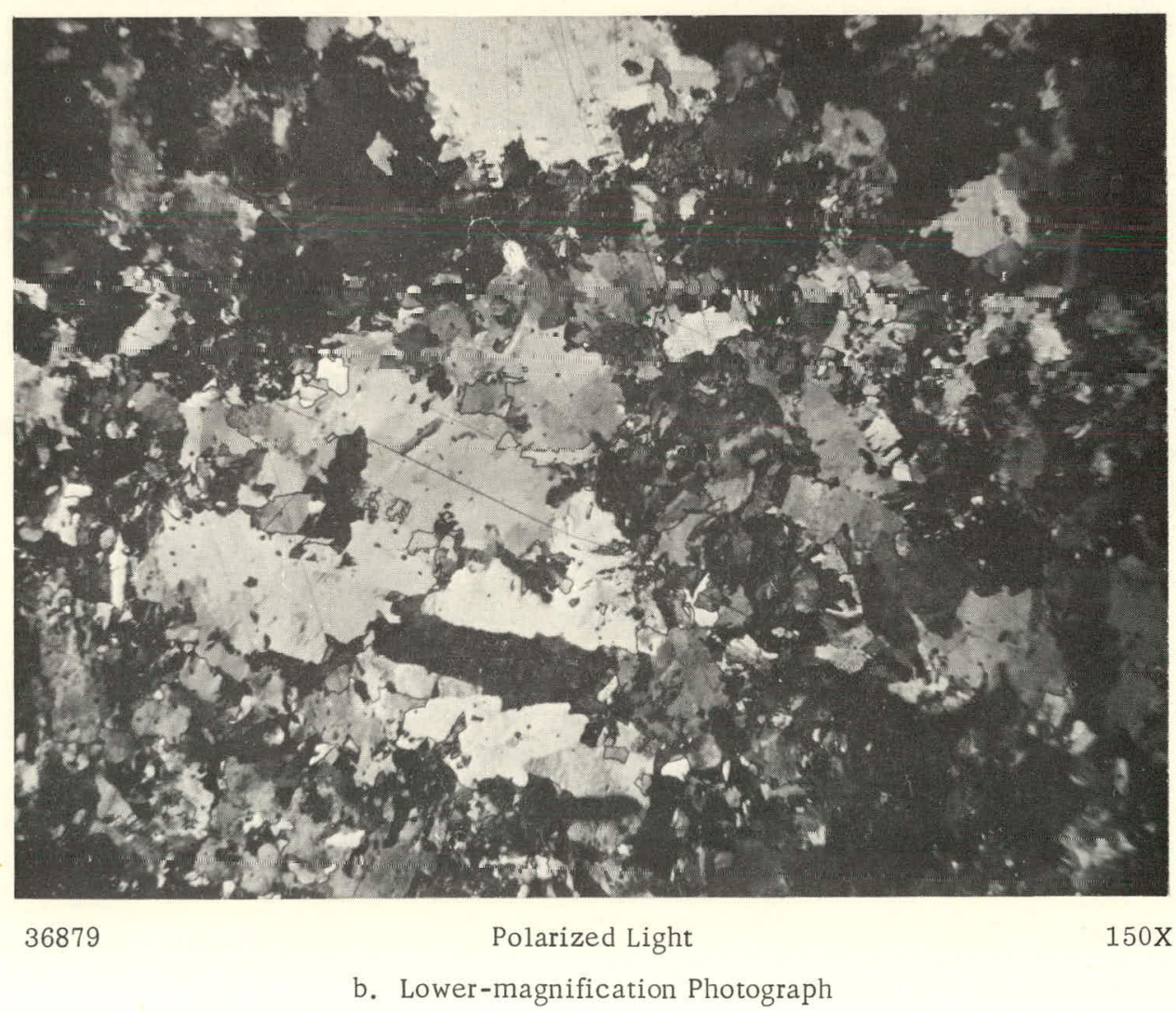

Fig. 29. Microstructure of Specimen CM-29-10 after Isothermal Transformation at $358^{\circ} \mathrm{K}$ for $7 \mathrm{~min}$ and Quenching to $291^{\circ} \mathrm{K}$ to Complete the Beta $\rightarrow$ Alpha Transformation 
Figure 30 is a photomicrograph of a specimen transformed at $326^{\circ} \mathrm{K}$. The columnar grains were less prominent and smaller than those in the specimen transformed at $361^{\circ} \mathrm{K}$. The number of fine grains was greatly increased, and they occupied the major part of the area. In this microstructure, the fine grains were more elongated in shape. The number of voids and microcracks was less than in the previously discussed samples.

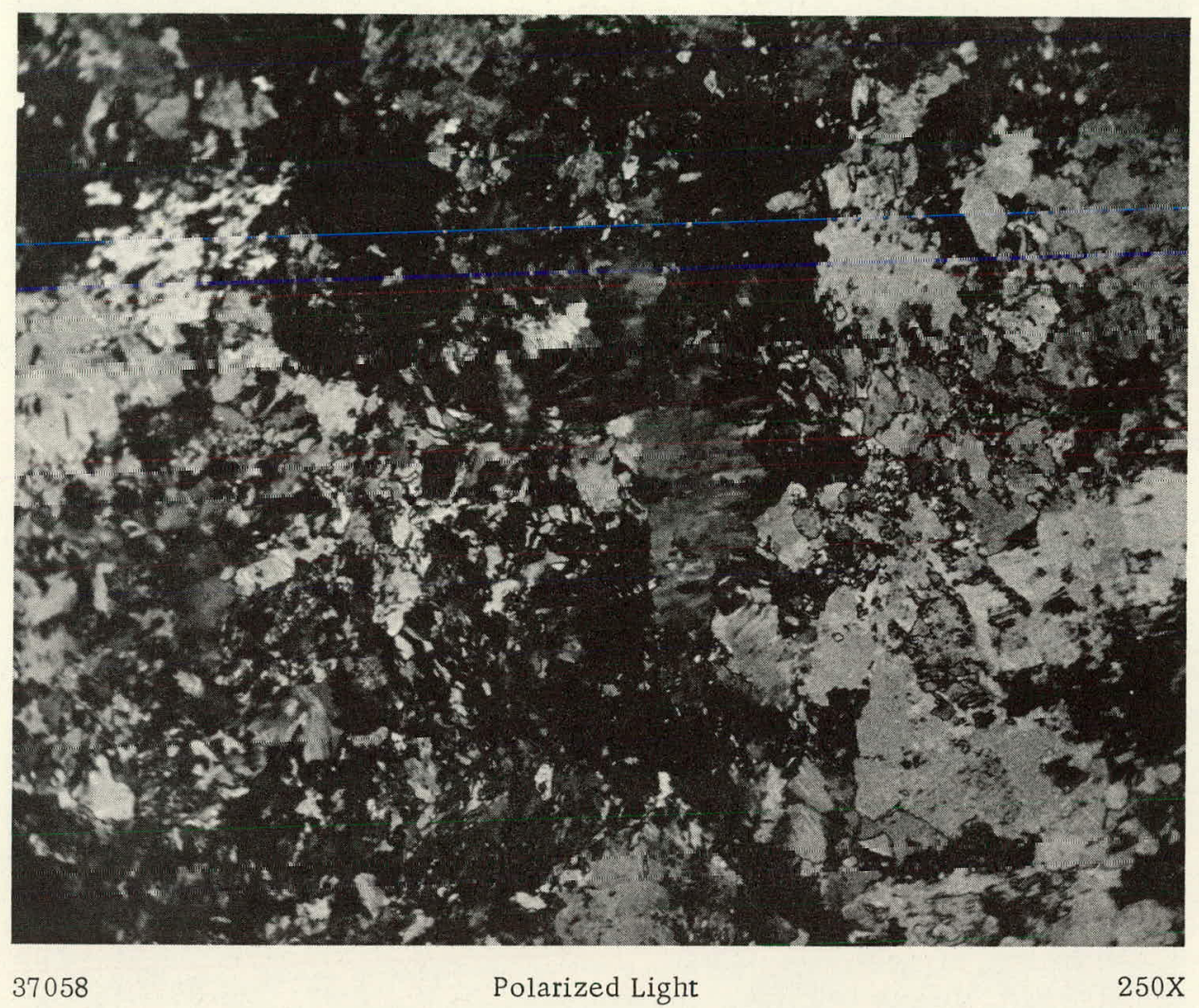

Fig. 30. Microstructure of Specimen CM-28-2 after Isothermal Transformation at $326^{\circ} \mathrm{K}$

The grain structure after transformation at room temperature is shown in Fig. 31. The columnar grains were not evident, and fine grains were randomly distributed throughout the structure.

Figure 32 shows the microstructure of a specimen transformed at $199^{\circ} \mathrm{K}$. The elongated fine grains with jagged boundaries had a definite acicular appearance. Groups of acicular grains appear to have a common orientation, and, presumably, each group delineates a prior-beta grain.

The influence of cycling 17 times between 453 and approximately $250^{\circ} \mathrm{K}$ on the microstructure is illustrated in Fig. 33. This treatment produced an extremely fine-grained microstructure, with clusters of somewhat large grains. Structural damage was extensive; there were numerous voids, and macrocracks were found at the periphery of the specimen. Ultrasonic measurements during an isothermal treatment at $245^{\circ} \mathrm{K}$ of the 12 th cycle 


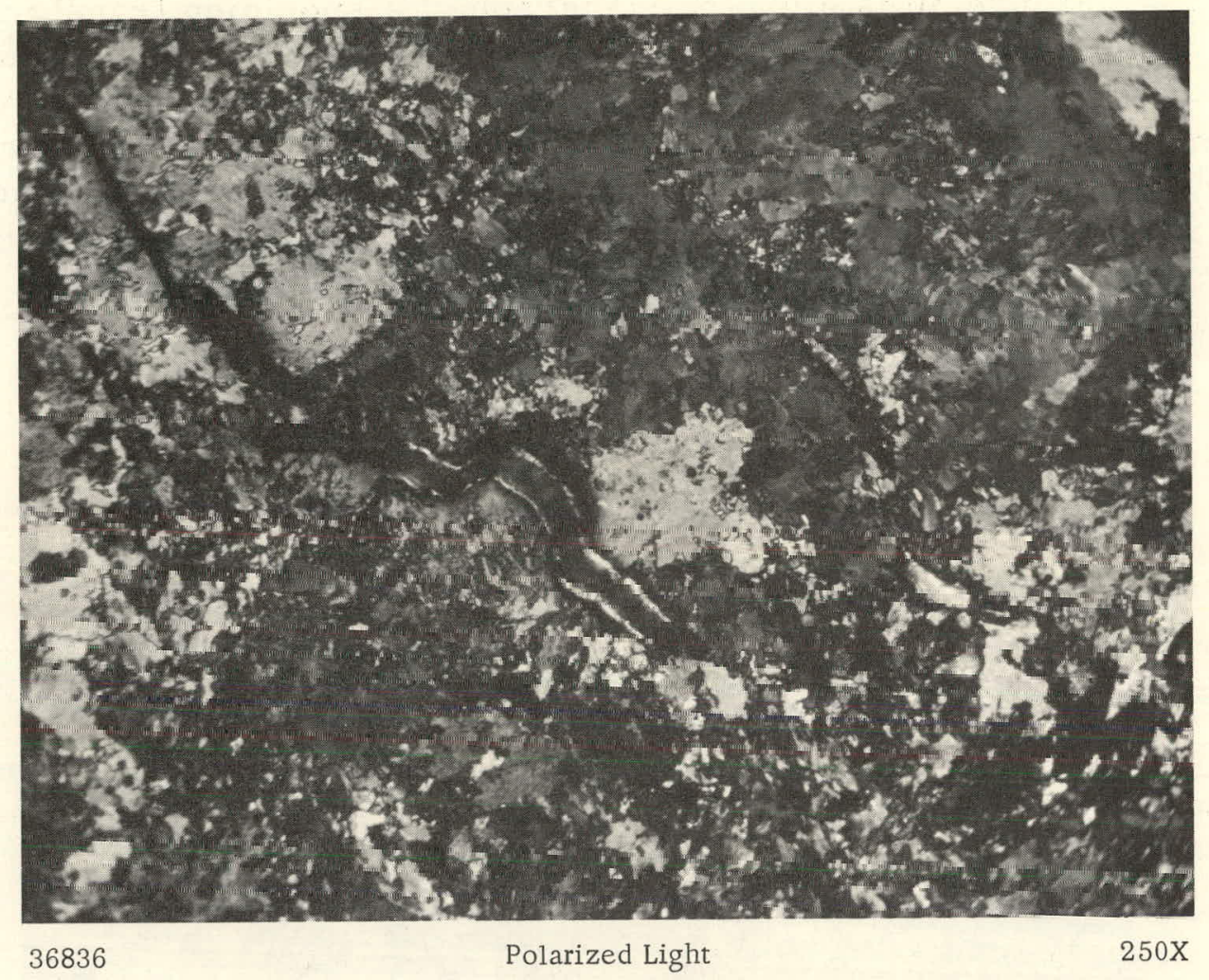

Fig. 31. Microstructure of Specimen CM-28-1 after Isothermal Transformation at $296^{\circ} \mathrm{K}$

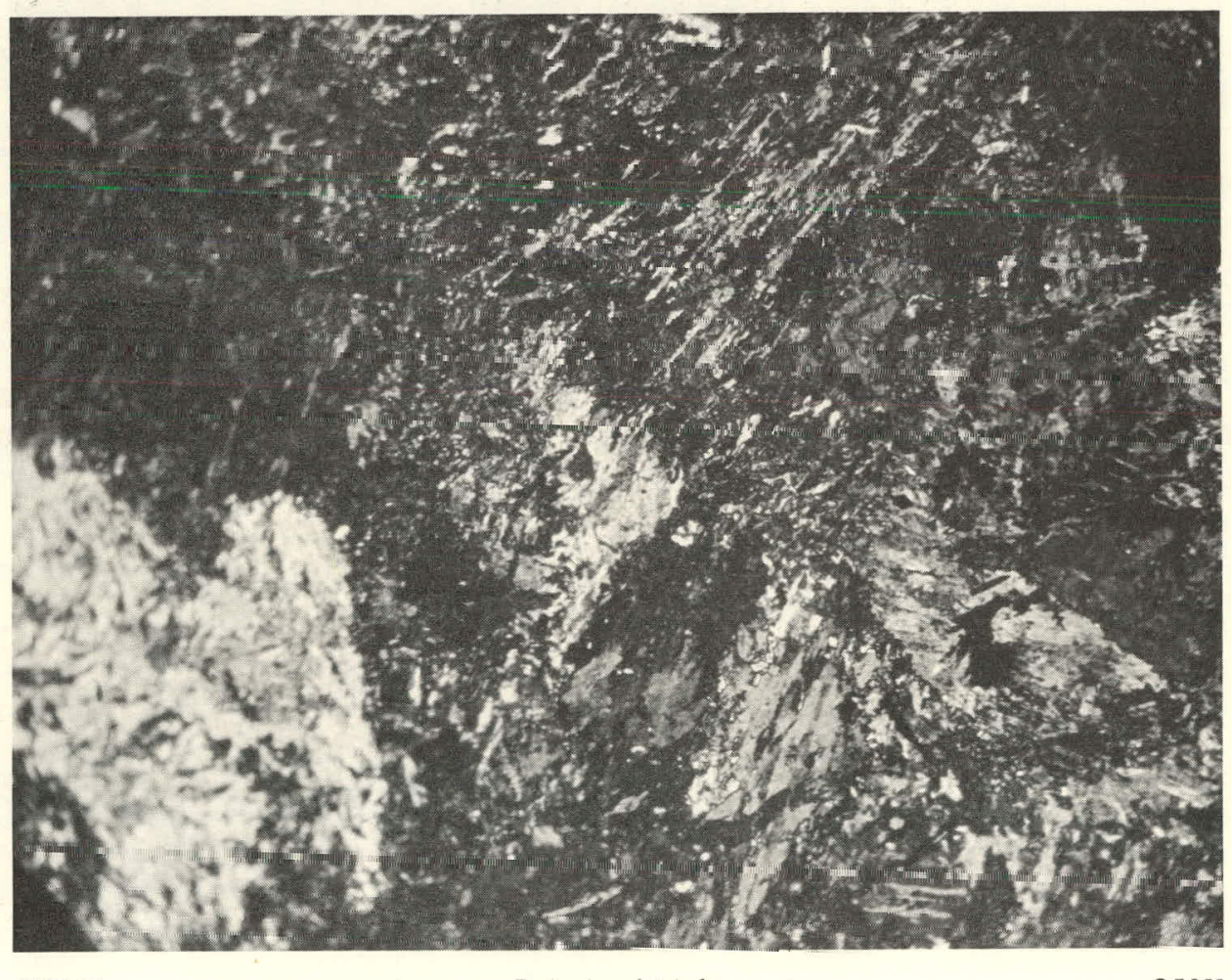

36843

Polarized Light

$250 \mathrm{X}$

Fig. 32. Microstructure of Specimen CM-29-11 after Isothermal Transformation at $199^{\circ} \mathrm{K}$ 


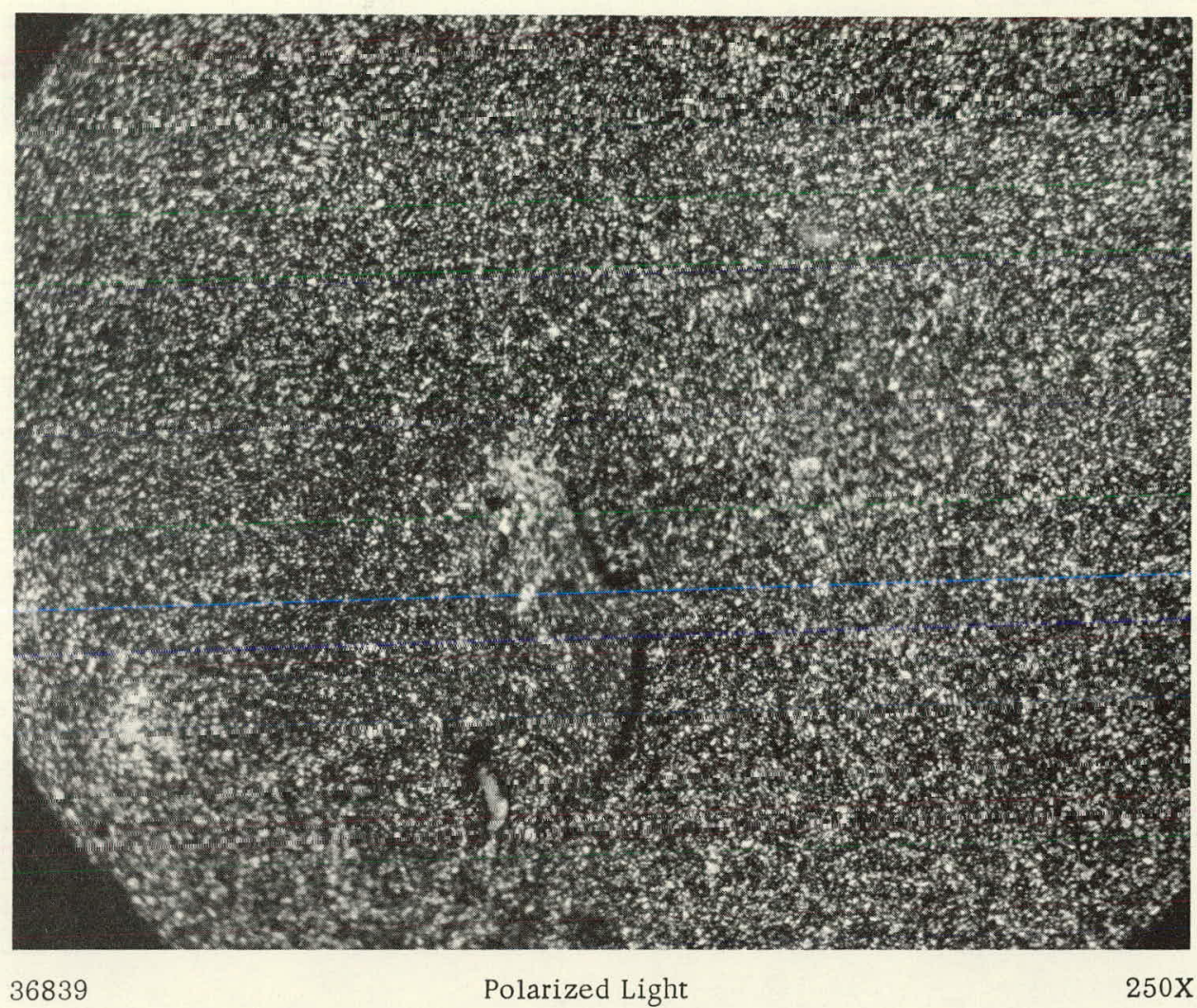

Fig. 33. Microstructure of Specimen CM-29-3 after 17 cycles through the Alpha $\rightleftarrows$ Beta Transformation between 453 and $253^{\circ} \mathrm{K}$

indicated that the transformation did not go to completion after holding for about $\mathrm{l} \mathrm{hr}$, at which time the apparent finish of the reaction was achieved, as seen in Fig. 23. The density decrease in this specimen after 17 cycles, followed by storage at room temperature for several days, was about $0.1 \mathrm{~g} / \mathrm{cm}^{3}$. This was attributed to the formation of porosity and voids, and not to retention of beta. The clusters of relatively large grains are believed to be alpha grains that had transformed at room temperature during the several days of storage. The coarser grain size is explained by the higher temperature at which the transformation went to completion.

An attempt was made to observe inclusions and deformation markings, such as twins, in the various metallographic specimens. None of the samples showed any discernible deformation markings. A few angular-appearing inclusions were found. Upon short-time electrolytic polishing, to delineate inclusions, all samples showed a "network" of fine etchpits, as shown in Fig. 34. It was speculated that this network delineated the grain boundaries of high-temperature phases, possibly beta grains. 


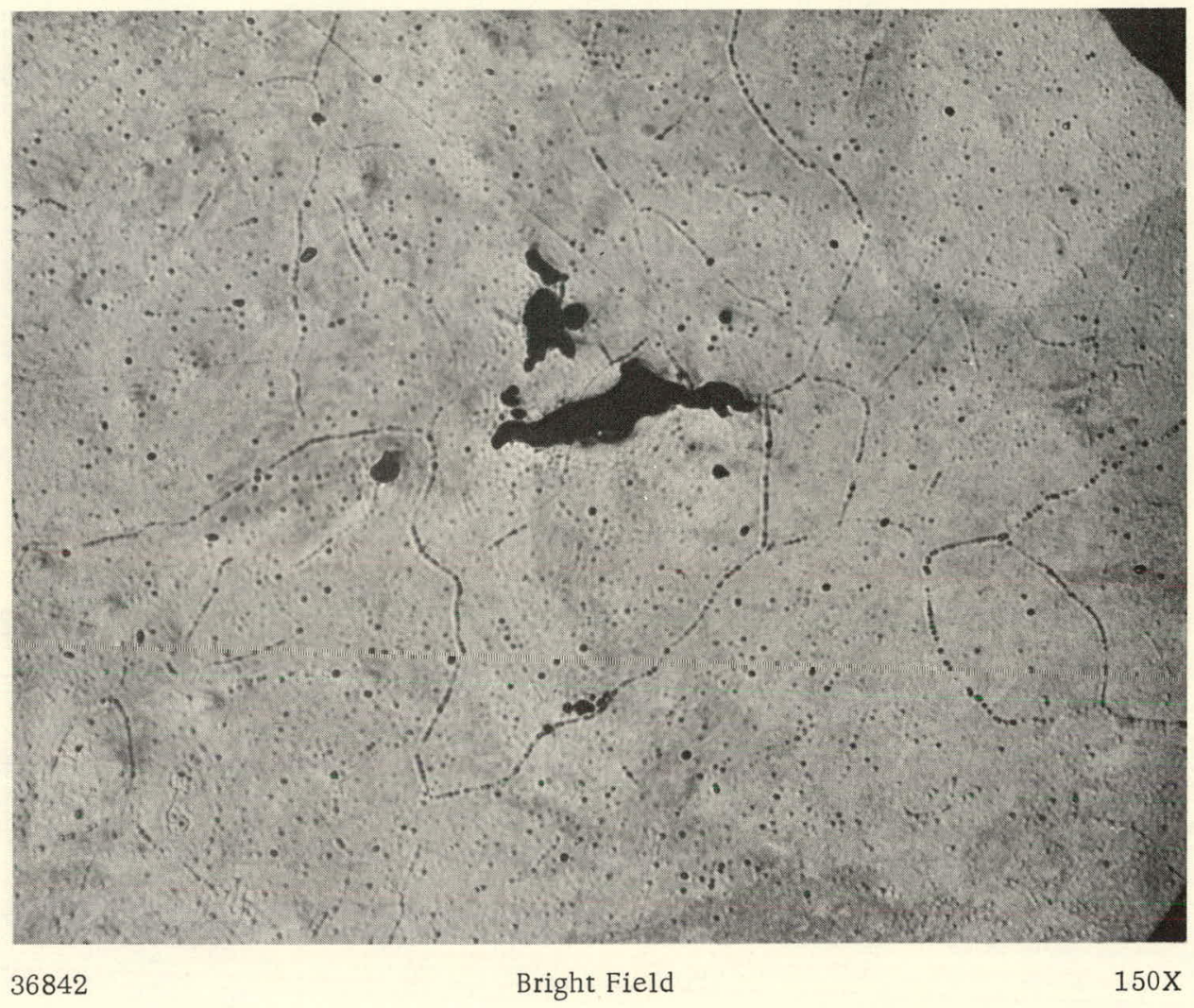

Fig. 34. Ghost-grain Boundaries in Specimen CM-29-11 that Were Developed by Electropolishing for a Short Period of Time

10. Ultrasonic Attenuation during the Is othermal Tests

The variation of the relative attenuation during the beta $\rightarrow$ alpha transformation at various temperatures is shown in Fig. 35. These curves display several features that are present at all temperatures; chronologically, from the time after immersion of the specimen into the isothermal bath, they are: (1) a decrease in attenuation during the initial stages of the transformation, (2) the main attenuation peak, (3) a decrease in attenuation as the transformation progressed, and (4) the subsidiary peak at the final stages of the transformation.

A significant dip (e.g., Fig. 35k), prior to any observable changes in sound velocity, occurred within the so-called induction period. The depth and width of this dip and the variation of attenuation within the dip depended upon the transformation temperature. For the elevated temperatures, the attenuation decreased smoothly, whereas for lower temperatures the behavior in this portion of the curves was oscillatory. Figure 36 shows the time of the start and recovery of the dip at the various transformation temperatures. Comparison of Fig. 36 with Fig. 22 showed that the time for the recovery of the dip corresponded with the time for the "start" of the transformation as indicated by the sound velocity. 

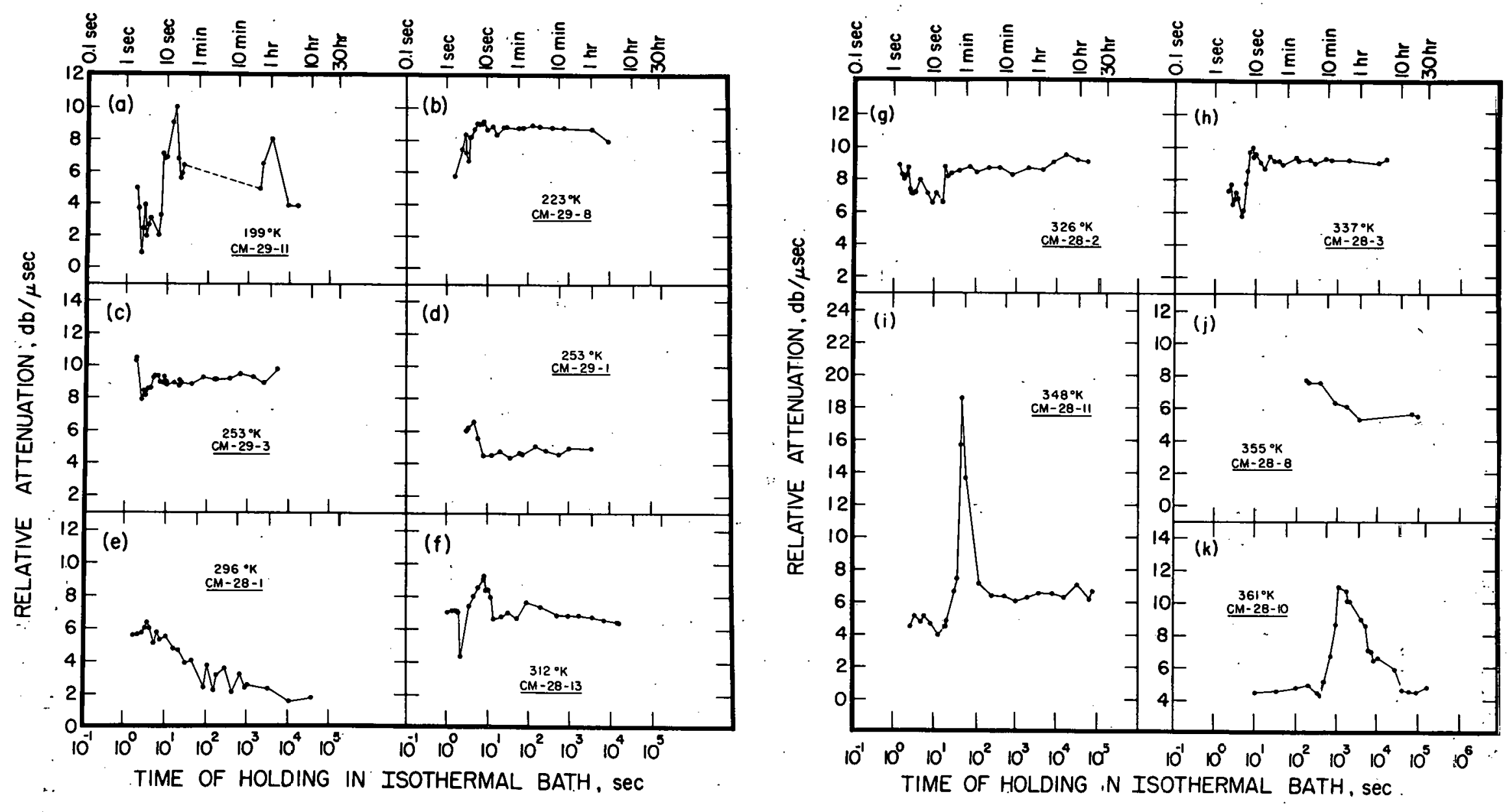

Fig. 35. Relative Attenuation of Longitudinal Waves in Plutonium, as a Function of Holding Time at Various Isothermal Transformation Temperature: 

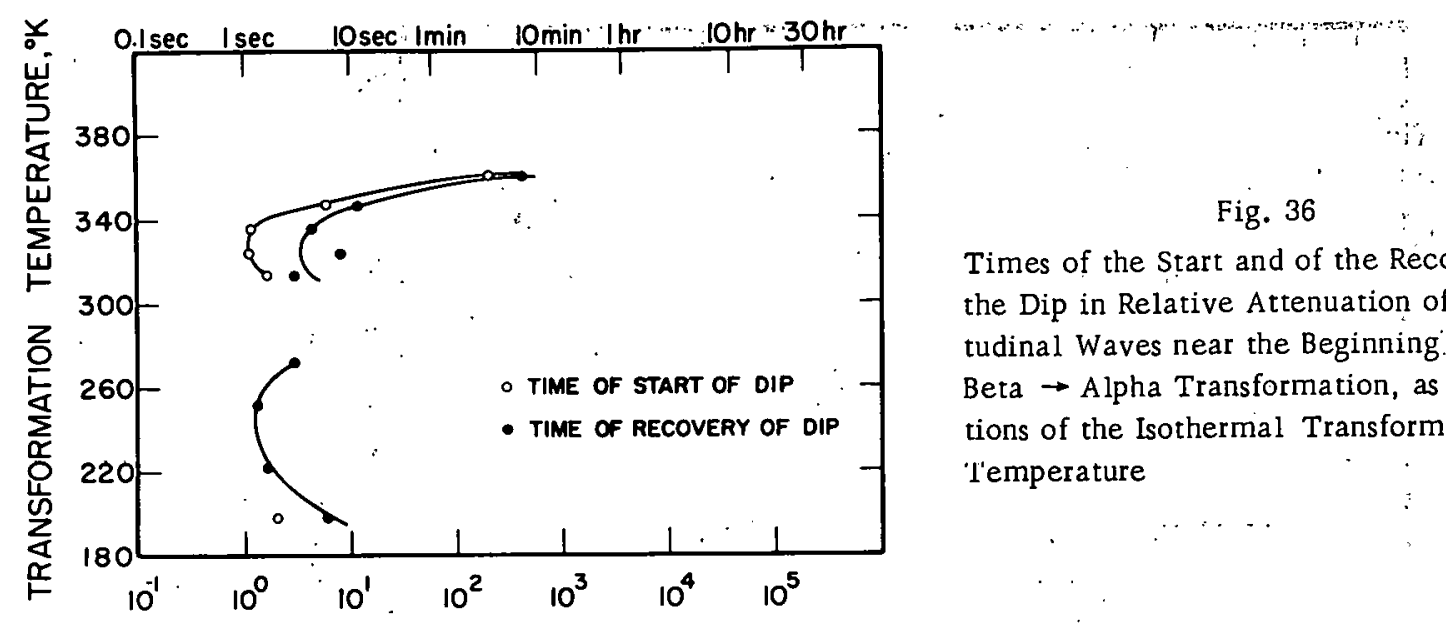

Fig. 36

Times of the Start and of the Recovery of the Dip in Relative Attenuation of Longitudinal Waves near the Beginning. of the Beta $\rightarrow$ Alpha Transformation, as Functions of the Isothermal Transformation 'l'emperature

TIME OF HOLDING IN ISOTHERMAL BATH, sec 42904

After the recovery of the pretransformation dip; the attenualion increased to the main peak (e.g., Fig. 35k). Figure 37 shows the times of occurrence of the maxima of the main attenuation peaks as a function of the transformation temperature. As shown in Fig. 38, the fraction of the beta

Fig. 37

Times of the Maxima in the Main Peaks and the Subsidiary Peaks of Relative Attenuation of Longitudinal Waves, as Functions of the Isothermal Transformation Temperature

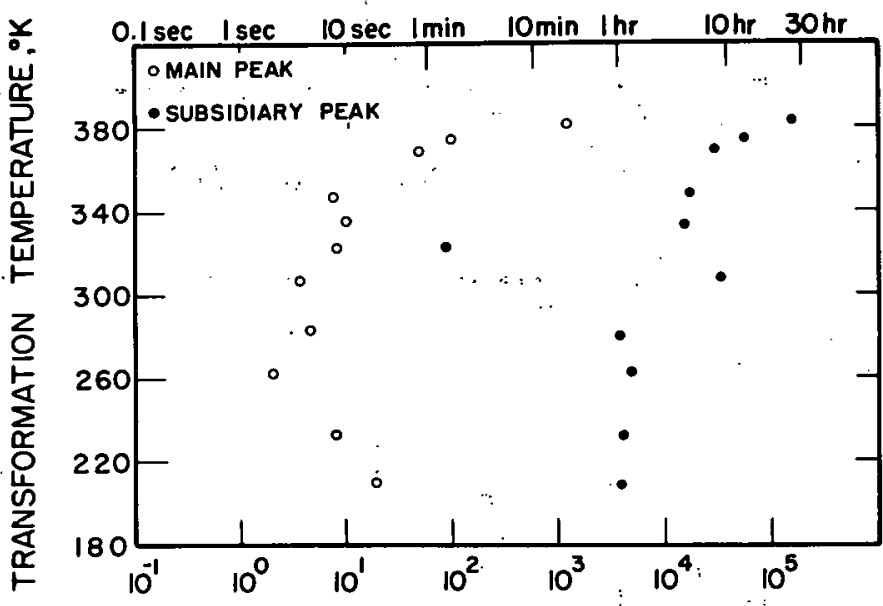

42905

TIME OF HOLDING IN ISOTHERMAL BATH, sec

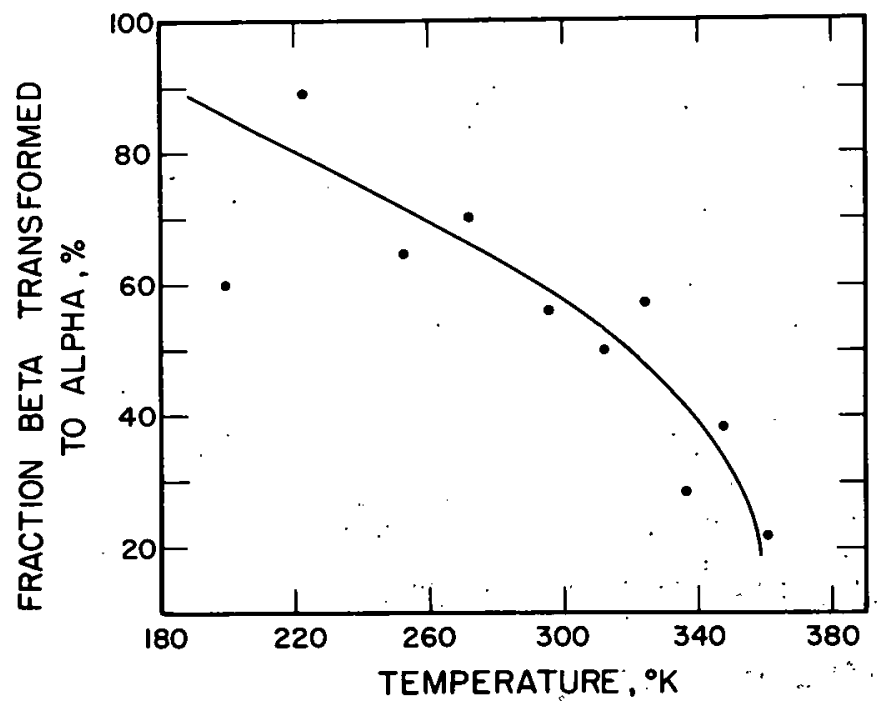

Fig. 38

Fraction of Beta Plutonium Transformed. to the Alpha Phase at the Times of the Maxima in the Main Peaks of Relative Attenuation of Longitudinal Waves, as a Function of the Isothermal Transformation Temperature 
phase that had transformed to alpha at the time of occurrence of the maxima in the main peaks depended on the transformation temperature. At $361^{\circ} \mathrm{K}$, the maximum corresponded to $21 \%$ transformation of beta to alpha, whereas at $223^{\circ} \mathrm{K}$ the extent of transformation was $87 \%$.

Figure 37 also shows the times for the maxima in the subsidiary attenuation peak that appeared close to the apparent, or actual, finish of the beta $\rightarrow$ alpha transformation.

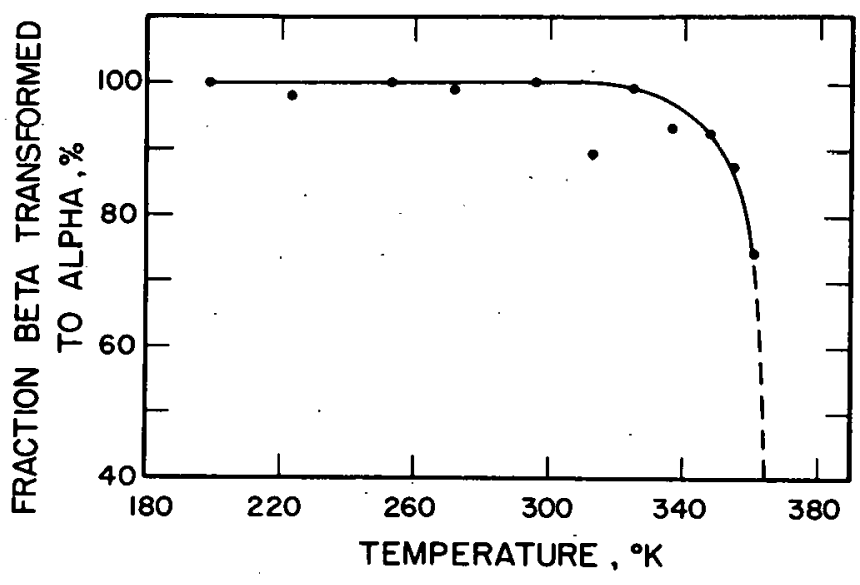

42907

Fig. 39. Fraction of Beta Plutonium Transformed to the Alpha Phase at the Times of the Maxima in the Subsidiary Peaks of Relative Attenuation of Longitudinal Waves, as a Function of the Isothermal Transformation Temperature Figure 39 depicts the extent of the phase change as a function of the times of occurrence of the maxi$\mathrm{ma}$ in this subsidiary peak.

In the isothermal test at $361^{\circ} \mathrm{K}$, plotted in Fig. $35 \mathrm{k}$, the relative attenuation attained its main peak a short time after the start of the pretransformation dip. This curve showed a typical feature, encountered particularly at higher temperatures, in that the attenuation decreased slowly from the first peak to the final value after prolonged times. The magnitudes of the attenuation while the specimen was still in the beta phase, and of the attenuation after the apparent completion of the reaction, were almost identical. The curve did not show a subsidiary peak.

The initial stages of the is othermal transformation at $355^{\circ} \mathrm{K}$ were not recorded; however, Fig. $35 \mathrm{j}$ shows that the attenuation decreased quite slowly from its main peak. The subsidiary peak was quite prominent.

A similar pattern was found in the curve for the sample transformed at $348^{\circ} \mathrm{K}$, shown in Fig. 35i. The attenuation after the apparent completion of the transformation was higher than the attenuation before the phase change.

The fact that the attenuation leveled off at a higher value than that before the transformation was true at lower transformation temperatures, as shown in Fig. $35 \mathrm{f}-\mathrm{h}$. In this temperature range, the attenuation, both before and after the main peak, showed an oscillatory character.

Figures $35 a-d$ show the attenuation behavior at temperatures below room temperature. The same general pattern was observed, although the attenuation at the beginning of the transformation was detected only at $199^{\circ} \mathrm{K}$. At this temperature, the pretransformation dip consisted of 
oscillations in attenuation, and then the attenuation ros exapidly to the main peak. The subsidiary peak was more pronounced than at any other temperature.

The relative difference in the magnitudes of the attenuation at the main peak and at the end of the isothermal treatment as a function of the transformation temperature is shown in Fig. 40. The two-branch nature of the curve, similar to the TTT diagram (Fig. 22), is evident.

The attenuation exhibited a temperature dependence. Thus, a change in the attenuation was observed when the sample was brought from its transformation temperature to the room temperature, as plotted in. Fig. 41. At some of the temperatures, the attenuation while the specimen was still beta plutonium was different from the attenuation after the test, as seen in Fig. 42; the difference in the attenuation at low temperatures was very small, but the difference was quite significant at the elevated temperatures.

Figure 43 shows the behavior of the attenuation during the 12 th cycle through the alpha $\rightleftarrows$ beta transformation between 453 and $245^{\circ} \mathrm{K}$. The absolute magnitude of the main peak of attenuation was much larger than during a regular isothermal run. The oscillatory character of the attenuation was more pronounced than at any other heat treatment.

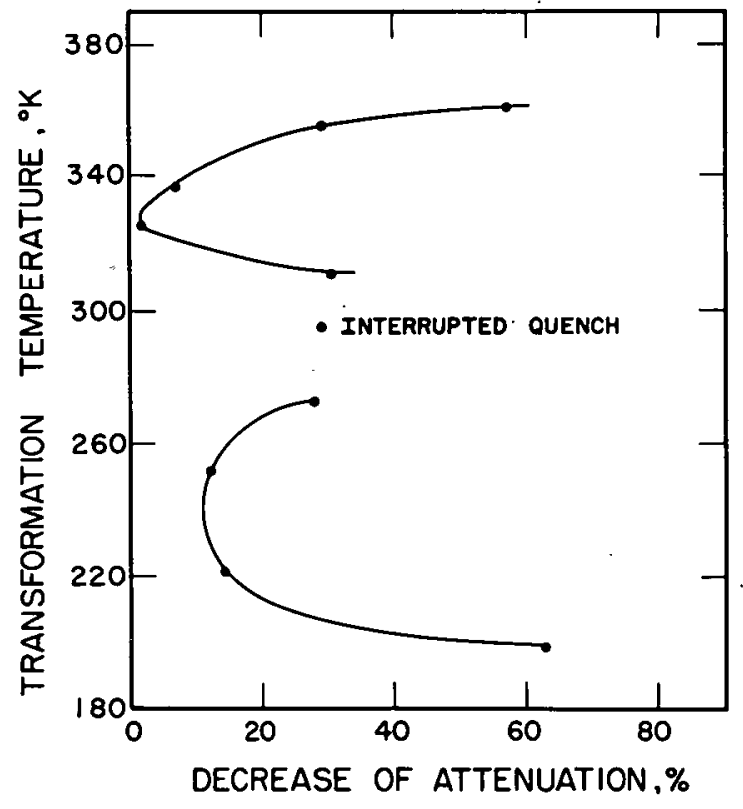

42908

Fig. 40. Magnitude of the Decrease from the Main Peak of Relative Attenuation of Longitudinal Waves to Its Final Value, as a Function of the Isothermal Trans formation Temperature

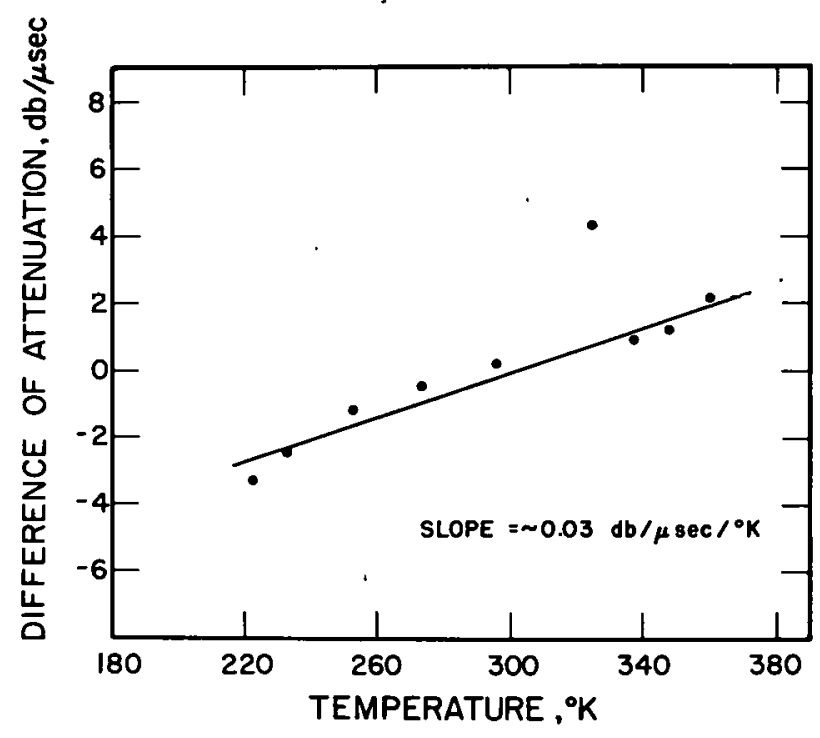

42909

Fig. 41. Difference between the Relative Attenuation of Longitudinal Waves at Room Temperature and at the Isothermal Transformation Temperatures after the Completion, or Apparent Completion, of the Beta $\rightarrow$ Alpha Transformation, as a Function of the Isothermal Transformation. Temperature 


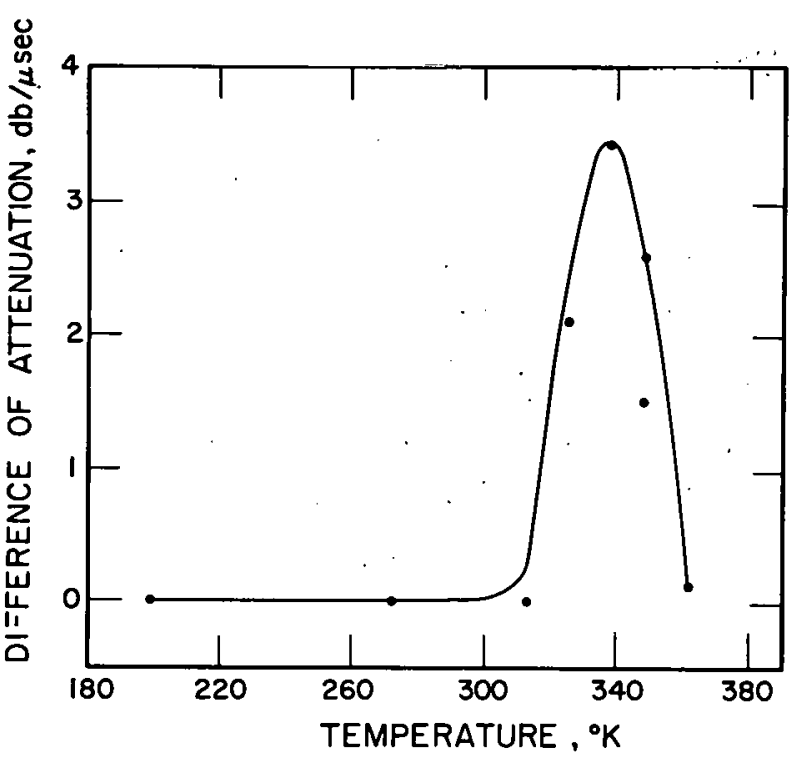

42910

Fig. 42. Difference between the Relative Attenuation of Longitudinal Waves after the Completion, or Apparent Completion, of the Beta $\rightarrow$ Alpha Transformation and While the Specimen Was Beta Plutonium, as a Function of the Isothermal Transformation Temperature

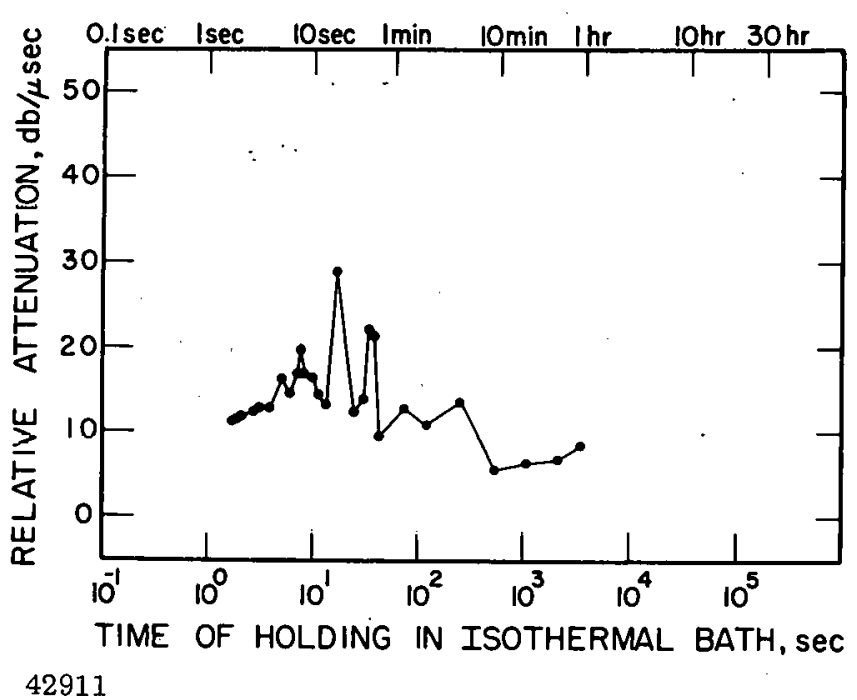

Fig. 43. Relative Attenuation of Longitudinal Waves in Specimen CM-28-3 during the 12th cycle between 453 and $245^{\circ} \mathrm{K}$, as a Function of the Time of Holding at $245^{\circ} \mathrm{K}$

The attenuation during the room-temperature portion of the interrupted-quench test is plotted in Fig. 44. Since about 50\% of the beta $\rightarrow$ alpha transformation occurred during the isothermal holding at $358^{\circ} \mathrm{K}$, the figure shows the final stages of the transformation. The attenuation was. that expected at room temperature.

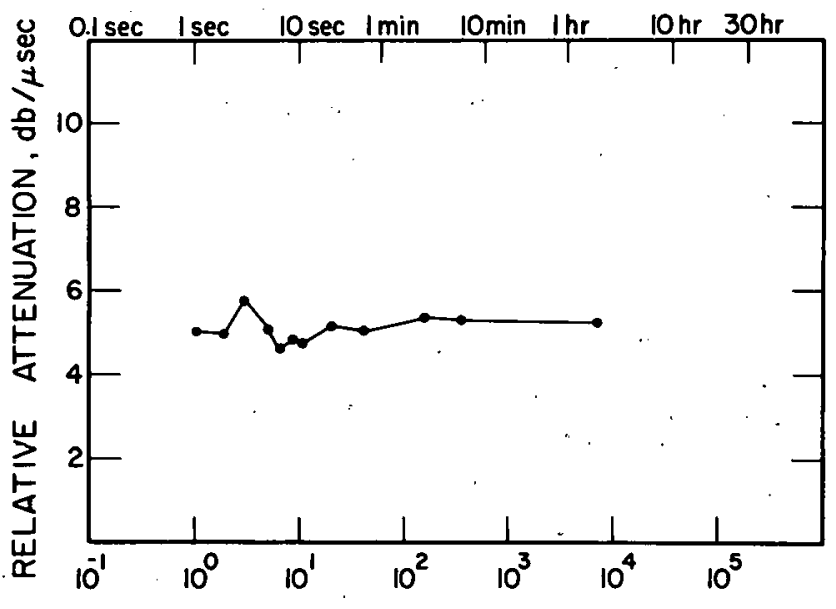

Fig. 44

Relative Attenuation of Longitudinal Waves in Specimen CM-29-10 during Isothermal Holding at Room Temperature, after Approximately $.50 \%$ Transformation at $358^{\circ} \mathrm{K}$, as a Function of the Time of Holding

TIME OF HOLDING IN ISOTHERMAL BATH, Sec 


\section{DISCUSSION}

A. Anomaly at $200^{\circ} \mathrm{K}$

The variation of sound velocity with temperature upon slow heating showed a change in slope in the region of about $200^{\circ} \mathrm{K}$, as seen in Figs. 8 and 9. A similar behavior was found on the attenuation curve (Fig. 11). Hardness measurements ${ }^{1}$ also indicated a change in slope in this temperature region. A. relaxation process, the nature of which has not been further investigated in the course of the present study, may be operative in this region.

B. Anomaly at $350^{\circ} \mathrm{K}$

High-purity plutonium specimens displayed anomalous behavior in the vicinity of $350^{\circ} \mathrm{K}$ during slow heating. The longitudinal-wave velocity (Fig. 8) shows a dip in this region, while the shear velocity (Fig. 12) also changed slope. The attenuation exhibited a peak near $350^{\circ} \mathrm{K}$, as seen in Fig. 10, and finally Poisson's ratio, plotted in Fig. 14, indicated a dip in the same region.

Gardner and $\mathrm{Mann}^{72}$ reported that the plasticity of unalloyed plutonium increased to a maximum near $345^{\circ} \mathrm{K}$ with rising temperatures. Such behavior was observed under both tensile and compressive deformations and at various testing speeds.

Low-frequency (about 2-cps), internal-friction measurements on unalloyed uranium ${ }^{127}$ showed a peak at $373^{\circ} \mathrm{K}$ that disappeared upon annealing in the high alpha-uranium region. No explanation was offered with regard to possible reasons for this peak. Another small hump in the curve, which disappears after a beta-range anneal, was observed at $770^{\circ} \mathrm{K}$. A similar internal-friction peak was found in high-purity strontium metal at $373^{\circ} \mathrm{K} .{ }^{128}$ This peak was attributed to a possible grain-boundary effect. The authors indicated that 373 to $393^{\circ} \mathrm{K}$ was the recrystallization region of strontium.

Gardner and Mann ${ }^{72}$ speculated that a change in the deformation mechanism, possibly caused by recrystallization, took place at about $340^{\circ} \mathrm{K}$ in unalloyed plutonium. But Schonfeld ${ }^{129}$ and Ianniello ${ }^{130}$ reported that deliberate attempts to recrystallize alpha-plutonium after introduction of various amounts of strain did not produce any recrystallization. The attenuation peak at $350^{\circ} \mathrm{K}$ (see Fig. 10) and the corresponding dip in. Poisson's ratio (see Fig. 14) quite strongly indicate the possible occurrence of a relaxation of stress as a result of a recovery process. 


\section{Microvoid Formation and Cycling Damage}

Based upon the assumption that the specimens always were alpha plutonium at room temperature, as evidenced by the sound-velocity measurements, the density defect represented the extent of void formation within the samples. A significant density decrease was observed in specimens that underwent the beta $\rightarrow$ alpha phase change isothermally at temperatures above $313^{\circ} \mathrm{K}$, plotted in Fig. 27, i.e., in the high-temperature branch of the TTT diagram (Fig. 22). The density measurements were qualitatively confirmed by metallographic observations.

Several discrepancies were revealed when the present experimental evidence was compared with that of Nelson ${ }^{1}$ and of Loasby and Lowe. ${ }^{5}$ Such factors as the complicated crystal structures, the anisotropy in the elastic constants, the large difference in the elastic properties between the alpha and beta phases, and the mechanism of the polymorphic transition contribute to the formation of porosity in plutonium, but the most important factor is probably the metal purity. Holden ${ }^{131}$ found that porosity develops with an increasing number of thermal cycles in commercially pure uranium, but high-purity uranium did not develop any porosity. Plutonium seems to follow this trend. A specimen that was rapidly cycled for 17 times through the alpha $\rightleftarrows$ beta transformation between 453 and $250^{\circ} \mathrm{K}$ showed a total decrease in density of only $0.1 \mathrm{~g} / \mathrm{cm}^{3}$, whereas Nelson ${ }^{4}$ reported a decrease of $0.1 \mathrm{~g} / \mathrm{cm}^{3} /$ cycle, and Loasby and Lowe ${ }^{5}$ reported as much as $0.3 \mathrm{~g} / \mathrm{cm}^{3} /$ cycle. The largest density defect observed in this study, $0.15 \mathrm{~g} / \mathrm{cm}^{3}$ (see Fig. 27), was in a specimen transformed isothermally at $361^{\circ} \mathrm{K}$. Specimens that slowly cooled at a rate of $0.3^{\circ} \mathrm{K} / \mathrm{min}$ from the beta region to room temperature showed a density decrease of $0.11 \mathrm{~g} / \mathrm{cm}^{3}$. Nelson ${ }^{4}$ reported a density decrease of $0.6 \mathrm{~g} / \mathrm{cm}^{3}$ in a specimen cooled at $2^{\circ} \mathrm{K} / \mathrm{min}$.

The number of voids in the isothermally transformed specimens seemed to be more dense at the center than at the periphery. Such a morphology also was observed by Nelson. ${ }^{78}$ Loasby and Lowe ${ }^{5}$ maintained that voids started to form only after $50 \%$ beta transformed into the alpha phase. This assertion, was not confirmed in this work. A step-quenched specimen was isothermally transformed $50 \%$ from beta to alpha at $358^{\circ} \mathrm{K}$, and the remainder of the beta was transformed at room temperature to yield a total density decrease of $0.09 \mathrm{~g} / \mathrm{cm}^{3}$. Taking the weighted effect of each transformation temperature, one finds that the first $50 \%$ of the beta $\rightarrow$ alpha transformation at $358^{\circ} \mathrm{K}$ contributed the major part to the total density decrease: Complete transformation at room temperature yielded a density decrease of only about $0.025 \mathrm{~g} / \mathrm{cm}^{3}$, as seen in Fig. 27 .

The creation of microvoids that develop into voids and cracks upon repeated cycling is probably due to mechanical effects. The anisotropy of the elastic properties and the large difference in the elastic constants of the beta and alpha phases should be responsible for the formation of steep 
stress gradients that finally produce the microvoids.. Stresses.are also developed because of the anisotropy of the thermal contraction. These processes, which reduce the final density of the plutonium sample, act mainly during the beta $\rightarrow$ alpha transformation and particularly at elevated transformation temperatures in the alpha region.

Thermal cycling through the alpha $\rightleftarrows$ beta transformation region caused both extensive structural damage (see Fig. 33) and marked changes in the isothermal transformation kinetics (see Fig. 24). Cycling under quasi-equilibrium conditions affected the temperature-hysteresis loop only to a minor extent, but rapid cycling for 12 times between 453 and $250^{\circ} \mathrm{K}$ yielded isothermal transformation kinetics at $245^{\circ} \mathrm{K}$ very different from that obtained during one isothermal run, as seen in Fig. 24. The induction period increased from less than $l$ sec to about $25 \mathrm{sec}$ for the multicycled specimen, and the completion of the transformation was retarded. The large plastic strains induced during cycling resulted in grain refinement and fragmentation, as shown in Fig. 33, which created conditions conducive to considerable dislocation blocking and immobilization and, consequently, to retardation of the mechanical processes that lead to the phase transformation. Thus, a substantial delay in the initiation of the transformation was expected. This was contrary to Nelson's observations ${ }^{76}$ that thermal cycling through the transformation for less than 15 times had no effect on the transformation kinetics.

\section{The Beta $\rightarrow$ Alpha Transformation in High-purity Plutonium}

The transformation kinetics and the behavior of attenuation during the beta $\rightarrow$ alpha phase change in high-purity plutonium, upon rapid cooling, can be adequately interpreted in terms of the dislocation dynamics of a displacive phase transformation rather than in terms of an atom-by-atom transfer over the interface that would be required by a diffusion process. The crystallographic and kinetic features of displacive transformations are most appropriately described by the dynamic behavior of dislocation arrays that constitute the moving interface. Frank's dislocation model ${ }^{132}$ for the structure of the interface between the parent and product phases consists of a set of equally spaced, parallel screw dislocations. The passage of these dislocations through the parent phase leaves behind a trail of heterogeneous shears on a fine scale. Knapp and Dehlinger ${ }^{133}$ extended Frank's model of the interface by surrounding the embryo of the transformationproduct phase with an array of dislocation loops. The growth of the reaction product then will be governed by the expansion of these loops and by the creation of new disiocation loops.

\section{1.. Nucleation}

The nucleation process in any phase change is the stage in which domains of the transformation product grow from an unstable size or configuration (their embryonic state) to a state from which they are capable of 
further growth. The nucleation problem of displacive, or shear-like, transformations has been treated by three approaches: homogeneous nucleation, ${ }^{134}$ heterogeneous nucleation, ${ }^{8,135}$ and operational nucleation. ${ }^{53}$ The last two approaches are similar to each other and assume that the nucleation occurs at preferred sites in the parent phase. Such a concept satisfactorily explains both athermal and isothermal phase transformations. The preferred sites are considered to be pre-existing embryos in the hightemperature parent phase. They can be viewed as localized regions of very high free energy as the result of dislocations that provide the driving force for the evolution of embryos for the low-temperature transformation product. Knapp and Dehlinger ${ }^{133}$ suggested that certain pairs of dislocations in the parent phase are able to displace atoms and achieve the lower freeenergy configuration of the martensitic transformation product. Experimental evidence that confirmed these ideas was found.in austenitic ironnickel alloys where embryos of a size consistent with this theory were observed by transmission electron microscopy. ${ }^{136}$

The nucleation of alpha plutonium from the beta phase can be considered analogously. Localized regions consisting of dislocation arrays of higher free energy form alpha embryos in the beta-phase temperature range. When the specimen is quenched into the alpha temperature range, these embryos attain stability and are ready for continued growth. The net driving force for the phase transformation comes from the excess of the chemical free-energy change, which is temperature-dependent, over the nonchemical components, ̈.e., interfacial and strain energy. This difference of free energy causes the dislocation loops surrounding the embryos to increase in size and also causes generation of new dislocation loops. The coordinated transfer of atoms from their initial positions in the beta structure to their final positions in the alpha structure is accomplished by the motion of the dislocation loops. The rate of transformation from one phase to the other then is governed by propagation of the dislocation loops.

The nucleation stage of the isothermal beta $\rightarrow$ alpha transformation extends to the time of the first observable variations in the sound velocity. The pretransformation dip in the attenuation, as seen in Fig. 36, was related to what can be termed a preparation stage that preceded the phase change. As was described in Section V-C-10, the dip recovered and started climbing up to the main attenuation peak exactly at the time of the beginning of the beta $\rightarrow$ alpha transformation. The depthand width of the dip, as well as the behavior of the attenuation during the time of occurrence of the dip, were strongly dependent on the transformation temperature. With decreasing temperature, the attenuation within the limits of the dip assumed a more oscillatory character. 
Transformation behavior ${ }^{8}$ that is consistent with Knapp and Dehlinger's model requires the aid of thermal fluctuations to expand dislocation loops of subcritical nuclei to a size capable of spontaneous growth. The duration of this process depended on the size distribution of the subcritical nuclei, on the critical size requirements; and on the amplitude of the thermal fluctuations, and therefore on temperature. Since the thermal fluctuations and the nuclei criticality requirements are temperatureinterdependent, a $\mathrm{C}$-type behavior was expected for the induction period before the actual phase change.

The pretransformation dip in attenuation was consistent with this model. During the final portion of the induction period, a decrease was observed in the attenuation. It was due to the increase in density of the dislocation loops, which caused dislocation tangles and, rnnsequently, a net decrease in attenuation, according to the Granato." and Lücke theory. ${ }^{97}$ But along with the increase in the density of dislocations, some of the loops, aided by thermal fluctuations and by the criticality requirements at the transformation temperature, expanded sufficiently to yield a positive contribution to the attenuation. The pretransformation dip, although.generally showing a decrease in the attenuation, should be looked upon as composed of two competing contributions. Therefore, the oscillatory character of the attenuation within the limits of the pretransformation dip was expected at all temperatures, but predominated at the lower ones.

\section{Transformation}

Displacive transformations are associated with synchronous motions of groups of atoms accompanied by cooperative displacements. For the transformation product to grow, the dislocation loops surrounding the embryo must expand and multiply. Appreciable growth occurs only when the chemical free energy overbalances. the nonchemical or mechanical components of the free energy. The nonchemical free energies act as back stresses on the propagating dislocations and retard their mobility. The crystal structures and the available deformation mechanisms in the lattices of the phases at the corresponding transformation temperature play an:important role. The observed rates of transformation, and in general, the reaction kinetics, whether athermal, isothermal, or mixed, are determined by the mechanical processes that take place in the lattice and that are responsible for the relief of back stresses.

The propagation of the transformation dislocation through the lattice is impeded by frictional forces. ${ }^{137}$ These forces, which depend on the crystal structure and temperature, limit the speed of propagation of the dislocation arrays and, consequently, the transformation rates. The increase in attenuation during the transformation was due to two main mechanisms: (1) scattering losses caused by grain boundaries, impurity 
atoms, microvoids, etc., and (2) dislocation damping. When the transformation is in progress, the dislocations are moving about the crystal lattice; they are no longer anchored to their original pinning sites. Thus they can interact with the sound wavelike long loops, which, according to the GranatoLücke theory, causes large attenuation of the sound. Therefore; when the transformation rates are high, and large numbers of "free" dislocations are present, a high attenuation is expected. The behavior of attenuation during the isothermal transformations (e.g., Fig. 35k) was consistent with this model. The pretransformation dip recovered, and the attenuation started. to increase to its peak. 'The point of recovery corresponded exactly with the initiation of the beta $\rightarrow$ alpha transformation as determined by the measurements of transit time.

The time of occurrence of the main attenuation peak as a function of temperature is shown in Fig. 37. Figure 38 shows the fraction of the beta phase transformed to alpha at the time of the attenuation peak for the various isothermal treatments. The peaks of attenuation and the points of inflection of the transit-time curves (see Fig. 16) occurred at the same time. Since the transformations are proceeding at the greatest rates at the points of inflection, the attenuation during the phase change was proportional to the speed of the transformation. Figure 38 shows that, although long induction periods were encountered at both 361 and $199^{\circ} \mathrm{K}$, the rate of reaction in the latter was much higher once the phase change was initiated. But long induction periods at these two temperatures were due to different reasons, according to the requirements and conditions of propagation of the transformation dislocations.

\section{Kinetics}

The kinetic behavior of high-purity plutonium during the beta $\rightarrow$ alpha transformation upon rapid cooling and transforming at a temperature in the alpha phase range is compiled in the TT Tiagram (Fig. 22). It consists of two branches: (1) a high-temperature branch, above $313^{\circ} \mathrm{K}$; which exhibited an athermal character and where the amount of completion of the beta $\rightarrow$ alpha phase transition was temperature-dependent, as plotted in Fig. 20; (2) the low-temperature region, with a nose at $253^{\circ} \mathrm{K}$, which had isothermal kinetics. The two-branch system was confirmed by the attenuation measurements, plotted in Figs. 36 and 37, where both the pretransformation dip and the attenuation peak follow this pattern. A similar trend was encountered in the decrease of attenuation from its value at the:main peak to the ultimate value after the apparent completion of the transformation, as seen in Fig. 40 .

The main difference between the kinetics of the two branches was that the transformation in the high-temperature branch did not go to completion. The amount of beta phase that remained at the various temperatures is shown in Fig. 20. This athermal characteristic was confirmed 
qualitatively, by metallographic observations (e.g., Fig. 28). An extrapolation to zero beta $\rightarrow$ alpha transformation (see Fig. 20) indicated that the phase transformation could not be made to start at temperatures above $367^{\circ} \mathrm{K}$. Essentially the same temperature was obtained independently from extrapolation of the curves in Figs. 38 and 39 to zero transformation.

The isothermal displacive transformation, similar to the athermal mode, is achieved by the creation and expansion of dislocation loops and depends on the ability of the dislocations to propagate. But the probability of the occurrence of an isothermal mode at low temperatures is much higher. The reason for this is the more favorable balance between the embryo size requirements and the larger driving forces, on the one hand, and the lower plasticity of the transforming phases and the higher back stresses that imperie the motion of tlie dislocation, on the other hand. At higher temperatures, the isothermal mode.is partly masked by the predominant athermal reaction.

Although two separate branches are displayed on the TTT diagram (Fig. 22), the transformation mechanism in both is believed to be basically the same. The mechanism is displacive and is governed by the kinetics of dislocations in the transforming phase. The general pattern of the attenuation behavior confirmed this assumption. Nevertheless, the balance of forces, including the back-stress and dislocation-friction phenomena, in the two temperature regions affects the transformation kinetics differently and causes the athermal behavior in the high-temperature branch.

The beta $\rightarrow$ alpha transformation under quasi-equilibrium conditions began at $362^{\circ} \mathrm{K}$ and was very rapid, some $50 \%$ of beta transforming to alpha within $2 \mathrm{~min}$. Then the transformation proceeded in a sluggish manner with further decrease of temperature. At about $323^{\circ} \mathrm{K}$, the cooling curve joined the heating curve, where both represented the velocity of sound in alpha plutonium, as seen in Fig. 8. The apparent sluggishness of the transformation was due to the incomplete phase change at temperatures above $323^{\circ} \mathrm{K}$. The attenuation, plotted in Fig. 10, was similar to that obtained during an isothermal transformation in the high-temperature region of the TTT diagram. The extent of void formation and the corresponding density change, as well as the surface rumpling, were identical to those of a specimen isothermally transformed at about $358^{\circ} \mathrm{K}$. It can be concluded that the transformation mechanism was the same, whether the phase change was performed under quasi-equilibrium conditions, or whether the specimen was rapidly quenched from the beta temperature range into an isothermal bath in the high-temperature portion of the TTT diagram. This was, of course, what would be expected from a displacive transformation where the rate of temperature change does not affect the transformation mechanism. 
The transformation on heating under quasi-equilibrium conditions started at $395 \pm 1^{\circ} \mathrm{K}$ and extended over a temperature range up to $403^{\circ} \mathrm{K}$. Complete transformation was achieved within $30 \mathrm{~min}$. The attenuation (see Fig. 10) showed a gradual decrease to that for the beta phase. No peaks were observed, although in some specimens the decrease of attenuation from the value for the alpha phase occurred as a series of oscillations. Although the mechanism of the transformation during heating would be expected to be similar to that during cooling, they certainly would not be identical because of the more elevated temperatures that are involved during the transformation on heating.

A hysteresis of $33^{\circ} \mathrm{K}$ was observed bctween the temperature of the transformation on heating and that on cooling under quasi-equilibrium conditions. Cycling for three to four times through the alpha $\rightleftarrows$ beta transformation did not affect the width of the hysteresis loop. A temperature hysteresis is a typical and required feature of a displacive transformation where large driving forces are required to balance the nonelastic strains that occur during the reaction and where substantial amounts of energy are dissipated by frictional processes during the propagation of the transformation dislocations. Extensive supercooling and superheating are necessary to yield a sufficiently large free-energy difference between the phases to compensate for these irreversible processes. Therefore, regardless of the rate of heating and cooling, a temperature hysteresis will always be observed in displacive transformations. The diffusion-type phase change requires very little temperature hysteresis since the atomby-atom motion is performed by a very small work of displacement, although high activation energies may be required. Large hysteresis arising from nonequilibrium conditions when cooling rates are greatly increased may appear in diffusion processes.

The existence of a temperature-hysteresis loop, even at slow cooling rates, along with the surface veining during the beta $\rightarrow$ alpha phase transformation in plutonium, and, finally the fact that the transformation occurs at a temperature at which diffusion rates are likely small, all lend support to the sound velocity and attenuation data that can be interpreted only within the frame of a displacive transformation mechanism governed by the kinetics of transformation dislocations. The experimental conditions then are responsible for whether the beta $\rightarrow$ alpha transformation proceeds in an athermal, isothermal, or mixed fashion.

\section{SUMMARY AND CONCLUSIONS}

1. The behavior of the sound velocity and the relative ultrasonic attenuation during the beta $\rightarrow$ alpha transformation in high-purity plutonium under different heat-treatment conditions was consistent with the dislocation model of displacive, or martensitic-type, transformations. 
2. The TTT diagram of high-purity plutonium, as determined by measurements of sound velocity during isothermal.transformation at. various temperatures in the alpha range, displayed two distinct branches:

a. A high-temperature branch, above $313^{\circ} \mathrm{K}$, where the beta $\rightarrow$ alpha transformation exhibits a definite athermal character that extrapolates to zero transformation from beta to alpha at $367^{\circ} \mathrm{K}$. The nose of this branch is in the vicinity of $323^{\circ} \mathrm{K} 3 \mathrm{sec}$ after immersion of a specimen in the isothermal bath.

b. A low-temperature region, where strictly isothermal characteristics were observed. The nose of this branch is at $253^{\circ} \mathrm{K}$ after an immersion time of less than $l$ ser

3. A tempcrature-hysteresis loop of about $30^{\circ} \mathrm{K}$ between the temperature of transformation on heating and on cooling was observed even at very low rates of temperature variation. The hysteresis was an inherent feature of the alpha $\rightleftarrows$ beta transformation in plutonium and was related to the displacive character of this phase change.

4. Cycling through the phase-transformation temperature range caused extensive structural damage of the specimen in the form of porosity and fragmentation of the grains. The kinetics of subsequent phase transformations were affected strongly since the structural damage created conditions conducive to a dislocation blocking and immobilization, and, consequently, to a retardation of the phase change.

5. The isothermal beta $\rightarrow$ alpha transformation, particularly at high transformation temperatures as well as under quasi-equilibrium conditions, leads to formation of microvoids. Voids started to form at the beginning of the phase change. The number of voids that were formed during transformation at temperatures. in the lower branch of the TTT diagram was very small.

6. An anomaly at $200^{\circ} \mathrm{K}$ was demonstrated by discontinuities in the curves of sound velocity and attenuation as functions of temperature.

7. Sound velocities and attenuation displayed discontinuities in their variation with temperature in the vicinity of $350^{\circ} \mathrm{K}$. The attenuation peak and the corresponding dip in Poisson's ratio indicated a possible relaxation of stresses by a recovery process.

8. The present study showed the feasibility of using a special ultrasonic technique for the investigation of rapid phase transformations under different experimental conditions on specimens only $0.75 \mathrm{~mm}$ thick. Information on both the kinetics and the mechanism of the phase transition can be gained by concurrent measurements of sound velocity and relative attenuation. 


\section{ACKNOW LEDGMENTS}

This work was performed under the guidance of F. G. Foote and H. H. Chiswik. The authors would like to thank D. R. Hutchinson:for his assistance in the experimental measurements, and also M. D. Odie, W. J. Stuparitz, and A. P. Baudino, Jr., for their technical services. : One of us (M. Rosen) also wishes to extend his thanks to the Agency for. International Development, U. S. Department of State, and to the Israel Atomic Energy Commission for financial support during his stay at Argonne National Laboratory. 
$\because$ REFERENGES

1. W. M. Minér, A. S. Coffinberry, F. W. Schonfeld, J. T. Waber, R. N. R. Mulford, and R. E. Tate, "Plutonium;" Rare Metals Handbook, 2nd ed., editor, C. A. Hampel, Reinhold Publishing. Corporation; 1961, pp. 336-392.

2. W. H. Zachariasen and F. H. Ellinger, The Crystal Structure of Alpha Plutoniurn Metal, Acta Cryst. 16, 777-783 (1963).

3. W. H. Zachariasen and F. H. Ellinger, The Crystal Structure of Beta Plutonium Metal, Acta Cryst. 16, 369-375 (1963).

4. R. D. Nelson, Transformation Kinetics of Plutonium: Part TII, $\mathrm{HW}-70859^{\circ}$ (Des 1961).

5. R. G. Loasby and J. N. Lowe, "Kinetics of the $\beta-\alpha$ Transformation in Plutonium," Plutonium 1960, editors, E. Grison, W. B. H. Lord and R. D. Fowler, Cleaver-Hume Press Ltd., London (1961), pp. 3-16.

6. F. Förster and E. Scheil, Investigation of Time Relationships of (Click-Over) Reactions in Metals, Z. Metallkunde 32, 165-173 (1940).

7. R. F. Bunshah and.R. F. Mehl, Rate of Propagation of Martensite, Trans. AIME 197, $1251-1258$ (1953).

8. L. Kaufman and M. Cohen, "Thermodynamics and Kinetics of Martensitic Transformations," Progress in Metal Physics, editors, B. Chalmers and R. King, Pergamon Press (1958), Vol. 7, $165-246$.

9. G. V. Kurdyumov and O. P. Maksimova, Kinetics of the Transformation of Austenite into Martensite at Low Temperatures, Dok1. Akad. Nauk SSSR 61, 83-86 (1948).

10. R. E. Cech and J. H. Hollomon, Rate of Formation of Isothermal Martensite in Fe-Ni-Mn Alloy, Trans. AIME 197,685-689 (1953):

11. E. S. Machlin and M. Cohen, Isothermal Mode of the Martensitic Transformation, Trans. AIME 194, 489-500(1952).

12. S. A. Kulin and G. R. Speich, Isothermal Martensite Formation. in an Iron-Chromium-Nickel Alløy, Trans. AIME 194, 258-263 (1952).

13. C. H. Shik, B. L. Averbach, and M. Cohen, Some Characteristics of the Isothermal Martensitic Transformation, Trans. AIME 203, $183-187$ (1955).

14. A. N. Holden, The Isothermal Transformation of Metastable BetaUranium Single Crystals, Acta Met. 1, 617-623 (1953).

15. C. R. Houska, B. L. Averbach, and M. Cohen, The Cobalt Transformation, Acta Met. 
16. C. J. McHargue and H. L. Yakel, Jr., Phase Transformations in Cerium, Acta Met. $\underline{8}$, 637-646 (1960).

17. L. Kaufman and M. Cohen, The Martensitic Transformation in the Iron-Nickel System, Trans. AIME 206, 1393-1401 (1956).

18. D. S. Lieberman, discussion, Mechanisms of Phase Transformations in Metals, Inst. of Met., Monograph 18, London (1956), p. 321.

19. C.S. Barrett, "Transformations in Pure Metals," Phase Transformations in Solids, editor, R. Smoluchowski, John Wiley, New York (1951), pp. 343-365.

20. J. E. Schirber and C. A. Swenson, The Naturc of the $\alpha \rightarrow \beta$ Transition in Mercury, Acta Met. 10, $511-513$ (1962).

21. O. S. Edwards and H. Lipson, An X-ray Study of the Transformation of Cobalt, J. Inst. Metals 69, 177-188(1943).

22. A. R. Troiano and J. L. Tokich, The Transformation of Cobalt, Trans. AIME 175, 728-741 (1948).

23. F. Sebilleau and H. Bibring, "The Allotropic Transformation of Cobalt," Symposium on Mechanism of Phase Transformation in Metals, Inst. Metals, Monograph 18 (1955), pp. 209-217.

24. M. Aucouturier and P. Lacombe, Mise en évidence par les radiotraceurs de l'hérédité de structure entre les phases $\beta$ et $\alpha$ du cobalt, Compt. Rend. 255, 1110-1112(1962).

25. G. V. Kurdyumov and L. G. Khandros, Thermoelastic Equilibrium in Martensitic Transformations, Dokl. Akad. Nauk SSSR 66, 211-214 (1949).

26. L. C. Chang and T. A. Read, Plastic Deformation and Diffusionless Phase Changes in Metals: The Gold-Cadmium Beta Phase, Trans. AIME 191, 47-52 (1951).

27. M. W. Burkart and T. A. Read, Diffusionless Phase Change in the Indium-Thallium System, Trans. AIME 197, 1516-1524 (1953).

28. B. A. Bilby and J. W. Christian, "Martensitic Transformations," Symposium on Mechanism of Phase Transformations in Metals, Inst. Metals, Monograph 18, 1955, pp. 121-172.

29. M. Cohen, "The Martensite Transformation," Phase Transformations In Solids, editor, R. Smoluchowski, John. Wiley, New York, 1951 , pP. 588-660.

30. P. Gaunt and J. W. Christian. The Cubic $\rightarrow$ Hexagonal Transformation in Single Crystals of Cobalt and Cobalt-Nickel Alloys, Acta Met. $\underline{7}$, 529-.533 (1959).

31. L. P. Srivastava and J. G. Parr, Martensite Transformations in Zirconium, Titanium, and Titanium-Copper Alloys, Trans. AIME 224, $1295-1297(1962)$. 
32. P. Gaunt and J. W. Christian, The Crystallography of the Beta $\rightarrow$ Alpha Transformation in Zirconium and in Two TitaniumMolybdenum Alloys, Acta Met. 7, 534-543 (1959).

33. E. E. Hayes and A. R. Kaufmann, "Observations on the Alpha $\rightarrow$ Beta Transformation in Zirconium," Zirconium and Zirconium Alloys, Amer. Soc. Metals (1953), pp. 24-253.

34. Y. A. Bagaryatskii and G. I. Nosova, The $\beta \rightarrow \alpha$ Transformation in Titanium Alloys During Quenching: A Singular Kind of Martensitic Transformation, Phys. Met. and Metallography 13, 92-101 (1962).

35. P. Duwez, Effect of Rate of Cooling on the Alpha-Beta Transformation in Titanium and Titanium-Molybdenum Alloys, Trans. AlME 191, $765-771(1951)$.

36. A. J. Williams, R. W. Cahn, and C. S. Barrett, The Crystallography of the $\beta \rightarrow \alpha$ Transformation in Titanium, Acta Met. $2,117-128$ (1954).

37. J.S. Bowles and J. K. Mackenzie, The Crystallography of Martensitic Transformation, Acta Met. 2, 129-137(1954).

38. E. Eichen and J. W. Spretnak, The Mechanism of the Allotropic Transformations in Iron and Uranium, Trans. Am. Soc. Metals 51, 454-475 (1959).

39. A. R. Entwisle, discussion, Mechanisms of Phase Transformations in Metals, Inst. of Met., Monograph 18, London (1956), p. 315.

40. B. R. Butcher, The Beta to Alpha Phase Change in Pure Uranium, Part I, The Nature of the Phase Change, Part II, Thermal Cycling Through a Martensitic Phase Change, AERE-M/R-1944 (May 1956).

41. P. M. Kelly and J.: Nutting, The Morphology of Martensite, J. Iron and Steel Inst. 197, 199-211 (1961).

42. G. V. Kurdyumov, Phenomena Occuring in the Quenching and Tempering of Stee1, J. Iron and Steel Inst. 195, 26-48 (1960).

43. G. V. Kurdyumov, Bezdiffuzionnye (martensitnye) Prebrashcheniia V Splavakh, Zh. Fiz. 18, 999-1025 (1948).

44. S. A. Kulin, M. Cohen, and B. L. Averbach, Effect of Applied Stress on the Martensitic Transformation, Trans. AIME 194,661-668 (1952).

45. J. R. Patel and M. Cohen, Criterion for the Action of Applied Stress in the Martensitic Transformation; Acta Met 1, 531-538 (1953).

46. H. Beisswenger and E. Scheil, Einfluss von Zugspannungen auf die Temperatur der beginnenden Martensitbildung, Arch. Eisenhuttenwesen 32, 501-502(1961). 
47. A. L. Roitburd, To the Theory of Nucleation of Martensite, Phys. Met. and Metallography 10, Section 2, 1-8 (1960).

48. H. K. Hardy and T. J. Heal, "Nucleation-and-Growth Processes in Metals and Alloys," Mechanisms of Phase Transformations in Metals, Inst. of Met., Monograph 18, London (1956), p. 1.

49. D. W. White, Jr., Transformation Kinetics in Uranium-Chromium Alloys, Trans. AIME 203, 1221-1228(1955).

50. O. P. Maksimova and A. I. Nikonorova, Microstructural Investigation of Martensitic Transformation, AEC-Tr-2924, translated from Problemy Metallovedeniya i Fisiki Metallov, B. Ya. Lyubov; Redaktor, Moskva, 1955,670 pp. (1955), pp. 69-100.

51. B. Edmondson and T. Ko, Spontaneous Deformation of Austenite During Martensitic Transformations, Acta Met. 2, 235-24l (1954).

52. E. S. Machlin and M. Cohen, Burst Phenomenon in the Martensitic Transformation, Trans. AIME 191, 746-754 (1951).

53. M. Cohen, Nucleation of Solid-State Transformations, Trans. AIME $212,171-183(1958)$.

54. H. H. Chiswik and L. T. Lloyd, Some Aspects of the Beta to Alpha Transformation in Uranium: Metallographic Structure and Orientation Relationships, ANL-5777 (Nov 1959).

55. E: Cohen, The Allotropy of Metals, Trans. Faraday Soc. 7, 122-135 (1911).

56. W. G. Burgers and L. J. Groen, Mechanism and Kinetics of the Allotropic Transformation of Tin, Discussions Faraday Soc. 23 , 183-195 (1957).

57. C. G. Durdaller, W. H. Robinson and G. M. Pound, Nucleation Rates in the Alpha to Beta Transformation of Tin, Trans. AIME 230., No. 1, 193-200(1964).

58. E. V. Potter, H. C. Lukens, and R. W. Huber, Transformation of Gamma to Alpha Manganese, Trans. AIME 185, 399-404 (1949).

59. I. A. Gindin, B. G. Lazarev, and Y. D. Starodubov, Low Temperature Metallography of Lithium, Phys. of Met and Metallography 11 , 49-54 (1961).

60: A. Gilbert and W. S. Owen, Diffusionless Transformation in IronNickel, Iron-Chromium and Iron-Silicon Alloys, Acta Met 10 , 45-54 (1962).

61. H. H. Kelpfer and P. Chiotti, Characteristics of the Solid State Transformations in Uranium, USAEC Report ISC-893 (June 1957).

62. P. Lehr and J. P. Langeron, Comparative Study of the Allotropic Transformations of Iron and Uranium, Rev. Met. 55, 829-839 (1958). 
63. H. Aubert, Contribution a l'etude de la transformation $\beta \rightarrow \alpha$ dans l'uranium et ses alliages, CEA-2186-(1962).

64. I. F. Barwood and B. R. Butcher, The $\alpha-\beta$ Phase Transformation in Uranium, AERE-R 4128 (1962).

65. G. Donze, Nature de la Transformation $\alpha \rightleftarrows \beta$ de l'uranium au Voisinage de l'équilibre, J. Nucl. Mat. 5, 15-152 (1962).

66. J. Burke and P. H. Dixon, The $\alpha \rightleftarrows \beta$ Phase Transition in Pure Uranium, J. Nucl. Mat. $\underline{7}, 38-45$ (1962).

67. A. R. Troiano and A. B. Greninger, The Martensite Transformation, Metal Progress 50, 303-307 (1946).

68. L. Kaufman, The Lattice Stability of Metals, I - Titanium and Zirconium, Acta Met. 7, 575-587 (1959).

69. G. V. Kurdyumov, Phenomena Occurring in the Quenching and Tempering of Steels, J. Iron and Steel Inst. 195, 26-48 (1960).

70. J. D. Hill, Exploring the Transformation Behavior of the Allotropes of Plutonium, J. Less-Common Met. 4 , 376-386 (1962).

71. R. D. Nelson, Hanford Laboratories, private communication.

72. H. R. Gardner and I. B. Mann, "Mechanical Property and Formability Studies on Unalloyed Plutonium," Plutonium 1960, editors, E. Grison, W. B. H. Lord, and R. D. Fowler, Cleaver-Hume Press Ltd., London (1961), pp. 513-570.

73. C. T. Horton and B. J. Ward, "Rolling and Mechanical Testing of Plutonium," ibid, pp. 499-512.

74. T. Ko and S. A. Cottrell, The Formation of Bainite, J. Iron and Steel Inst. 172, 307-313 (1952).

75. A. S. Coffinberry and M. B. Waldron, "A Review of the Physical Metallurgy of Plutonium,". Progress in Nuclear Energy, editors, H. M. Finniston and J. P. Howe, Pergamon Press, London (1956), Vol. 1, Series V, pp. 354-410.

76. R. D. Nelson, Transformation Kinetics of Plutonium; Part I - A Study of Beta to Alpha and Alpha to Beta Transformations, HW-55778 (Apr 1958).

77. R. Pascard, A Study by Thermal Analysis of the Allotropic Transformations of Plutonium, Acta Met. 2, 305-318 (1959).

78. R. D. Nelson, Thermal Cycling of Plutonium; Part 1: Observations of the Physical Damage Resulting from Thermal Cycling Plutonium Through its Low Temperature Phase Transformations, HW-61681 (Sept 1959).

79. P. W. Bridgman, Compression and the Alpha $\rightarrow$ Beta Phase Transition of Plutonium, J. Appl: Phys. 30, 214-217 (1959). 
80.: F. W. Schonfeld and W. C. Spindler (unpublished data, 1947) quoted. by A. S. Coffinterry and W. B. Waldron, "A Review of the Physical Metallurgy of Plutonium," Progress in Nuclear Energy, Pergámon Press, London, Vol. 1, Series 5 (1956), p. 384.

81. D. J. Dean, A. E. Kay and R. G. Loasby, Note on the Specific Heat of Plutonium Metal, J. Inst. Metals 86, 464 (1957-1958).

82. S. A. Kulin, M. Cohen, and B. L. Averbach, Effect of Applied Stress on the Martensitic Transformation, J. Metals 4,661-668 (1952).

83. E. Scheil and W. Normann, Untersuchung thermodynamischer Grössen der martensitischen $\gamma \neq \alpha$-Umwandlung von Eisen-Nickel-Legierungen, Arch. Eisenhuttenwesen 30,751-754 (1959).

84. L. Kaufman, A. Leyenaar, and J. S. Harvey, The Effect of Hydrostatic Pressure on the Potency of Martensitic Embryos, Acta Met. 8 , $270-272(1960)$.

85. A. E. Kay and P. F. T. Linford, "The Elastic Constants of Plutonium," Plutonium 1960, editors, E. Grison, W. B. H. Lord, and R. D. Fowler, Cleaver-Hume Press, London (1961), pp. $51-58$.

86. H. B. Huntington, "The Elastic Constants of Crystals," Solid State Physics, editors, F. Seitz and D. Turnbull, Academic Press, Ltd., New York (1958), p. 330.

87. E. Grüneisen, Einfluss der Temperatur auf die Kompressibilität der Metalle, Ann. Physik 33, 1239-1274(1910).

88. M. M. Pisaresakii, Determination of the Young's Modulus and of the Shear Modulus of Some Steels at $20-600^{\circ} \mathrm{C}$ by the Radiotechnicalmethod, Kotloturbostroenie Issue 3, 24-26 (1948).

89. W. Köster, Die Temperaturabhangigkeit des Elastizitatsmoduls reiner Metalle, Z. Metallkunde 39, 1-9 (1948).

90. : M. E. Fine, Elasticity and Thermal Expansion of Germanium Between 195 and $275^{\circ} \mathrm{C}$, J. Appl. Phys. 24, 338-340 (1953).

91. W. Köster and J. Scherb, Bestimmung des Ganges der Poissonzahl Wahrend elastischer und Geringer Plastischer Beanspruchung,

Z. Metallkunde 49, 501-507. (1958).

92. P. Chevenard, So-called Secondary Mechanical Properties: Internal Friction, Viscous Relaxation, Reactivity, Poisson Ratio, Rev. Met. 40, 289-300(1943).

93. P. Chevenard and C. Crussard, Influence des Traitements Thermiques et Mecaniques sur le Coefficient de Poisson das Métaux et des Alliages, Compt. Rend. 216, 685-687 (1943).

94. H. Pursey, A New Investigation of Anomalies in Chromium, J. Inst. Metals 86, 362-368(1957-1958). 
95. R. Truell and C. Elbaum, "High Frequency Ultrasonic Stress Waves in Solids," Handbuch der Physik, editor, S. Flügge, SpringerVerlag, Berlin (1962); Vol。XI/2, pp. 153-258:

96. W. P. Mason, Physical Acoustics and the Properties of Solids, D. Van Nostrand Co., Inc., London (1958), pp. 197-285.

97. A. Granato and K. Lücke, Theory of Mechanical Damping Due to Dislocations, J. Appl. Phys. 27, 583-593 (1956).

98. P. Bordoni, Elastic and Anelastic Behavior of Some Metals at Very Low Temperatures, J. Acoust. Soc. Am. 26, 495-502 (1954).

99. A. Seeger, "Theorie der Gitterfehlstellen." Haindhich Dcr Physik, edilor, S. Flügge, Springer-Verlag, Berlin (1955).Vol. VII/1, pp. $383-665$.

100. K. Lücke and A. Granato, "Internal Friction Phenomena due to Dislocations," Dislocations and Mechanical Properties of Grystals, editors, J. C. Fisher, W. G. Johnston, R. Thomson, and T. Vreeland; Jr., John. Wiley, New York (1957), pp. 425-457.

101. T. A. Read, The Internal Friction of Single Metal Crystals, Phys. Rev. 58, $371-380(1940)$.

102. J.S. Koehler, "The Influence of Dislocations and Impurities on the Damping and the Elastic Constants of Metal Single Crystals," Imperfections in Nearly Perfect Crystals, editor, W. Shockley, John Wiley, New York (1952), pp. 197-216.

103. G. A. Alers, Ultrasonic Attenuation in Zinc Single Crystals While Undergoing Plastic Deformation, Phys. Rev. 97, 863-869 (1955).

104. J. Weertman and J.S. Koehler, Internal Friction and Young's Modulus of Cold-Worked Copper Single Crystals, J. Appl. Phys. 24, 624-631(1953).

105. D. H. Niblett and J. Wilks, Dislocation Damping in Metals, Advan. in Phys. 9, 1-88 (i960).

106. R. Truell, Influence of Deformation and Temperature on the Cobalt Gamma-Irradiation of Sodium Chloride: Evidence for Electrical Interaction Between Dislocations and Point Defects, J. Appl. Phys. 32, 1601-1604.(1961).

107. D. O. Thompson and D. K. Holmes, Effects of Neutron Irradiation upon the Young's Modulus and Internal Friction of Copper Single Crystals, J. Appl. Phys. 27, 713-723 (1956).

108. E. Scheil and J. Müller, Die Dämpfung mechanischer Schwingungen während der Martensitbildung in Eisen-Nickel-Legierungen, Arch. Eisenhuttenwesen 27,801-805 (1956).

109. B. Blumenthal and M. B. Brodsky, "The Preparation of High Purity Plutonium," Plutonium 1960, editors, E. Grison, W. H. B. Lord, and R. D. Fowler, Cleaver-Hume Press, London (1961). pp. 171-186. 
110. W. J: McGonnagle, Nondestructive.Testing, McGraw-Hill, New York (1961), pp. 231-232.

111. B. Carlin, Ultrasonics, McGraw-Hill, New York (1960), p. 221.

112. Arenberg Ultrasonic Laboratory, Electrical Design News (Sept 1958).

113. B. Chick, G. Anderson, and R. Truell, Ultrasonic Attenuation Unit and Its Use in Measuring Attenuation in Alkali Halides, J. Acoust. Soc. Am. 32, 186-193 (1960).

114. H. J. McSkimin, Notes and References for the Measurement of Elastic Moduli by Means of Ultrasonic Waves, J. Acoust. Soc. Arr. 33, 606-615(1961).

115. W. P. Mason, op. cit., p. 51.

116. E. H. Jacobsen, Sources of Sound in Piezoelectric Crystals, J. Acoust. Soc. Am. 32, 949-953(1960).

117. E. H. Jacobsen, "Experiments with Phonons at Microwave Erequencies," Quantum Electronics, editor, C. H. Townes, Columbia University Press, New York (1960), pp. 468-484.

118. E. G. Cook, Transient and Steady-State Response of Ultrasonic Piezoelectric Transducers, IRE Convention Record, Vol. 4, Part 9, 61 (1956).

119. M. Redwood, Transient Performance of a Piezoelectric Transducer, J. Acoust. Soc. Am. 33, 527-538(1961).

120. M. Redwood, A Study of Waveforms in the Generation and Detection of Short Ultrasonic Pulses, Appl. Materials Res. 2 , 76-84 (1963).•

121. E. A. Henry, Construction and Refinement of Prototype U1trasonic Inspection Equipment Phase I, Interim Report No. 1, Sperry Products Inc. Eng. Dept., Contract AF 33 (600)-32131, Feb. 17, 1956 to May 31, 1956 (AD 100845).

122. A. M. Murdoch and H. E. Van Valkenburg, Ultrasonic Equipment for Inspection of Bonded Sheet Metal Aircraft Components, Phases I, II and III, Final Eng. Report, Sperry Products Inc., Eng. Dept., Sperry Rep. TR-083; AMC Tech. Rep., 59-7-224 A-1; Contract AF 33 (600)32131, Feb. 15, 1956 to May 31, 1959 (June 1959).

123. Reference 121: Drawing $50 \mathrm{~K} 1494$.

124. R. Goldman, Ultrasonic Technology, Reinhold Publishing Corp., New York (1962), pp. 38-40 and 48-56.

125. B. Blumenthal, Density Measurements in Gloveboxes, ANL-6671 (Sept 1963). 
126. F. G. Foote, "Physical Metallurgy of Uranium," Progress in Nuclear Energy, Pergamon Press, London and New York, editors, H. M. Finniston and J. P. Howe (1956), Vol. l, Series V, p. 120.

127. A. I. Dashkovskii and Y. M. Savitskii, "Temperature Function of Internal Friction, Young's Modulus and Shear Modulus of Zirconium, Niobium and Zirconium-Niobium Alloys," Metallurgy and Metallography of Pure Metals, editor, B. Chalmers; Gordon and Breach, New York (1962), pp. 218-227.

128. A. I. Dashkovskii and Y. M. Savtskii, The Damping Capacity of Strontium, Phys. of Met. and Metallography 11, 153-154 (1961).

129. F. W. Schonfeld, "Discussion on Mechanical Properties of Plutonium," Plutonium 1960, editors, E. Grison, W. B. H. Lord, and R. D. Fowler, Cleaver-Hume Press, London (1961), p. 587.

130. L. Ianniello, The Recrystallization of Alpha Plutonium, Trans. ASM 57, 768 (1964).

131. A. N. Holden, Physical Metallurgy of Uranium, Addison-Wesley Publishing Co., Inc., Massachusetts (1958), p. 181.

132. F. C. Frank, Martensite, Acta Met. 1, 15-21 (1953).

133. H. Kriapp and U. Dehlinger, Mechanics and Kinetics of Martensite Formation Without Diffusion, Acta Met 4, 289-297 (1956).

134. J. H. Hollomon and D. Turnbull, "Nucleation," Progress in Metal - Physics, editor, B. Chalmers, Interscience Publishers Inc., New York (1953), Vol. 4, pp. 333-388.

135. A. B. Greninger and V. G. Mooradian, Strain Transformation in Metastable Beta Copper-Zinc and Beta Copper-Tin Alloys, Trans. AIME 128, 337-377 (1938).

136. M. H. Richman, M. Cohen, and H. G. F. Wilsdorf, Experimental Evidence for Martensitic Embryos, Acta Met 7, 819-820 (1959).

137. K. Lücke, Die von den Kristallbaufehlern und insbesondere von den Versetzungen verursachten Dampfungserscheinungen, Z. Metallikunde 53, 57-71 (1962). 
